Portland State University

PDXScholar

Spring 6-11-2018

\title{
Dual Immersion Leadership: a Case Study of Three K-5 Principals Who Show Success with Emergent Bilinguals
}

Ivonne Karina Dibblee

Portland State University

Follow this and additional works at: https://pdxscholar.library.pdx.edu/open_access_etds

Part of the Bilingual, Multilingual, and Multicultural Education Commons, and the Educational Leadership Commons

Let us know how access to this document benefits you.

\section{Recommended Citation}

Dibblee, Ivonne Karina, "Dual Immersion Leadership: a Case Study of Three K-5 Principals Who Show Success with Emergent Bilinguals" (2018). Dissertations and Theses. Paper 4390.

https://doi.org/10.15760/etd.6274

This Dissertation is brought to you for free and open access. It has been accepted for inclusion in Dissertations and Theses by an authorized administrator of PDXScholar. Please contact us if we can make this document more accessible: pdxscholar@pdx.edu. 
Dual Immersion Leadership: A Case Study of Three K-5 Principals Who Show Success with Emergent Bilinguals

$$
\text { by }
$$

Ivonne Karina Dibblee

A dissertation submitted in partial fulfillment of the requirements for the degree of

\section{Doctor of Education}

in

Educational Leadership: Administration

Dissertation Committee:

Deborah Peterson, Chair

Anita Bright

Samuel Henry

Yves Labissiere

Portland State University

2018 
(C) 2018 Ivonne Karina Dibblee 


\begin{abstract}
In the past decade the number of dual language immersion programs in US public schools has grown to more than 2000 (Maxwell, 2011). The benefits of dual language immersion for emergent bilinguals (EBs) have been confirmed by numerous studies. However, lacking from this literature is research which focuses on leadership within dual immersion schools. Despite an upsurge in the number of immersion schools, few studies examine the characteristics of effective immersion leaders. The aim of this study is to examine the leadership characteristics of principals leading K-5 dual language immersion programs who have increased student achievement among EBs.

The purpose of this case study is to identify leadership characteristics of three successful K-5 dual immersion principals and to understand the relationship of such characteristics to the student growth of Emergent Bilinguals (EBs). In the literature review, I present the theoretical framework of Bolman and Deal (2003), historical perspectives of immersion in the United States, learning perspectives in the area of dual language immersion, and leadership and student achievement.

The research approach for this study is a case study design. The subjects for this study are experienced principals who are successful in terms of student achievement for EBs as measured by school performance exceeding their district performance average and that of comparison schools. To answer the research question about the characteristics of successful leaders of dual immersion schools, I conducted a qualitative study to include principal interviews, school document review, and teacher focus groups.
\end{abstract}


As schools increase their focus on reducing racial inequities (Collier \& Thomas, 2014; Darling Hammond, 2007; Garcia-Matthewson, 2017; Gay, 2010; Theoharis, 2007; Zacarian, 2011), how to reduce educational inequities among EBs must also be a focus. By understanding the characteristics of leaders who are successful with EBs, we can impact school district hiring practices, principal preparation programs, and district policies. 


\section{TABLE OF CONTENTS}

Abstract................................................................. i

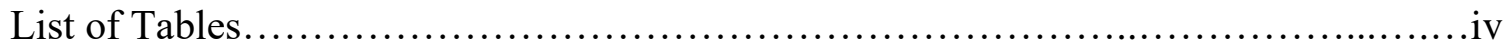

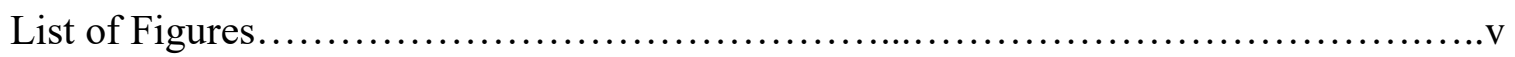

Chapter 1

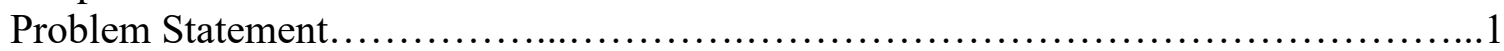

Chapter 2

Literature Review .......................................................... 15

Chapter 3

Research Design and Methodology.........................................6 60

Chapter 4

Results.......................................................................

Chapter 5

Discussion............................................................... 118

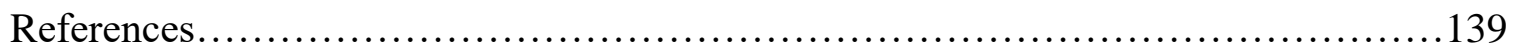

Appendices.................................................................... 145

Appendix A. Informed Consent Form (Principals) ............................ 145

Appendix B. Informed Consent Form (Focus Groups)......................... 147

Appendix C. Protocol for Document Analysis.................................. 149

Appendix D. Interview Protocol...........................................150

Appendix E. Focus Group Protocol.............................................153 


\section{LIST OF TABLES}

Table $\quad$ Page

2.1 Bolman and Deal's Assumptions of Each Organizational Frame ............................18

2.2 Theoretical Framework Applied to Learning Theory and Dual Immersion ................38 


\section{LIST OF FIGURES}

Figure $\quad$ Page

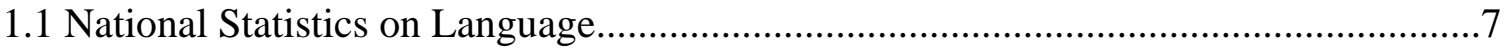

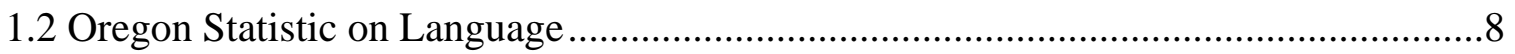

2.1 Theoretical Framework for Dual Language Immersion Leadership.........................17

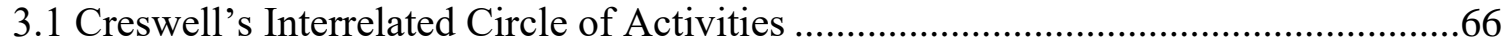

4.1 Attride-Sterling's Structure of Thematic Framework.......................... 78

4.2 Summary of Data by Individual Principal Response............................79

4.3 Summary of Data by Collective Principal Response............................80

4.4 Summary of Principal Interview Themes Coded within the Organizational Frames.................................................................... 87

4.5 Summary of Data by Individual Focus Group Response.........................91

4.6 Summary of Data by Collective Focus Group Response..........................92

5.1 Modification of Theoretical Framework....................................... 128 


\section{CHAPTER 1}

\section{PROBLEM STATEMENT}

\section{Introduction}

Language diversity in the United States has increased in the past few decades as the United States has continued to be a destination for people from other lands (US Census, 2011). By the year 2030 EBs are projected to encompass 40 percent of the k-12 school enrollment (Thomas \& Collier, 2002; US Census, (2017) shows that the Latino student population has grown $102 \%$ in the last decade; 17.8 million students make up $22.7 \%$ of students enrolled in school. Thomas and Collier conducted the largest longitudinal study on language acquisition programs in the United States, and their findings confirmed that our educational system cannot continue current ineffective practices for educating EBs and should expand immersion programs, whose results surpass the results of other language program models. Additional researchers support dual immersion models (Cummins, 1984; Garcia, et al., 2011; Krashen, 1982; Ogbu, 1992). Recent research by Lindholm-Leary and Block (2010) provides additional support to the original Thomas and Collier research in which Latino students, whether English dominant/monolingual (EP) or English learning (ELLs), outperform their peers in mainstream classes on tests in English. They state, "This was the case for both EP and ELL Hispanics in the dual language programs in the segregated settings examined here, and both in English language arts as well as in mathematics" (p. 57). Additional research finds that these positive results hold for EBs if dual language begins at the inception of 
the students' learning experience. When starting in Pre $-\mathrm{K}$, students have shown positive results as early as the third grade (Espinosa, 2013; Lindholm-Leary, 2013).

As a bilingual, first-generation American immigrant who also has been the recipient of bilingual education and subsequently served as a teacher and school leader, it is my belief and is also supported by a strong literature base, that dual immersion is an effective strategy for all learners, and more specifically EBs. Educational leadership research often looks to find characteristics of good leadership, leadership models, and frameworks. Thus, the aim of this study is to examine the leadership characteristics of principals leading dual language immersion programs in which student achievement among EBs surpass their district and state average.

\section{Background of the Problem}

\section{Emergent Bilinguals and Educational Disparities}

With a population of 317 million, (US Census, 2013) US residents include indigenous peoples speaking 169 languages in addition to immigrants speaking 381 languages (Siebens \& Jullian, 2011). Spanish is the second most commonly used language in the US with $13 \%$ percent speaking Spanish in the home compared to $79 \%$ percent speaking English in the home (US Census, 2011), as well as indigenous people speaking a plethora of indigenous languages. Ovando (2011) notes that language used for instruction in schools has been discussed since this nation's founding days. When immigrants come to this land, they want to keep their language for a variety of reasons. As Ovando noted: “Because of a strong sense of identity derived from a person's ancestral language, many new immigrant communities hung onto their maternal 
languages for religious services, community, newspapers, and private and public schools" (p 4).

Historically, policy in the late 1800's focused efforts on the oppression of indigenous people, including forbidding the use of indigenous languages in schools and repressing all cultural activities (Crawford, 1995). Further, many indigenous children were removed from their homes and communities and sent to non-reservation boarding schools outside their communities, forced to speak English only, with the goal of assimilation into the "'mainstream' way of 'American way of life'; the Protestant Republican ideology of the mid- $19^{\text {th }}$ century" (American Indian Relief Council, n.d.). During this period there was a call for action and the American Protective Association promoted English only-laws. In the 1900's when most immigrants were European, some states authorized bilingual education and in fact, Oregon "legalized monolingual German schools in 1872" (Peterson, 2012, p. 7). Prior to World War I, Tyack (1974) found that there were notable laws requiring that German be allowed as a language of instruction (Peterson, p. 7). World War I created more sentiment towards English only and it wasn't until World War II, which "served as the first wake-up call regarding the United States inadequacies in foreign language instruction" (Ovando, 2010, p. 7) that the language policies changed.

Many laws govern the educational experiences of children of color and EBs. Although the Supreme Court ruled over sixty years ago in Brown v. Board of Education (1954) that Black students have a right to receive the same education as White students, there are still disparities for many students in our educations system. The Department of 
Education reported that despite this court ruling, "disparities still exist for Black students, minority students and students with disabilities" (Sandusky Register, 2014). One additional group, which faces educational disparities, is Emergent Bilinguals (EBs). This group is largely comprised of students of color - make note that while some Latino/a children are White, as an ethnic group they experience educational disparities. While Latino children not only have to acquire language they are also often erroneously placed into special education that may or may not be masked by language. This is common if professionals do not understand language acquisition and apply knowledge as if a student is monolingual without taking into consideration their second language. Several court cases have outlined educational requirements for EBs: Lau v. Nichols (1974), Castañeda v. Pickard (1978), Rios v. Reed (1978), that require providing effective educational experiences for EBs. Lau v. Nichols (1974) ensures that districts provide instructional programs so that EBs can perform classroom tasks/work in English. Castañeda v. Pickard (1978) challenged the segregation of Latinos students and ruled to establish educational programming that was based on sound research, provided resources and was evaluated for effectiveness. Rios v. Reed (1978) supported a child's right to meaningful education despite not knowing English. So while there are additional groups that experience educational disparities, because of the growing number of EBs in this nation, this study aims to examine the characteristics of principals leading K-5 dual language immersion programs in order assure student growth among Emergent Bilinguals.

This chapter covers the areas of this study, which include the problem statement, significance of the problem, and key concepts and terms, concluding with a summary. 


\section{Statement of the Research Problem}

The dynamics of our world continue to change as the world becomes more flat and technology allows us to collaborate, discuss and even compete, and our communication mechanisms make it easier for us to connect (Friedman, 2005). Migliore (2011) noted the increased need for bilingualism, given the increase of globalization and increase in bilingual children and families. The immigrant population continues to grow with the Spanish-speaking residents comprising the largest growing demographic in the United States (US Census, 2012). This changing demographic requires using new strategies in our schools. The Oregon Department of Education (ODE) has made dual language programs a key strategy to closing the opportunity gap among EBs and more dual language programs are being started, developed and supported throughout the state (2013). Corbaz (2014) examined leadership in a dual immersion school and states that the type of leadership needed for immersion schools is more complex and multifaceted than leadership needed in monolingual schools. Corbaz concurs with Coffman (1992), stating, "the immersion school principal's role is even more vital, requiring additional talents, skills and qualifications" (p.155) while acknowledging that there is little literature that specifically targets leadership in dual immersion schools. Our system needs to invest in leaders and build leadership skills that can strategically navigate and influence multiple groups while also handling the management of a school community.

Decades of research have been done in the area of dual language and best practices for EBs (Collier \&Thomas, 2002; Cummins 1984, 1999; Krashen, 1982) and additional authors such as Fullan (2001), Heifetz (1997), Cotton (2003). Marzano, Waters 
and McNulty (2005) have written on the complexity of school leadership. Nevertheless, little research has specifically examined or explicated the work of a leader in the dual immersion setting.

Kerper-Mora (2009) describes our responsibility in finding a better path for students learning the English language. In summary she includes the following points:

1) Conflicting attitudes and anxieties play out as various societal groups attempt to define the role of public education in integrating immigrants to the American mainstream; 2) schools need to implement programs that meet the academic needs of their linguistically diverse learners; 3) students have rights to meaningful and equitable education, regardless of their native language and proficiency in English. Bernhardt (1992) explains that the role of a principal in a dual immersion setting is complex. She highlights the thoughts of a principal in this setting, who writes, "we continue to work on many challenges and issues with one main goal in mind - providing a quality instructional program that strives to meet the varied educational needs of our students" (pp. 169-170).

I concur with Corbaz (2014) who writes that, "little knowledge [exists] about which elements contribute to effective language immersion school leadership" (p.4). Thus, this study proposes the following question: What leadership characteristics are needed to lead a dual language immersion school to increase student achievement for EBs?

\section{Significance of the Research Problem}

In October of 2012 the US Census reported an estimate of 54,030,000 students in our K-12 public schools. Of these, $4 \%$ of primary school students and $7 \%$ of high school 
students are foreign born. If $79 \%$ of K-12 students speak English fluently and $21 \%$ of K12 students speak a language other than English at home, then, approximately six million students need language acquisition programs. In Oregon, the 2013-2014-fall enrollment report shows a total enrollment of 567,098 students of which approximately $22 \%$ are Emergent Bilinguals (ODE, 2014). This mirrors the national trend where the same percentage of students needing services in order to attain language proficiency, which not only qualifies them for these services but also makes academic content available. These statistics indicate that approximately 122,000 need language bilingual programs as a strategy for English acquisition and 434,000 need world language instruction. Figure 1.1 reports most commonly reported home languages of English language learner (ELL) students nationally for the 2014-2015 school year and updated in March of 2017.

Figure 1.1: 77.1\% speak Spanish, 4.8\% Chinese, Tagalog, Vietnamese and French with $2.6 \%, 2.3 \%$, and $2.1 \%$ respectively (NCES, 2017).

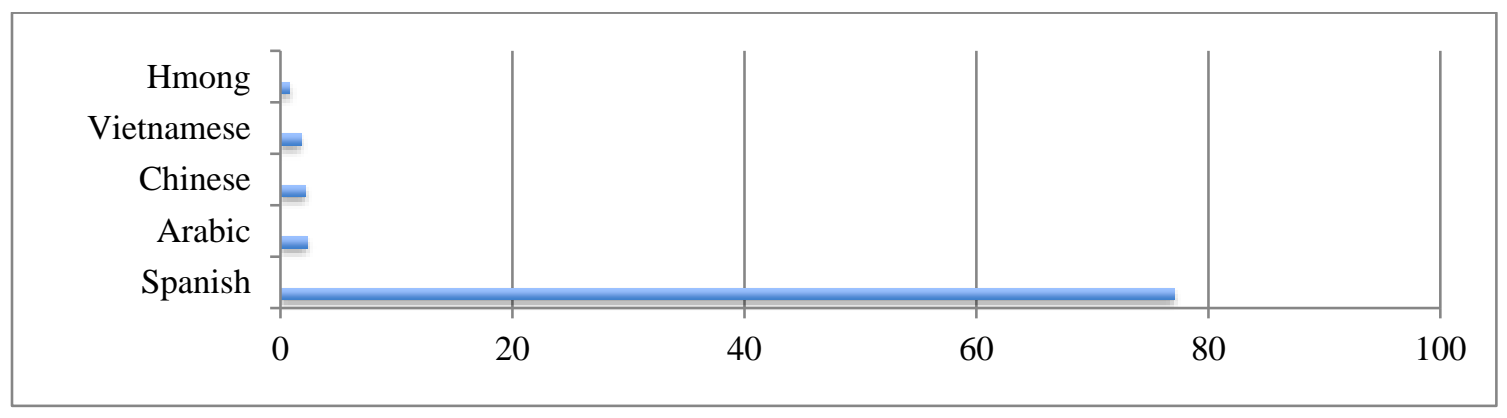


Figure 1.2 provides Oregon statistics on language spoken respectively.

Figure 1.2: $15.35 \%$ speak Spanish, .9\% Russian, .8\%, Vietnamese, .6 Chinese and Arabic with .3\%, (Oregon Department of Education, 2017).

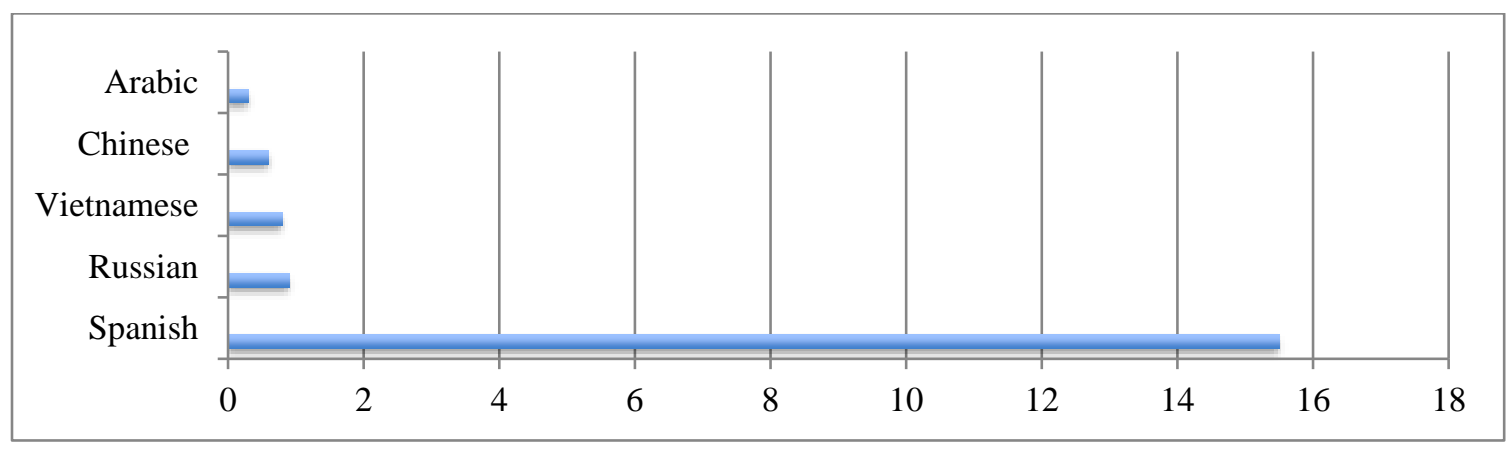

Academic achievement disparities exist among EBs in reading and mathematics, with Oregon EBs $20 \%$ points lower in both reading and mathematics, as compared to their White counterparts (ODE, 2013). The last reported benchmark for the graduation rates for the state of Oregon also show EBs falling 22\% points below their White peers. This educational disparity indicates school leaders are not fulfilling their moral obligation to ensure all children learn. Further, for 2001-2011 the ELL population rose 48\% (ODE, 2011), pointing to the urgency to educating EBs successfully.

Language programs, specifically two-way dual immersion programs, have provided significant gains for all students that also benefit EBs. Programs include the most effective models such as two way dual immersion (Thomas \& Collier, 1997), one way immersion, ESL push-out, ESL push-in, ESL content, transitional bilingual and developmental bilingual. The model most used in schools seems to be more policy driven than evidence driven. Portes and Rumbaut (2001) have also confirmed Thomas 
and Collier's findings, noting that immigrant students with ties to their parents' culture and language are more successful than monolingual peers.

Dual immersion is also offered at the elementary level albeit as a conduit for academic content and instruction in the target language is used at least $50 \%$ of the day. The difference between the $90 / 10$ and 50/50 model is the ratio of time spent in the target language initially. Both language programs have goals, which attempt to keep a balance of two groups of language speakers and share goals, school settings and language distribution. The difference between the two programs is the initial time for target language distribution in the earliest stages of the program, which is usually pre-k, kinder and first grade. Time in the target language decreases annually until they reach a 50-50 balance by $4^{\text {th }}$ or $5^{\text {th }}$ grade. Dual language programs have proven to be a significant strategy that works for EBs (Collier \& Thomas, 1999). EBs should continue to solidify their native language through practice of reading and writing skills while they are also simultaneously learning English. Students should practice their native language literacy skills while they learn English to accomplish true bilingualism.

When analyzing research on EBs, Goldenberg (2008) says, there is no way to know whether EBs tested in English score low because of lagging content knowledge and skills, or because of limited English proficiency, or because of other factors that interfere with their test performance - or some combination. Whatever the explanation for these achievement gaps, they bode ill for English learners' future educational and vocational options. They also bode ill for society as a whole as our demographics change. Goldenberg further emphasizes, "the cost of large-scale underachievement are very high" 
(p.4). Former Oregon Deputy Superintendent Saxton says the following of EBs in

Oregon:

Our education system is in a time of change, but unfortunately, that change isn't happening fast enough for our English Learners. We need to move forward aggressively with our reform efforts to ensure we are providing our English Learners with the instruction supports, and opportunities they need to master academic English and graduate ready for college and career. Declines like we saw last year just reaffirm the need for significant changes to how we support, teach, and assess our state's English Learners (ODE, 2013.).

These comments came after the state reported a decline in the three targets; 1)

progressing in English Language Acquisition; 2) exiting or reaching English Language

proficiency; 3) English Learners annual measurable objectives, of the Annual Measurable Achievement Objectives (AMAO).

Educational systems are slow to change. Bridges (1991) claims, "It has become a truism that the only constant today is change" (p.99). Yet despite this popular belief, change is difficult for many people. Issues with bilingual education have caused many changes in our political system, a subject of debate before our nation was founded. Perhaps it is an idealistic vision that constituents and policy makers will someday see that bilingualism is in the best interest of our nation and our children. School leaders must also navigate contractual constraints and the backlash of political perspective when leading a dual immersion school.

The aim of this study is to examine the leadership characteristics of principals leading K-5 dual language immersion programs successful with EBs. This work will incorporate the research on dual language programs and change. The findings of this 
study will contribute to the body of research providing insight into dual immersion leadership and successfully educating EBs.

\section{Presentation of Methods and Research Questions}

In order to identify the leadership characteristics of successful dual immersion K5 principals and to understand the relationship of such to the growth of student achievement of EBs this study asks: What are the leadership characteristics of K-5 principals who have successfully increased the achievement of EBs? Related questions include the following:

- How do principals in dual immersion schools understand and communicate the program model and its effect on Emergent Bilinguals?

- How do school principals influence school climate in schools and communities with English - only and dual immersion programs within one school?

- What focus is explicit within the vision and mission of the school?

- What is important for leaders of immersion schools to know about successfully leading an immersion school?

These questions will guide the study, as the intention of this study is to conduct qualitative research, in which the researcher explores to find what is significant in the situation, and by describing in words (Krathwohl, 2009).

\section{Definition of Key Terms}

The following section includes definitions for terms used throughout this paper. 
Culture. Culture is defined as "a set of practices and beliefs that is shared with members of a particular group that distinguishes on group from others" (Lindsey, Robbins, \& Terrell, 2009, p.11).

Dual Immersion. Dual Immersion, a type of bilingual education program, is a model in which the student's home language is used as the language of instruction for a portion of the school day (Thomas \& Collier, 1999). Dual Immersion is an enrichment model that "adds to what a student already knows, including knowledge of another language used as resources for learning, and as essential building blocks" (p.1).

Emergent Bilinguals. Although the acronym ELL, which stands for English Language Learners, is commonly used in all documents and policy this paper will follow the work of Garcia, Kleifgen, and Falchi (2008) who refer to those categorized ELLs as Emergent Bilinguals (EBs). They state using ELL further perpetuates inequities and discounts students' home language.

Equity. Equity is "the outcome of practices that result in the same outcomes for members of a group" (Lindsay, Robbins, \& Terrell, 2009, p.166).

Language Proficiency. Language proficiency refers to the degree to which the student exhibits control over the use of language, including the measurement of expressive and receptive language skills in the areas of phonology, syntax, vocabulary, and semantics and including the areas of pragmatics or language use within various domains or social circumstances. Proficiency in a language is judged independently and does not imply a lack of proficiency in another language (United States Department of 
Education, n.d.). This concept is important because proficiency determines qualification for services and provides access to the curriculum in English.

Latino/Hispanic. Latino/Hispanic are politically charged words and this paper will use the word Latino, following the theory of Peterson (2012) who "uses the word Latino to describe those that identify as such and trace their descent from people who also identify as Hispanic or Latino, generally from Spanish-speaking nations of Latin America, Portugal, Brazil and Spain. Hispanic is not used so to not create a false generalization that dismisses the diversity among people of these continents (p.23).

Target Language. Target language primarily refers to the language of instruction but can also refer to the language that the student is acquiring. The home language or native language of a student is often referred to as the student's first language (L1) and the target language is often referred to as the second language (L2).

\section{Summary}

Preparing students to be proficient in English as well as an additional language has important consequences for the broader domain of our global economy and the role of the US in today's world market. Nieto (as cited in Lindsey et al., 2009) notes that future workers with "a monocultural perspective in the workplace can legitimately be considered educationally ill-prepared" (p.2). Beyond acquiring the technical skills of a language, learning multiple languages at a young age allows students to attain the skills to be successful with the demands of our current system and society. Students must complete targeted benchmarks and also must be equipped to navigate our culturally and 
linguistically diverse global society. Educators have a moral obligation to equip students with the skills needed to cognitively meet benchmark tasks, which define academic achievement, and to also hone the skills needed to navigate and be successful in our global society.

This chapter identified a problem within historical, social and cultural contexts. Further, this chapter explained a broader significance situated in equity and our need to assure success for our largest growing population - EBs. Chapter two will analyze literature in both immersion and leadership as well as provide a theoretical framework that is relevant to the problem. Chapter three will outline the methodology for this study. 


\section{CHAPTER 2}

\section{LITERATURE REVIEW}

\section{Introduction}

This chapter will begin with the review of the literature related to this study. The guiding developmental theory for this study is that of Bolman and Deal (2003). Thomson (2000) states, "Bolman and Deal's theory postulates that successful organizations, including leaders and managers, are those that understand and utilize a multi-frame orientation of thinking in assessing situational and environmental characteristics and anomalies." Bolman and Deal's four frame organizational theory is extremely useful because it sheds light on the difficult problem of the lack of literature focus on dual language immersion leadership. Nevertheless, it is also important to identify the literature, which addresses a history of dual language immersion, the principles of learning and practice for dual immersion and models for organizational leadership and theory in the field as they pertain to this four-framework theory. I will identify critical variables, synthesize findings, and note the important relationships within these variables as they pertain to leadership within dual immersion models. Finally, the chapter will end with a summary of the literature.

\section{Theoretical Framework}

The work of Bolman and Deal (2003) is an important theoretical framework that will be utilized in this study examining the characteristics of dual immersion principals who have increased student achievement among EBs. The theory posits that large, complex, and effective organizations need to understand the multiple frames and 
understand how to operate within them. Bolman and Deal (2003) affirm that their theory consolidates major premises of organizational thought into four perspectives - the structural, human resource, political, and symbolic frames. They write, "Like maps, frames are both windows on a territory and tools for navigation" (p.13). Bolman and Deal (2014) revisit these models and explain why frames are so vital. "Our mental models, whether rich or impoverished, determine the breath and depth of our personal reality" (p. 11). Thus, leaders need accurately map and need to apply these frames to multiple situations.

Bolman and Deal (2003) offer an explanation of the properties of organizations in the following manner: First, they explain that organizations are complex where people and their behaviors are difficult to understand. Second, organizations are surprising; what is expected often is different from what happens. Third, Bolman and Deal state that organizations are deceptive, with multiple camouflaged surprises. Additionally, they state that organizations are ambiguous, noting, "The sum of complexity, unpredictability and deception is rampant ambiguity" (p.26). Bolman and Deal further posit that, "learning multiple perspectives, or frames is a defense against cluelessness..." and "as organizations have become pervasive and dominant, they have also become formidably difficult to understand and manage" (pp. 18-19). Therefore, operating under multiple perspectives provides a powerful tool for gaining clarity, options and strategies that work. Bolman and Deal note that reframing is a means of sizing things up and making sense so to think about things in more than one way. Different mental models allow the dissection of what is happening, providing a more comprehensive view of opportunities. These 
frames can be applied to situations holistically, as well as to each situation. Bolman and

Deal (2014) describe the four frames of organizations as a navigational tool:

Leaders have to find new ways to shift points of view when needed. Like maps, frames are like windows are tools for navigation. Each window offers a unique view; each tool has strengths and limitations. Only experience and practice bring you the adroitness and wisdom to take stock of a situation and use suitable tools with confidence and skill (p. 14).

Thus, the theoretical framework that illustrates leadership in a dual immersion school incorporates leadership in all four frames in order to move achievement for EBs

Figure 2.1: Theoretical Framework for Dual Immersion Leadership

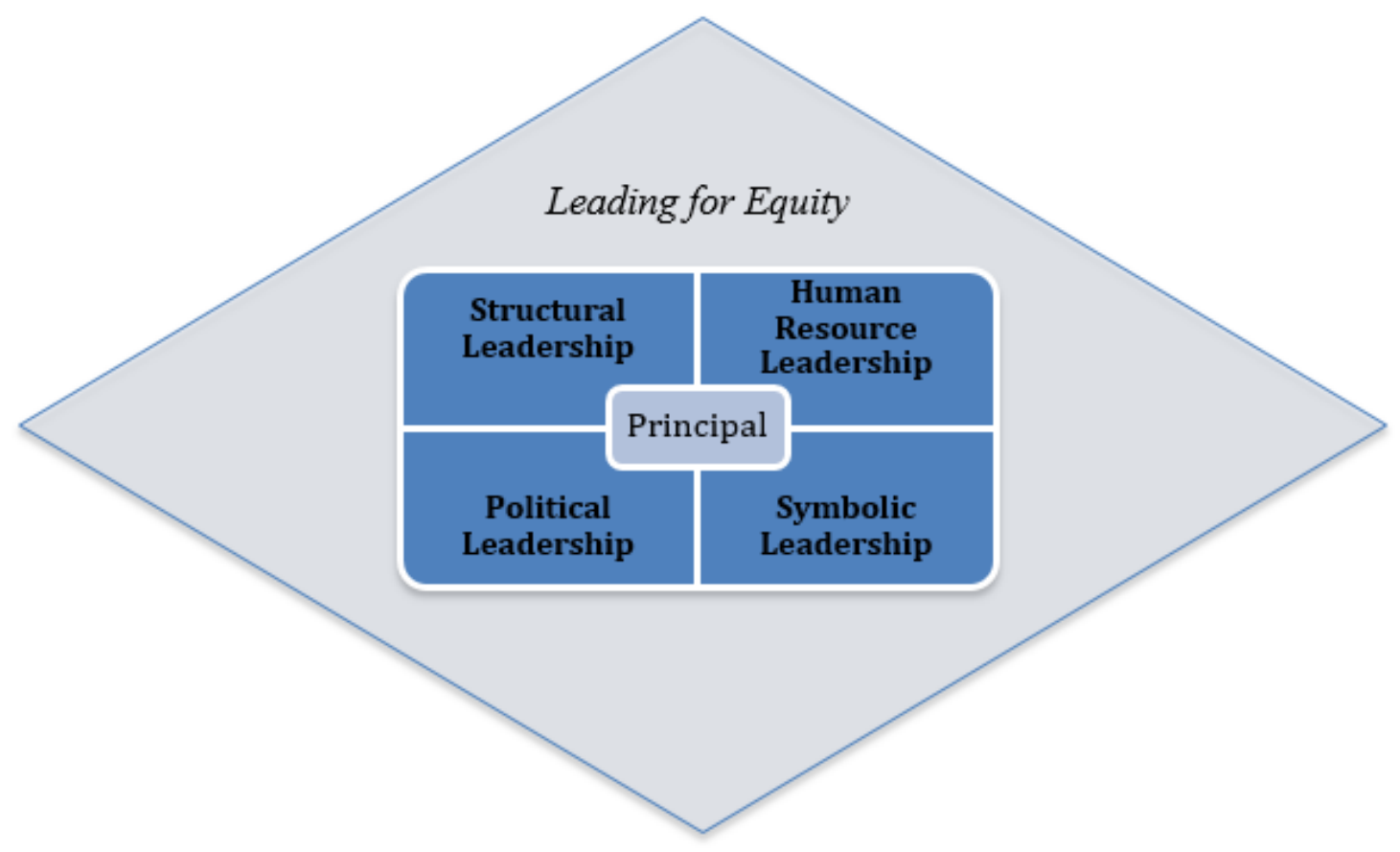

This theoretical framework merges an inclusive framework embracing four distinctive ideas about leadership. Leaders need to realize that although personal tendencies might go towards one particular frame, it is imperative that leaders take advantage of what all 
frames have to offer. For instance, dual immersion is still a relatively young program and each frame provides insight to how leadership can develop programs (structural frame), build community among staff (human resource), navigate power to advocate for EBs (political frame), and celebrate culture and diversity (symbolic frame). In the case of dual immersion, it will mean a leader must be able to communicate the benefits of having such programs in their schools and demystify the notion that dual language programs take away from students when the research indicates the contrary.

\section{Assumptions}

The assumptions provided the Bolman and Deal (2003) as they pertain to the organizational frames are outline in the table below:

\section{Table 2.1:}

Bolman and Deal's (2003) assumptions of each organizational frame

\begin{tabular}{|l|ll|}
\hline STRUCTURAL (p. 45) & HR (p.115) \\
- $\begin{array}{l}\text { Organizations exit to achieve } \\
\text { established goals and objectives } \\
\text { and enhance performance through } \\
\text { specialization and clear division of } \\
\text { labor }\end{array}$ & $\begin{array}{l}\text { Organizations exist to serve } \\
\text { human needs rather than the } \\
\text { reverse. }\end{array}$ \\
Rational and effective & $\begin{array}{l}\text { People and organizations need } \\
\text { each other: Organizations need }\end{array}$ \\
$\begin{array}{l}\text { coordination of individuals and } \\
\text { teams are best }\end{array}$ & $\begin{array}{l}\text { ideas, energy, talent; people need } \\
\text { careers, salaries, and opportunities }\end{array}$ \\
$\begin{array}{l}\text { Structures must fit the } \\
\text { organizations circumstances as }\end{array}$ & $\begin{array}{l}\text { When the fit between the } \\
\text { individual and system is poor, one } \\
\text { analysis of the restructure }\end{array}$ \\
& $\begin{array}{l}\text { or both suffer: individuals will be } \\
\text { exploited or will exploit the } \\
\text { organization-or both will become } \\
\text { victims. } \\
\text { A good fit benefits both: } \\
\text { individuals find meaningful and } \\
\text { satisfying work, and organizations } \\
\text { get the talent and energy they need } \\
\text { to succeed. }\end{array}$ \\
\hline
\end{tabular}




\begin{tabular}{|c|c|}
\hline $\begin{array}{l}\text { POLITICAL (p. 186) } \\
\text { - Organizations are coalitions of } \\
\text { diverse individuals and interest } \\
\text { groups } \\
\text { - There are enduring differences } \\
\text { among coalition members in } \\
\text { values, beliefs, information, } \\
\text { interests, and perceptions of reality } \\
\text { - Most important decisions involve } \\
\text { allocating scarce resources - who } \\
\text { gets what. } \\
\text { Scarce resources and enduring } \\
\text { differences make conflict central } \\
\text { to organizational dynamics and } \\
\text { underline power as the most } \\
\text { important asset. } \\
\text { Goals and decisions emerge from } \\
\text { bargaining, negotiation, and } \\
\text { jockeying for position among } \\
\text { competing stakeholders }\end{array}$ & $\begin{array}{l}\text { SYMBOLIC (pp. 242,243) } \\
\text { - What is most important is not what } \\
\text { happens but what it means } \\
\text { Activity and meaning are loosely } \\
\text { coupled; events have multiple } \\
\text { meanings because they interpret } \\
\text { the experience differently } \\
\text { - In the face of widespread } \\
\text { uncertainty and ambiguity, people } \\
\text { can create symbols to resolve } \\
\text { confusion, increase predictability, } \\
\text { find direction, and anchor hope } \\
\text { and faith } \\
\text { Many events and processes are } \\
\text { more important for what is } \\
\text { expressed that what is produced. } \\
\text { They form a cultural tapestry of } \\
\text { secular myths, heroes, ceremonies, } \\
\text { and stories that help people find } \\
\text { purpose and passion in their } \\
\text { personal and work lives } \\
\text { Culture is the glue that holds an } \\
\text { organization together and unites } \\
\text { people around shared values and } \\
\text { beliefs }\end{array}$ \\
\hline
\end{tabular}

However, like our education system these assumptions are White, male normed, they do not necessarily focus on gender, language, culture, or race.

\section{Review of the Research Literature}

Bolman and Deal (2014) have synthesized research in the area of leadership and used by academics and practitioners, creating an "inclusive framework embracing four ideas about leadership. The ideas are powerful enough to capture the subtlety and complexity of leadership, yet simple enough to be helpful" (p.15). The frames are organized in their historical significance. 


\section{The Four Frames of Organizational Leadership}

Structural Frame. According to Bolman and Deal (2003), the structural frame is one of the oldest and most widely used ways of thinking about organizations. The origins of the structural frame focus on principles of specialization span of control, authority and delegation. The forms and functions of the structural frame influences what happens in the workplace. Examples of structural frame look at the roles of leaders, how groups function as units and tasks: "The right structure depends on prevailing circumstances and considers an organization's goals, strategies, technology, and environment” (p.49).

Further, Bolman and Deal (2003) state

Organizations operating rapidly changing, turbulent, and uncertain environments need much more complex and flexible structures. Understanding the complexity and variety of design possibilities can help create structures that work for, rather than against, both the people and the purposes of the organizations (p. 67).

Schools operate by incorporating teams towards a common task. Bolman and Deal highlight research of highly effective teams by identifying the following; 1) high performing teams shape purpose in response to demand or an opportunity; 2) translate common purpose into specific, measurable performance goals; 3 ) are a manageable size; 4) develop the right mix of expertise; 5) develop common commitment to working relationships and 6) hold themselves accountable. The structural frame highlights the importance of the structures of systems as well as the structure of the team. Bolman and Deal (2014) write, "A designated leader is no guarantee that a team will be well led. An 
effective team requires leadership that aligns the group structure with the groups tasks and circumstances" (p. 48).

The structural frame is often a good place to start when examining an organization. Bolman and Deal (2014) share that in order to apply the structural frame, one needs to know what is going on, what is working, what needs to change, what problem needs to be solved (p. 32). When applying a structural frame, they claim that there are times where the problem becomes worse before it gets better. Additionally, they explain, "If structural thinking is one of your strengths, your natural inclinations can make you a valuable contributor in any team or organizational context" (p. 35).

The Human Resource Frame. This frame focuses on relationships. "Great human resource leaders see people as the key to success, they apply a consistent set of people friendly principles, they communicate a strong belief in people, they develop a philosophy and practices to put their belief in action, they are visible and accessible, they empower others" (Bolman\& Deal, 2014, p. 49). The human resource frame calls attention to the interrelation of people and organizations. This frame suggests the alignment of the needs of both the organization and the people. When organizations embrace ways in which to align, the workforce is viewed as an investment rather than a cost (p. 129). Bolman and Deal cite Waterman (1994) who notes the impact of aligning employer and employee goals (p. 92), "Modern behavioral scientists such as Abraham Maslow have shown that virtually every person has a hierarchy of emotional needs, from basic safety, shelter and sustenance to the desire for respect, satisfaction, and a sense of 
accomplishment. These values have appeared as the centerpiece of progressive company policies, always with remarkable results" (p.118).

Bolman and Deal (2014) claim interpersonal blindness is a cause of leadership failure (p. 63). Many leaders don't know their impact on other. They assume others see them as they see themselves and then blame others when things go wrong. "Regardless of how you see yourself, what matters is how you are seen by those you hope to lead" (p. $68)$.

In exercising the human resource frame, there are principles and specific practices that should be implemented. Bolman and Deal (2003) outline,

The principles include building and implementing a management strategy, hire the right people, keep, invest and empower people and promote diversity. The practices promote the development of a shared philosophy and building systems to implement the philosophy, know who you want and be selective, reward and protect jobs as well as promote from within, invest in learning, encourage autonomy and participation. Lastly, be explicit and consistent in the organization's diversity philosophy (p. 136).

These practices reflect the principles respectively. "No single strategy is likely to be effective by itself. Success typically requires a comprehensive strategy undergirded by a long term human resource management philosophy" (p. 159). Additionally, they state how leading within the human resource frame requires leaders to practice and learn from advocacy and inquiry, which will lead them to enhance their skills and communicate with others effectively.

The Political Frame. In examining the political frame, Bolman and Deal describe politics in the following way: "politics is simply the realistic process of making decisions and allocating resources in a context of scarcity and divergent interest" (p.181). 
Bolman and Deal note the notion of authority, "The political frame views authority as only one among many forms of power", with the question "how does each group articulate preferences and mobilize power to get what it wants?" (p. 192). Bolman and Deal discuss the notion of conflict as a natural and inevitable and that it is not a sign that something is awry and that in fact it "challenges the status quo [and] stimulates interest and curiosity (p. 198). They explain,

From a political perspective, goals, structure, and policies emerge from an ongoing process of bargaining and negotiation among major interest groups...Government agencies may be controlled more by the permanent civil servants than by the political leaders at the top. The dominant group in a school district may be the teachers' union rather than the school board or the superintendent...but the political view suggests that eh exercise of power is a natural part of an ongoing contest. Those who get and use power best will be winners (p. 201).

Additional, they state, "constructive politics is a necessary possibility if we are to create institutions and societies that are both just and efficient (p. 201).

Bolman and Deal (2014) explain the power of relationships is a crucial compliment to the power of position.

There are four skills highlighted in the political frame: 1. Agenda setting 2. Mapping the political terrain 3. Networking and forming coalition 4. Bargaining and negotiating. In reflecting on leadership at Xerox, agenda outlines structures of goals and activities, yet politically the agenda must address the interest and the ways for getting the goods. The first step is creating an agenda that has a vision, which is formed with all key parties and a strategy for achieving this vision while recognizing internal and external forces. Therefore, leaders must map a political terrain including a two dimensional diagram illustrating players (who is involve) and power (how much clout each wields) and interest (what players want). From here, focus on networking and building coalitions are needed. Leaders must build relationships and also find those that could help get things done and complete what you need. Further, "political dynamics are inevitable 
under conditions most managers face very day: ambiguity, diversity and scarcity" (p. 211).

Organizational change and effectiveness depend on political skills, which can aid in recognizing and understanding political realities. Bolman and Deal (2014) state, "to be an effective leader you need to understand and leverage political dynamics rather than shy away from them" (p.80). Leaders as politicians, consider potential for collaboration, the importance of long-term relationships, and most important their own values and ethical principles.

The Symbolic Frame. Stories provide insight to the history of the organization as well as convey value and identity. "Symbols carry powerful intellectual and emotional messages; they speak to both the mind and the heart. The symbolic frame focuses on how humans make sense of the messy, ambiguous world in which they live" (p.240). Bolman and Deal (2003) ask whether leaders shape culture or are they shaped by it? They later articulate, "leaders who understand the power of symbols are better equipped to understand and influence their organizations" (244). According to Bolman and Deal, the symbolic frame allows organizations to use symbols as a way to make meaning, vision brings cohesion and heroes provide role models for others to emulate.

Bolman and Deal (2014) suggest, "If leaders assume that history starts with their arrival, they typically misread their circumstances and alienate their constituents. Wise leaders attend to history and link their initiatives to the values, stories, and heroes of the past" (p. 114). Thus, stories in high performing groups are ways in which traditions can 
be articulated and they can also guide behavior. Hence, the stories bring meaning and value of their work; all great groups believe that they can make a difference.

Leaders get more done when they develop and use key leadership strategies. Bolman and Deal $(2003,2014)$ suggest an integration of frames for effective practice, as problems and situations do no arise in neat single frame. Instead a multi-frame approach aids with the challenges of leadership. Reframing is a powerful tool for generating possibilities. Each of the frames generates its own alternative scenario and each provides a different set of consequences. A leader needs to balance what needs to be done with what will provide needed results.

Bolman and Deal (2003) suggest, "There are guiding questions that aid in choosing a frame" (p. 310). However they add, "these questions are no substitute for judgment and intuition in deciding how to frame or respond to a situation" (p. 312). Additionally, Bolman and Deal conclude, "several lines of recent research find that effective leaders and effective organizations rely on multiple frames. Studies of effective corporations, of individuals in senior management roles, and of public administrators all point to the need for multiple perspectives in developing a holistic picture of complex systems” (p. 319). Versatility, understanding, and understanding of all four frames are valuable for any leader. Few leaders are completely symmetrical. As the number of dual immersion programs grows within the state, so do its leaders. The ability of immersion leaders to navigate leadership through the four frames is imperative to the growth in achievement of EBs. 


\section{Historical Perspective of Dual Language}

Sixty-four years ago, Brown v. Board of Education (1954), deemed that Black students have a right to receive the same education as White students. While the ruling does not specifically name other students of color, it does apply to students similarly situated. Historically, discussion around bilingual education has been prominent although it has had different areas of focus. German immigrants supported bilingual education prior to a movement towards English only. In 1965, in the midst of the civil rights movement, the Bilingual Education Act emerged. Lyons (1990) talks of the Bilingual Educational Act of 1965 as law that focused first on Spanish speaking children and then on emergent bilinguals. No Child Left Behind (NCLB), later reauthorized as the Elementary and Secondary Education Act (ESEA), brought new accountability. If nothing else, the NCLB law provided a snapshot of where the educational system was deficient and focused efforts towards seeing what was actually happening with students facing educational disparities. The Anti-Defamation League (2007) reports that groups, such as Federation for American Immigration Reform (FAIR) and Numbers USA (Numbers USA n.d.), exemplify the anti-immigration movements that not only want to refrain immigrants from bilingual education but are advocates for anti-immigration reform. Lau v. Nichols (1974) mandated bilingual education as a means to meet the needs of EBs. While many states have banned bilingual education, Oregon districts are increasing dual language immersion programs as a viable strategy for EBs (ODE, 2013) This illustrates that bilingual education, has been part of our nation's history and while there are political groups that work against initiatives and laws to provide access to 
bilingual education our state has taken a stance and has placed value on dual immersion as a viable option to eliminate educational disparities among EBs.

Peterson (2011) writes, "this concept of teaching in the language best understood by the child while the child acquires the target language has been called several names, the current being bilingual education [which intends to help] students maintain their native language or to continue to grow in their native language while acquiring a second language" (p.28). Historically, the United States has experienced a back and forth in regard to bilingual education, either bilingual education is promoted based on immigration patterns and enrichment for the privileged or it is opposed based on political situations that emerge. Peterson further explains, "the National Education Association supported an English-only movement in 1891, blaming immigrants for 'destroying distinctive Americanism"' (p.29). The current ideal of being American encompasses the actualization of the "American Dream" which promises upward mobility, regardless of social class, if one works hard. It promises freedom, opportunity, success and prosperity. The undeniable melting pot, one nation, one language, and assimilation is now challenged and often other analogies describe a more realistic perspective. For example, Garcia, Flores and Chu (2011) cite Crawford and Menken and remind us that in

The era of the No Child Left Behind Act (2002), bilingualism as a resource and tool in the education of emergent bilinguals has been increasingly marginalized (Crawford, 2004), as English-only high-stakes test become the only measure of academic accountability (Menken, 2008). Transitional bilingual education programs under attack, and in decline in terms of enrollments, although they are tolerated. In the past, most bilingual education programs at the secondary level have been transitional. Meanwhile, developmental bilingual education programs where language 
minority students, usually at the elementary level, are taught in two languages throughout schooling have mostly disappeared (p.8).

Leaders must pursue what Marshall describes as the critical policy approach, which embraces critical theory and social justice (Marshall \& Gerstl-Peppin, 2000, p.92). Furthermore she states, "the challenge of politics is also about making connections with and supporting communities engaged in political struggle" (p.119). Instead, bilingual educators must spend their time defending their stance knowing that many states, such as California and Arizona, have passed anti bilingual legislation leaving teachers vulnerable to law suits should they choose to teach children in their native language. As a bilingual school leader and educator, it is imperative to understand what has happened historically and to make sure to advocate for those that do not know how. Most do not understand the survival mode that many families of EBs are experiencing as they navigate the challenges of being in a new land. Many do come wanting that American dream, without realizing that there are systems that have negated their opportunity of achieving it. In the case of EBs, our school system needs not dishonor their language but instead use the benefits of bilingualism so that students gain command of two languages and use their skills to become productive citizens of our nation.

Moreover, not only do educators battle the xenophobic policies and initiatives but also have to deal with federal mandates of current NCLB law. A 2002 editorial mentioned that "the current attack on bilingual education denies children a basic human and civil right - the right to learn in their native language" and further states that this right is not only a civil right but also a human right because much of the English 
immersion classes' curriculum is incomprehensible (Rethinking Schools, 2003). The Castañeda v. Pickard decision of the US $5^{\text {th }}$ Circuit Court of Appeals (1981) provides the legal basis to question many of these assessment practices for ELL students. This ruling ignores the assumption that Lau v. Nichols (1974) mandated bilingual education to meet the needs of Emergent Bilinguals. This class action suit, by parents of non-Englishproficient Chinese students, was brought against the San Francisco Unified School District. In 1974, the Supreme Court rules that identical education does not constitute equal education under the Civil Rights Act of 1964. The court ruled that the district must take affirmative steps to overcome educational barriers faced by the non-English speaking Chinese students in the district [414 U.S. 563 (1974)]. Plyler v. Doe [457 U.S. 202 (1982)] further supported Lau v. Nichols by emphasizing that students, whether documented or undocumented, had the same right for a free public education.

More and more "English only" sentiments fill our political arenas as people like conservative business man Ron Unz who used his money and power to start statewide initiatives to ban bilingual education. These include the ballots that were passed in Arizona, California and Massachusetts even though Massachusetts had passed laws supporting bilingual education 31 years prior (Rethinking Schools, 2003). Moreover, Carter (2014) reports that California is looking to repeal proposition 227 which banned bilingual education in the 1990's. Bilingual education continues to be a controversial topic.

Counter to Castañeda v. Pickard (1981), there are cases that support bilingual education. Rios v. Reed (1978) was not only significant for recommending bilingual 
education but also for assuring that programs be held to a standard and that teachers receive the correct certification. Additionally the court wrote, "while the district's goal of teaching Hispanic children the English language is certainly proper, it cannot be allowed to compromise a student's right to meaningful education before proficiency in English is obtained" (IDRA, n.d.). Serna v. Portales and Gomez v. Illinois further support the efforts of these cases to provide for the needs of EBs. For as many cases that support bilingual education there are cases that erode its efficacy.

In Oregon, a measure to limit bilingual education, in which student were to be taught entirely in their non-English native language for all or part of the school day failed in 2008 but the fight was then compounded by Oregon's weak financial/budget situation. That same year, the Portland metro district met three different times to vote on the Spanish Immersion program. Administrators around the district were working and reworking the budget so that the program could be kept. The board voted four to one to suspend the program. The dialogue centered on lack of money to sustain the program versus keeping enrichment for the students in the program. Never was this dialogue about doing what was right for the ELL students that were in the district. More than 300 people filled the auditorium and most clapped when the decision was finalized. In a time of crisis, dual language immersion was the program to be eliminated.

Times have changed during these past ten years. Failure of benchmark achievement and low graduation rates for EBs have lead the Oregon Department of Education to embrace dual language as a strategy for success of these students. In the Oregon English Learners Statewide Strategic Plan 2013-2016 dual language development 
is outlined in its first goal. Such goals expect measurements indicating an increase in numbers of bilingual programs and number of EBs participating in English Learner programs. The strategic plan is also supported by the grant.

This August the State Board of Education approved a rule establishing a Dual-Language/Two-way bilingual Grant program as one of the methods to address the specific direction in HB 3233. The Dual Language/Two-Way Bilingual Grant is intended for districts, charter schools, or consortia of school districts to design, implement and/or improve dual language bilingual programs. These programs assist students in becoming academically proficient in two languages by providing research-based instruction that closes the academic achievement gap in English and continues to develop a student's first language (ODE, 2013).

Understanding these key legal issues is an integral part of being a leader for a dual immersion school. This understanding is foundation for the advocacy of such programs to improve achievement for EBs and a reason for developing and expanding these programs statewide.

It is good to see that not only are individual teachers, schools and districts embracing this paradigm shift, but also to see the state of Oregon fostering this culturally proficient leadership. Lindsey, Robins and Terrell (2009) define cultural proficiency "as a model for shifting the culture of the school or district; it is a model for individual transformation and organizational change (p.4).” Additionally, they say that cultural proficiency is "a mind-set, a worldview, a way a person or an organization make assumptions for effectively responding to, and planning for issues that arise in diverse environments" (p. 4). It is hopeful to think that the use of dual language immersion as a theoretical foundation informs practice, allowing school leaders to further emphasize the need to advocate for those who do not have a voice. 
As educators who believe in social justice we think it is important to fight for everyone's human and civil rights. Ultimately, we believe that all children should have the right to learn at least two languages, including their mother tongue. Throughout the world children become bilingual or multilingual and it is valued. We call upon everyone who believes in bilingual education to testify, organize and demand that our children's right be restored and protected (Rethinking Schools, 2003).

Despite the historical perspective of bilingual education in the United States, may states have gone away with efforts to increase bilingual education despite research that that shows that the command of a first language affects the learning of the language (Rethinking Schools, 2003). Ravitch (2000) reminds us that immigration has been a hot political issue from the beginning of our history with the only difference being that those northern Europeans, who experienced discrimination, as new immigrants, are not part of a dominant society. She states, "ethnic characterizations of the school children developed quickly into stereotypes. The poor academic performance of large proportions of the immigrant children was seen not as an indictment of the school, but as confirmation of popular attitudes about the new immigration" (p.176). A dual language model would be a first step at tackling education disparities for children of color, children of poverty and Emergent Bilinguals. The US Census Bureau has projected that the US White - NonHispanic population will become a minority (that is, less than half of the total population) during the 2040's. In December 2012, the Bureau projected that 2043 would be the year in which the majority of US residents would be minorities, with no single ethnic classification constituting a majority of the population. Therefore, our policy making should take into account not only working to erase educational disparities but also to 
prepare students for the nation that will look very different than what they have known and to be citizens of the world.

\section{Principles of Learning}

There are many theoretical frameworks for learning and for language acquisition. For the purpose of this discussion, the frameworks examined are guideline that guide quality instruction in second language and English language development every day. This discussion includes the work of Chomsky (1965), Krashen (1982), Cummins (1981), and Thomas and Collier (1987). Further, I will connect the above-mentioned theorists with the theories of Vygotsky (1978), Freire (1968), and Lave (1991). The frameworks of these theorists will connect to the problem of practice discussed in this paper, specifically how leaders can best serve the needs of Emergent Bilinguals through leadership in dual immersion programs.

The language acquisition theory of Chomsky (1965) revolutionized the study of linguistics. Chomsky's theory states that children can acquire language quickly. They are creative with language and they do not just remember a response to a question or situation but instead are creative in capturing a response suited for the situation. Omaggio (1986) reiterates this position, stating, "the creative aspects of language behavior implied that the human mind was involved in deep processing of meaning and was not simply mechanically producing memorized strings of learned responses to vaguely defined environmental stimuli" (p.26).

Chomsky (1965) influenced Krashen (1987) in that “Krashen’s 'monitor language hypothesis' also mirrors a version of Chomsky's aversion to structural linguistics as well 
as Chomsky's development of new transformational grammar approaches

(LingTECHguistics, 2008). The work of Krashen guides praxis in second language acquisition. Krashen's theory emphasizes the importance of "comprehensible input" in an environment that has low stress for language production. Krashen (2007) refers to this environment as one in which the "affective filter" is reduced. Krashen (1981) provides additional guidelines for comprehensible input as follows:

The best methods are therefore those that supply 'comprehensible input' in low anxiety situations, containing messages that students really want to hear. These methods do not force early production in the second language, but allow students to produce when they are 'ready', recognizing that improvement comes from supplying communicative and comprehensible input, and not from forcing and correcting production (pp. 60-73).

Cummins' (1981) theoretical framework illustrates the difference between communicative language and with academic language. Cummin's work speaks to Basic Interpersonal Communication Skills (BICS) and Cognitive Academic Language Proficiency (CALP). Cummins demonstrates that BICS are the "surface" skills of listening and speaking which many students typically acquire quickly while CALP is the basis for children's ability to cope with the academic demands placed upon them in the various subjects. Cummins states while many children develop native speaker fluency, specifically BICS, within two years of immersion in the target language; however, it takes between five to seven years for a child to be working on a level with native speakers as far as academic language is concerned (Cummins, 2000).

These teaching and learning theories have produced results that reduce educational disparities among EBs. Perhaps the most influential and significant study has 
been the work of Thomas and Collier (1997, 2004). Thomas and Collier attest that bilingual education benefits all. The ways in which dual immersion, an enrichment model, benefits include: 1. Enrichment models close the academic achievement gap in L2 and in first language L1 students initially below grade level. 2. Core academic curriculum, focused on real problem solving, creates a cognitive challenge and stimulates students to make more than one year's progress every year in both languages. 3 . Teachers can lead to a context where students from each language group learn to respect their fellow students as valued partners in the learning process with much knowledge to teach each other. 4. Parents of both language groups tend to participate much more actively in school because they feel welcomed, valued, and respected, and included in school decision making. Two decades of research and program design research has quantified these results. The data produced by Thomas and Collier certify that no other program has successfully closed the achievement gap as two-way dual immersion models have.

However, we must examine the learning theories that have influenced language acquisition theorists. Two prominent learning theories, social constructivism and situated learning are related to the theories of dual immersion programs.

In social constructivism the theory is that students can do tomorrow, without assistance, what could not be done today (Vygotsky, 1998). Therefore, learning happens as individuals engage in activities that are social in nature. The epistemology is constructed through the interactions that are shared in this social setting and/or culture. 
Indeed, in a model such as dual immersion where culture is valued, a student will experience the social aspects that culture brings.

When applying theories of constructivism to language acquisition, we must look at learners' social and linguistic contexts. Language is not a solitary action. Language is used to communicate with others. In dealing with constructivism we must look at what learners bring. Learners bring funds of knowledge, experience/s, perceptions, content knowledge, culture and feelings to name a few. In a social constructivist setting, a learner is making sense and building their understanding while learning in a social setting. The dual instruction model values the culture and experience of the learners. Whether you are a learner that speaks the L1 or L2 language, the models allow students' culture, prior knowledge, experience, and perception in a linguistic context that is viewed as a benefit.

Vygotsky (1998) speaks of the Zone of Proximal Development (ZPD). A common misconception is that children can learn language if fully immersed. But this is why the dual immersion model must develop a delicate balance. The ZPD matches learning with the student's developmental level. In essence, a child can't learn a second language unless that foundation is set in the first language. Therefore, if we are looking at the ZPD as applied to language acquisition, we cannot expect a child to make sense of input beyond the current level of input comprehension (Krashen, 2007). Language acquisition, in any of these models, provides this example of social constructivism as a child begins to learn the language as a need to communicate with the community of which he/she is a member. 
Another learning theory is that of situated cognition which also is influenced by Vygotsky's ZPD. Too often ELL classrooms handle the subject matter in a completely objective way. Ironically, language is handled like an object, where the expert (the teacher), "talks" about the language to the amateurs (the students) instead of using the language in a social setting. There is no sense of community in this setting. Classrooms across the nation work through language drills that are absolute and little emphasis is placed on actually communicating. The dual immersion models do quite the opposite. There is no hierarchy and students help and learn from each other and are able to explain what they know. Furthermore, dual immersion models provide a situation in which communication is authentic. Students learn their content while communicating in two languages becoming bilingual, bi-literate and bicultural beings. Making sense of this enculturation allows them to form their identity and even perhaps understand who they are as a person. In looking at both social constructivism and situated learning, it could be easy to confuse the subtle differences and their role in two-way immersion programs. For that reason, it is important to restate that social context is what provides learners the authentic learning situation and that it not only influences the learner but also, certainly makes the difference in their language acquisition. Table 2 synthesizes the major theoretical framework applied to learning theory and dual immersion learning theory. 
Table 2.2:

Theoretical Framework applied to learning theory and dual immersion

\begin{tabular}{|c|c|c|}
\hline heory & Key Points & $\begin{array}{l}\text { How it is practiced in a } \\
\text { Dual immersion classroom }\end{array}$ \\
\hline $\begin{array}{l}\text { Cummins: BICS } \\
\text { and CALP } \\
\text { Social interaction } \\
\text { and language - } \\
\text { academic content } \\
\text { language }\end{array}$ & $\begin{array}{l}\text { - Individuals construct } \\
\text { their meaning } \\
\text { - Meaning is influenced by } \\
\text { the social interactions of } \\
\text { our world } \\
\text { - All learners bring prior } \\
\text { knowledge } \\
\text { - Individuals engage in } \\
\text { activities that are social } \\
\text { in nature }\end{array}$ & $\begin{array}{l}\text { Learners aren't given } \\
\text { language; they must acquire } \\
\text { it on their own } \\
\text { - } \quad \text { Learners are put in a } \\
\text { classroom that more } \\
\text { similarly mirrors the world } \\
\text { around them. } \\
\text { - Students culture and } \\
\text { knowledge is valued and } \\
\text { shared } \\
\text { - Students actively engage to } \\
\text { communicate with each } \\
\text { other. }\end{array}$ \\
\hline $\begin{array}{l}\text { Vygotsky's Zone of } \\
\text { Proximal } \\
\text { Development } \\
\text { (social } \\
\text { constructivism) }\end{array}$ & 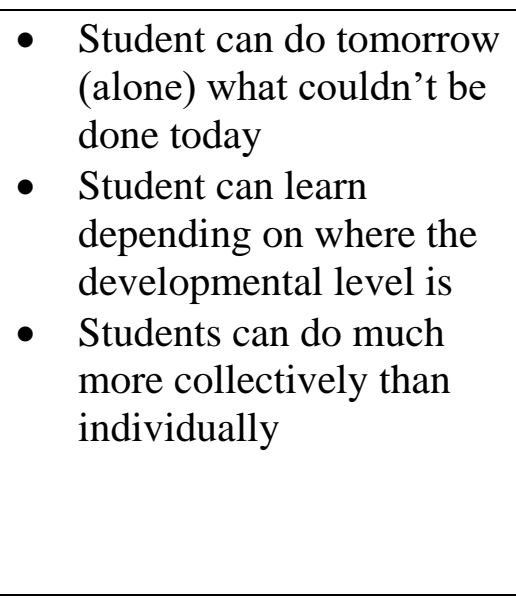 & 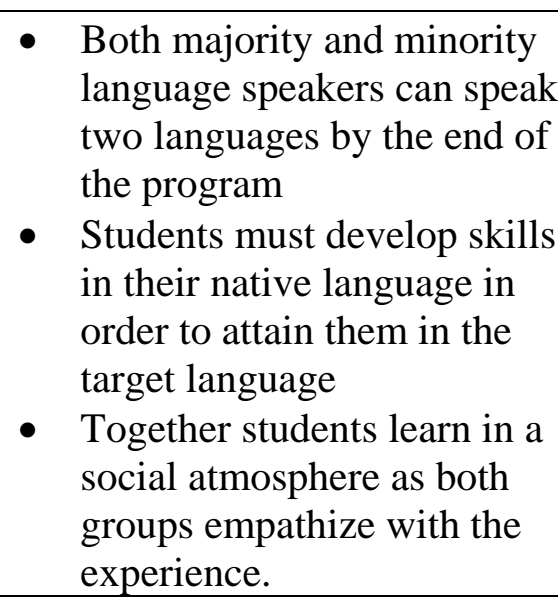 \\
\hline $\begin{array}{l}\text { Situated Learning } \\
\text { Theory } \\
\text { (Lave) } \\
\text { Thomas and } \\
\text { Collier: }\end{array}$ & $\begin{array}{l}\text { - Authentic activity, tool } \\
\text { and community } \\
\text { - Subject has multiple } \\
\text { experts and is available } \\
\text { for relationships } \\
\text { - Social context makes the } \\
\text { difference }\end{array}$ & $\begin{array}{l}\text { - TWI program model, } \\
\text { language and bilingual; bi- } \\
\text { literate and bicultural } \\
\text { community } \\
\text { - Students help learn from } \\
\text { each other, "masters" } \\
\text { explain what they know } \\
\text { - Community reflects the } \\
\text { world in which we live }\end{array}$ \\
\hline
\end{tabular}




\section{Leadership and Student Achievement}

Much research has examined the role of the principal and principal impact on student achievement. Studies show that while not direct, school leaders impact student achievement (Cotton, 2003; Fullan, 2001; Hattie, 2012; Marzano, Waters \& McNulty, 2005;).

Like the four frames presented by Bolman and Deal (2003), Marzano et al. (2005) discuss four leadership styles that define situational leadership. The four styles are defined as follows: 1) the telling style: "when followers are unable and unwilling to perform a given task, the leader directs the followers; actions without much concern for personal relationship" (p. 17); 2) the participating style: "When followers are unable but willing to perform the task, the leader acts with followers in a friendly manner but still provides concrete directions and guidance" (p. 17); 3) The selling style: "When followers are able but unwilling to perform the task, the leader does not have to provide much direction or guidance but must persuade followers to engage in the task (p. 17); 4) the delegating style: "when followers are able and willing to perform the task, the leader leaves the execution of the task to the followers with little or no interference" (p. 18). The importance is for the leader to be able to work within all four styles and to know the ability of the followers. He claims, "The effective leader realizes that no one leadership style is appropriate for all followers and all situations and accurately discerns which styles are appropriate for which followers in which situations" (p. 18).

Cotton (2003) summarizes her research by stating; “principal's behaviors have little direct impact on student outcomes but substantial indirect impact that is, impact 
mediated through teachers and others" (p. 73). However, Cotton describes behaviors that contribute to student achievement. She notes that the behaviors, 26 of them, fall within five categories, which she believes helps any principal in the time of high stakes accountability and results. The categories are outlined as follows:

The first is establishing a clear focus on student learning, including have a vision, clear learning goals, and high expectations for learning for all students. The second is interactions and relationships. This category includes behaviors such as communication and interaction, emotional/interpersonal support, visibility, and accessibility, and parent/community outreach and involvement. The third is school culture, which includes such behaviors as shared leadership/decision making, collaboration, support of risk taking and continuous improvement. The fourth is instructions, which includes such behaviors as discussing instructional issues, observing classrooms and giving feedback, supporting teacher autonomy, and protection instructional time. The fifth and final category is accountability, which includes monitoring progress and using student progress data for program improvement (p. ix-x)

Hattie (2012) talks of transformational and instructional leaders. Hattie speaks of teachers being the most important players in education when it comes to making a difference in student learning. Like Cotton, Hattie (2003) makes a point to show that leaders have an indirect impact on student results by having high expectations for all teachers and students. When speaking of transformational leadership, Hattie writes,

Transformational leaders are attuned to inspiring teacher to new levels or energy and commitment towards a common mission, which develops the school's capacity to work together to overcome challenges and reach ambitious goals, and then to ensure that teachers have time to conduct their teaching (p. 174).

Hattie describes the components of instructional leadership as follows:

Instructional leaders attend to the quality and impact of all in the school on student learning, ensure that disruption to learning is minimized, have high expectations of teacher for their students, visit classrooms, and are 
concerned with interpreting evidence about the quality and nature of learning in the school (p.174).

In the area of immersion and using dual immersion programs to eliminate disparities for Emergent Bilinguals, leaders must evaluate their sense of moral purpose. Fullan (2001) writes, "leadership, if it is to be effective, has to (1) have an explicit 'making-a-difference' sense of purpose, (2) use strategies to mobilize many people to tackle tough problems, (3) be held accountable by measured and debatable indicators of success, and (4) be ultimately assessed by the extent to which it awakens people's intrinsic commitment (p.20). Fullan's five components of leadership, moral purpose, understanding change, relationship building, knowledge creation and sharing, and coherence making, provide a framework for undertaking leadership when working to eliminate disparities for EBs.

Connected to Fullan's (2001) concept of relationship building, Spillane, Halverson and Diamond (2001) explain that distributive leadership involves three essential elements: leaders, followers and situation. These elements are not isolated instead they an interacting network. In order to support dual immersion programs and to fully assist bilingual instruction, leaders need to include all stakeholders. This means understanding the relationship between formal and informal leaders and their impact on disparities among EBs. Leaders must look at ways in which dual language immersion is not an either/or relationship, but instead viewed as a benefit for all.

Heifetz (2009) suggests that leaders who practice adaptive leadership embrace disequilibrium and lead by allowing others to experience a zone of disequilibrium. This 
way, stakeholders do not become complacent and can continue to work to question and eliminate the predictability of achievement for EBs. In the realm of dual language immersion, many leaders need to balance the needs of the neighborhood program, which houses all students that live within the boundary area of the school, and the dual immersion programs, which maintains enrollment of a half native and half non-native English speakers. Leaders experience disequilibrium when developing and expanding dual immersion programs as many families and teachers feel that they threaten the neighborhood programs. This sentiment is mainly explained, as opponents perceive dual immersion as a deficit model - the taking away from the neighborhood side. Heifetz suggests leaders neutralize potential opposition and recognize the problems the organization potentially faces. When keeping the needs of ELL's in the forefront and its connection to dual immersion, Heifetz encourages leaders to "reflect on today's journey, renew your emotional resources and recalibrate your moral compass" (Heifetz \& Linsky, 2002, p.11).

Fullan (2001) writes, "Understanding the change process is less about innovation and more about innovativeness. It is less strategy and more about strategizing” (p.31). Leading schools as advocates for dual immersion for EBs is a journey where leaders must 1) understand that change is difficult, 2) keep in mind the four frames (Bolman and Deal, 2003) which guide actions when working within complex organizations, 3) work with formal and informal leaders and stakeholders to assure that there is a distribution of leadership which looks to assure success for all, and 4) keep members in a zone of 
disequilibrium by embracing opposition which will keep the vision needed to provide educational opportunities and erase the disparities that still exist.

As a Latina leader, I have been educated and understand different educational systems, that of South America and the United States. My leadership opportunities have led to the advocacy of underrepresented students that too often fall into the predictability of achievement and EBs are too often over represented in statistics that continue to hinder their opportunities. We now have newly adopted common core state standards and higher accountability measures for graduation. As a leader, I take responsibility and feel that we must do all that we can to prepare our EBs to not only be successful in school but in life by honoring their gift - dual language. Further, one could ask if dual immersion is proven to help EBs, why not employ dual immersion to other groups of students who also experience educational disparities.

I have identified four areas of literature that relate to a principal leading dual immersion schools. The first is the literature that directly addresses the structure leadership within organizations. Secondly, I chose to review the literature that identifies the history of dual language programs in the United States. Thirdly, I present the literature, which presents an understanding of the learning perspectives as they pertain to dual language. Last, I have taken a look at the literature that specifically addresses the impact of leadership of student achievement.

\section{Critique}

While educational researchers have made a valuable contribution to the body of literature in the area of leadership, I critique their work in this next section. The section 
will review literature that focuses on general framework of leadership, change leadership, instructional leadership, culturally relevant leadership, and leadership for EBs. It concludes with dual language immersion research. These theorists have made a significant contribution to the understanding of effective leadership. However, most have incorporated a context that is a reflection of the white male dominant culture, which norms most of the processes in education.

Reeves (2006) describes leadership as multi-dimensional. He sites different themes or dimensions of leadership. In order to lead, there needs to be understanding of each facet of leadership. In this critique, I will explore each dimension that I found in the literature review and will synthesize each by giving a general description of the type of leadership, leadership dimension strengths and critiques of each.

General framework for leadership. The operating principles of Bolman and Deal (2003) encompass the notion that leaders must operate within four frames of leadership in order to garner solutions to difficult situations and/or problems in an organization. The strengths Bolman and Deal present, of their four-frame model, are that each model fits different situations within the context of the organization. Thus, we can all apply the frames to our work. They share vignettes that make each frame simple, broad and easily understandable. Each frame is presented with a story or stories to make this comprehension more concrete.

However, there are four critiques to the work of Bolman and Deal (2003) in the areas of individual strengths, reflections, context and cultural paradigms. We must assume that each leader can apply any of the four frames at any given time. While these 
frames are easily understandable and broad enough to apply to all situations, they are still complex in usage and leaders need to understand their own strengths in order reflect on their leadership and to not ignore other frames that may be more applicable to a situation.

While each frame is easily comprehensible. Bolman and Deal, themselves state, that it takes time and experience in order to do this. (Bolman and Deal, 2014). Bolman and Deal have little mention of self-reflection and importance of ensuring strategies are adjusted within a specific context. When analyzing the assumptions presented there is no discussion of race, gender and it is normed to a white male perspective.

Lastly, metaphors of the frames are culturally normed to white male leadership and cultural paradigms. The metaphors for the organization according to each frame include 1) Factory or machine for structural frame, 2) Family for human resource frame, 3) Jungle for the political frame and 4) Carnival, temple or theater for the symbolic frame and sees leaders as, 1) architects or tyrants 2) catalyst or wimp 3) advocate or hustler 4) prophet or zealot respectively. Thus, one may question whether these frames pertain more to male leaders or female leaders. Further, do these frames perpetuate the institutional disparities that exist in our educational system given that equity is not mentioned as a consideration within the frames?

Change leadership. As the achievement gap drives much of the conversation regarding school effectiveness, reform and change, we must embrace change as the norm (Bridges, 2003). Bridges states that change is constant. Thus, if change is constant, we as leaders must deal with transitions. He writes, "There can be a number of changes, but unless there are transitions, nothing will be different when the dust clears" (p. 4). The 
work of Fullan (2003), Diamond (2013) and Heifetz (1997) encourages leaders to understand the complexity of change and provide tools for the transitions that help manage the change.

Fullan (2003) adds to the literature by ensuring a moral purpose guides change: "Leaders who combine a commitment to moral purpose with a healthy respect for the complexity of the change process not only will be more successful but also will unearth deeper moral purpose" (p. 5). The strength of a focus on moral purpose lies in the inherent commitment to the moral purpose, which can change the lives of the students we educate (Bridges, 2003). Additionally, he states, "At the loftiest level, moral purpose is about how humans evolve over time, especially in relation to how they relate to each other" (p. 14).

Diamond (2013), citing the work of Spillane et al. (2004), discusses the distribution of leadership among multiple stakeholders. As Diamond noted, Spillane (2006), Spillane and Diamond (2007), and Spillane, Caburn and Pareja (2009) found "Research using this perspective demonstrates that leadership does not reside solely with principals or other formally designated leaders in schools and that it involves multiple individuals including teachers, professional staff members, and subject area specialists, among others" (p. 85). When speaking of distributive leadership Diamond adds, "Distributed leadership has been understood as shared or democratic leadership, linked to certain organizational outcomes, and discussed normatively as a desirable type of leadership" (p. 86). Bryk and Schneider (2003) also contribute the attribute of relational trust. They state, "Each party in a relationship maintains an understanding of his or her 
role's obligations and holds some expectations about the obligations of the other parties. For a school community to work well, it must achieve agreement in each role relationship in terms of the understandings held about these personal obligations and expectations of others". Thus, there is a balance of or shared responsibility among all involved in the school setting.

Heifetz and Laurie (1997) speak of the importance of adaptive leadership, which includes people as part of the solution versus looking at the leader for answers. They state,

Changes in societies, markets, customers, competition, and technology around the globe are forcing organizations to clarity their values, develop new strategies, and learn new ways of operating. Often the toughest task for leaders in effecting change is mobilizing people through the organization to do adaptive work (p. 124).

Further, they add, "adaptive problems are often systemic problems with no ready answers" (p. 124). Thus leaders must see the big picture, identify the challenge, and include all in the process. To summarize Heifetz and Laurie say, "Adaptive work generates distress because people can only learn so fast and reality brings new challenges. Thus a leader must motivate people without disabling them. Therefore, leaders must frame and debate issues, and clarify assumptions while focusing on priorities" (p. 127).

When speaking of moral purpose Fullan provides an example:

There are signs that moral purpose is on the ascendency in schools and businesses. A good example is Palmer's The Courage to Teach (1998), in which he shows how the best teachers integrate the intellectual, emotional, and spiritual aspects of teaching to create powerful learning communities (p. 27). 
However, absent from Fullan (2003) and Heifetz (1997) is a focus on equity. Diamond mentions equity within distributive leadership; however, cites two critiques of distributive leadership. First, he mentions that distributive leadership does not address issues of power and conflict within and organization. Second, it shies away from questions of the impact or effectiveness of leadership practice. Freire (2000) says the following about power. "Authentic authority is not affirmed as such by a mere transfer of power, but through delegation or in sympathetic adherence. If authority is merely transferred from one group to another, or it is imposed upon the majority, it degenerates into authoritarianism" (p. 178). Thus, while not using the term distributive leadership, leaders cannot arbitrarily impose a position on those who are accustomed to oppression. Lastly, Heifetz defines adaptive leadership as, "Leaders do not need to know the answers. They do need to ask the right questions" (p. 124). Yet, again, this is assuming that the leader is grounded in equity and that questions are about students and equitable outcomes. If the same questions are being asked, then we will foster the same results.

Instructional leadership. Instructional leadership is an important priority for all leaders due to the impact of teachers on students. Hattie (2012) accentuates the importance of teacher impact by saying, "as educators, we cannot change the student. It is this belief that is at the root of deficit" (p. 25). Thus, instructional leaders must focus on teacher beliefs and actions that impact student outcomes: "My point is that teachers' beliefs and commitments are the greatest influence on student achievement over which we can have some control" (Hattie, 2012, p. 25). 
Schmoker (2006) concurs with Hattie (2012), "to confront the fact that the single greatest determinant of learning is not socioeconomic factor or funding levels. It is instruction" (p. 7). Further he adds, “teaching needn't be exceptional to have a profound effect; continuous commonsense efforts to even roughly conform to effective practice and essential standards will make a life-changing difference for students across all socioeconomic levels" (p. 9). Thus, instructional leadership shifts the focus from blaming students for their achievement and instead assumes responsibility for impacting learning conditions of all students, ensuring an equity focus.

Cotton (2003) describes principal behaviors that impact student achievement. Five categories classify these behaviors. These include establishing a clear focus on student learning, interactions and relationships, school culture, instruction, and accountability. In the area of instructional leadership, Cotton writes "Since the beginning of research about principal's impact on student results, studies have shown that principals who are knowledgeable about and actively involved with their school's instruction program have higher achieving students than principals who manage only the noninstructional aspects of their schools" (p. 25). Cotton summarizes the research by highlighting elements for instructional leadership which include creating norms for continuous improvement and high levels of student learning, facilitating discussion of instructional issues, respecting teacher autonomy and encouraging risk taking, protecting instructional time, using data and progress monitoring, and recognizing both student and teacher achievement (p. 26). So while this type of leadership is called "instructional 
leadership," because the leader focuses on the impact of teaching on students, it might better be described as "leadership that examines the impact of teaching on students."

Balanced Leadership. Marzano, Waters, and McNulty (2005), build on Cotton's (2003) perspective on leadership and the effect on student achievement. Their work does not deny that certain instructional leadership behaviors do, in fact, affect student learning. However, they clarify,

Given the perceived importance of leadership in schools and the central role of the principal in that leadership, one might assume that suggestions regarding leadership practice in schools are based on a clear, well articulated body of research spanning decades. Unfortunately, this assumption is incorrect for at least two reasons. First, far less research on school leadership has been done as one might expect and second, the research that has been done on school leadership is quite equivocal, or at least perceived as such (p. 6)

Marzano et al. summarizes the research on instructional leadership in the following manner: "This responsibility addresses the extent to which the principal is directly involved in the design and implementation of curriculum, instruction, and assessment activities at the classroom level" (p. 53). Additionally, their research shows that principals should be directly involved in helping teachers design curricular activities and address assessment issues as well as instructional issues.

While Hattie (2012), Schmoker (2006), Cotton (2003) and Marzano et al. (2005) focus on mental models to organize the research and synthesize the body of information, they do not address equity. These mental models do provide an opportunity for reflection and some make mention to an achievement gap but they do not address the predictability 
of disparity among students of color and EBs. Thus, leaders need to prioritize culturally relevant leadership.

Culturally relevant leadership. Cultural proficiency according to Lindsey, Robins, and Terrell (2009) is,

A model for shifting the culture of the school or district; it is a model for individual transformation and organizational change. Cultural proficiency is a mind-set, a worldview, a way a person or an organization make assumptions for effectively describing, responding to, and planning for issues that arise in diverse environments (p. 4).

When applying this to leadership, Lindsey et al. explain, "Culturally proficient leaders display personal values and behaviors that enable them and others to engage in effective interactions among student educators and the community they serve" (p 4). Additionally, they state, "Leaders address issues that emerge when cultural differences are not valued in schools and other organizations" (p. 4).

Gay (2010), noted for her research on culturally responsive teaching, puts equity at the forefront of teaching. She writes,

"Culturally responsive teaching can be defined as using the cultural knowledge, prior experiences, frames of reference, and performance styles of ethnically diverse students to make learning encounters more relevant to and effective for them. It teaches to and through the strengths of these students. Culturally responsive teaching is the behavioral expressions of knowledge, beliefs, and values that recognize the importance of racial and cultural diversity in learning. (p. 31).

Gay looks at culture as an intersectionality of race, gender, poverty and sexual orientation. Culture exists within a balance where equity is a focus and where relationships are a highlight. Despite this, she adds, 
The greatest of all obstacles to culturally responsive teaching is mainstream ethnocentrism and hegemony. They effectively block the acquisition and application of new, culturally relevant pedagogical knowledge, skills, and will in teaching African, Latino, Native, and Asian American students. Some educators fail to realize that the assumptions, expectations, protocols, and practices considered normative in conventional education are not universal and immutable. They are based on the standards of the cultural system of one ethnic group - European Americans - that have been imposed on all others. This cultural system is a human creation and, as such, is fallible and mutable. Its biggest fallibility is its assumed universality and "that's the right way" justifications for its beliefs, values, and behaviors (pp. 243-244).

Although Lindsey et al. (2009) and Gay (2010) have a more focused approach to addressing the gap through equity, the literature does not address specifics to educational leadership programs nor the impact of leadership perspective on EBs. The literature requires the individual to understand their biases and assumptions and to be able to reflect on their roles as leaders. It does not provide a how to but instead guides a journey of selfreflection.

Leadership for EBs. Because the above-mentioned literature well documents best practices for educational leadership, there is still a need to look at leadership that is specific to EBs. Freeman, Freeman, and Mencuri (2002) write, "Simply put, English learners generally come from social groups that lack the power to shape social institutions, such as schools, to accommodate their needs. Schools, like other social institutions, tend to maintain the status quo of social groups" (p. 52). They summarize research mainly focused on older EBs. The key to this research highlights teaching in thematic units, drawing on experience and background, scaffolding to build academic language and building confidence in students as self and learners (pp. 52 - 58). Reyes 
(2006) sites research stating, "The research on programs for Emergent Bilinguals (EBs) show that the most successful programs are those programs with principal leadership, support, and knowledge of English, Language learners" (p. 145). She adds, "The principal's attitude toward bilingual education and the concern expressed for langue minority children affect the success of services provided for language minority children" (p. 147). Reyes concludes by stating, "The successful School Leadership Model implies, the students is the priority in any school and the principal must be aware of the academic, linguistic, and sociocultural domains that must be addressed throughout the schooling experience" Additionally, she explains,

The Successful School Leadership Model requires that the principal be an instructional leader, an advocate that understand and articulates a clear vision for the success of EBs. The principal must know how to work with parents, not at a bureaucratic level, but at a level that fosters caring and mentoring relationships (p.185).

Therefore, Reyes suggest a balance of understanding instructions as well as advocating and articulating a vision for success. Thus, immersion leaders not only have to have expertise and skills in areas required of all administrators, they need to also work to find equitable resources that specifically targets the growth of EBs.

Bernhardt (1992) offers biographical perspectives involving dual immersion classrooms. She sites Roger Coffman, a dual immersion principal. He offers perspective on being a principal and not knowing the language as well as feeling ill prepared for the job. He shares,

Nevertheless, there are many times when I have felt overwhelmed, frustrated, and inadequate, to the point of asking myself, 'What have I gotten myself into?' At the very least, the immersion principal must be 
knowledgeable about the school's immersion goals, well versed in current research and theory regarding first- and second-language acquisitions and immersion instructions, able to relate to what the classroom teacher is experiencing and doing with students, and have a strong interest in the immersion program and the language of instruction (p. 156).

He concludes with a final perspective on his time as a dual immersion principal by saying,

I have found that being an immersion principal is much harder than I ever imagined - the principal must deal with many additional program related issues and be a strong advocate for the program, the school and the students. The principal plays an important role in 'bringing all the end together' (p. 169).

There are common threads among the authors. Freeman, Freeman, and Mencuri (2002) touch upon the work of Gay (2010) and the importance of relationships. The perspective cited by Bernhardt (1992), while real is not based on a study, and are for further research.

Immersion Research. When discussing dual immersion research, Thomas and Collier (2002) have written the seminal work in this area. Their studies have the span of over 20 years, 2 million records at multiple sites. Thomas and Collier discuss their findings as follows, "Findings demonstrate the importance of providing a sociocultural supportive school environment for language minority students that allows natural language, academic and cognitive development to flourish in the native and second language" (p. 304). They add, "Bilingually school students outperform monolingual schooled students in all subject after 4-7 years of bilingual education. Short-term programs are not sufficient for EBs with no English proficiency” (p.314) 
Lindholm-Leary (2013) adds to this body of literature. Her findings find that the sooner you start dual language programs; the quicker students outperform their monolingual peers. Thus, there is a correlation in getting quick results from starting dual immersion earlier than kindergarten. The studies of Lindholm-Leary (2013) and Thomas and Collier (2002) compared bilingual students to their monolingual peers. However, Steele et al. (2015) completed a study that compared the academic achievement of students applying to enroll in immersion education who were admitted with those who applying to the same program and were not admitted over a four-year period. The variables whose impact they tested were: gender, SES, native language, receiving special education services and the impact on reading, math, and science scores on their state test, the OAKS test. The findings of this study suggest that students in dual immersion outperformed their peers in reading. There was about a 7-month gain in grade 5 and about a 9-month gain in grade 8. Further, students have lower rates of classification as EBs and this effect is larger among native language speakers of the partner language. This study continues to confirm the foundational study of Thomas and Collier (2004) and suggest that dual language immersion can be a conduit for educational equality.

These studies are of importance in the knowledge of program model and its impact on student achievement. However, the studies make little mention of implications for leadership. Further, the Rand (2015) study does not control for additional variables that impact the learning of emerging bilinguals (Ogbu, 1992).

In summary, the body of literature collected supports the work done by Corbaz (2014) as research addresses different foci and globally provides mental models, 
a focus on student learning as well as definitions of leadership. However, limited in all research is a focus on dual immersion leadership. Thus, this study aims to examine leaders who successfully impacted student achievement in immersion schools and address the question: What leadership characteristics are needed to lead a dual language immersion school to increase student achievement for EBs?

\section{Review of the Methodological Literature}

The aim of this study is to examine the leadership characteristics of principals leading dual language immersion programs under which student achievement among EBs has increased. A search of the existing literature on immersion leadership using the key terms leadership in dual immersion, dual immersion leadership, the principal and dual immersion, leadership and dual immersion found literature on dual immersion programs, school specific websites, and papers and presentations that did not cite or reference literature Note, the only study regarding immersion leadership and EB student achievement was one found through CARLA titled "Leadership in Language Immersion Schools: Case Studies of Four Elementary Principals” by Philippe Charles Corbaz.

Thus, I propose using two guiding paradigms that influence this study within dual immersion leadership. The first is the constructivist paradigm and the second is critical theory. This constructivist paradigm suits the purpose of this study as it aims to construct reality from perspectives of dual immersion principals and construct a reality that is holistic in nature. Creswell (2009) posits social constructivism as an approach that is often seen in qualitative research. Social constructivists seek to understand the world in which they live and work and develop meanings from such. The goal is to rely on 
participants' views and recognize that their background shapes the interpretation of the meaning created. Lincoln and Guba (1985) write of the reciprocal relationship between the knower and the known as a subjective relationship. This paradigm engages the researcher to approach the study using qualitative methods in a natural setting with human participants. The axiology is theory laden and the knowledge should represent the values of the investigator making data analysis inductive (Lincoln and Guba, 1985). The researcher can observe how the influences interact, because variables cannot be controlled.

Popkewitz (1990) provides a different and important perspective that must be considered when doing this study. He writes of critical theory in education by stating, "focus upon the conceptualization of educational problems as part of the social, political, cultural, and economic patterns by which schooling is formed" (p. 46). He clarifies the contradiction of educational practice where dreams and hopes contrast power relations and social regulation which the world in which we live (p. 46).

This paradigm suits dual immersion leadership as the research suggests dual immersion is the strongest predictor for student achievement among EBs (Thomas \& Collier 2002; Lindholm-Leary 2013; Steele et al, 2015). The role of the critical paradigm in the dual immersion programs allows question of the roles of social regulation, unequal distribution, and power, in constructing the world (or events, perspectives, processes) as it is. The critical paradigm questions how we came to have a monolingual program even though this country is a country of immigrants. How were politics and power involved in education policy in the US, historically English 
dominated, and how were politics and power involved now that dual immersion programs are growing and expanding nationwide? Therefore, studying this issue through a critical paradigm allows for a contribution to understanding the history of leadership and language programs as a means to change power and policy.

To summarize, the social constructivist paradigm and critical theory paradigm are worldviews that guide the scope of this study. Each constructs reality, one through participants, and the other through history. The intended outcome is that the constructivist paradigm will provide meaning through the sharing of experience and critical theory, providing a way to view leadership as transformational.

\section{Summary of the Research Literature and Application to the Study}

This chapter reviewed the literature about organizational leadership framework, the historical perspective of language instruction in the United States, principles of learning, leadership for student achievement, the synthesis and critique of leadership perspectives and lastly, a review of the methodological literature. Corbaz (2014) aimed to inform both theory and practice by describing the beliefs, attitudes and dispositions of immersion principals. He writes, "This data and findings could contribute to the leadership literature as well as open the door for more studies in this area of conceptualizing leadership in language immersion schools" (p. 14). As we find an increase in literature focused on race in order to end the predictability of achievement, so must we address leadership in terms of how to ensure recent immigrants who are EB are 
also successful in schools. This study adds to the body of literature with a focus on dual immersion leadership. 


\section{CHAPTER 3}

\section{RESEARCH DESIGN AND METHODOLOGY \\ Introduction}

The purpose of this case study is to identify leadership characteristics of three K-5 dual immersion principals and to understand the relationship between leadership characteristics and student growth of Emergent Bilinguals (EBs). Dual language programs have proven to be a significant strategy that works for EBs (Collier \& Thomas, 1999). Zacarian (2011) supports dual immersion, citing Collier and Thomas (2002) finding that "students who participated in a bilingual biliterate model had the best outcome among all of the program models that they studied" (p. 29). EBs should continue to solidify their native language through practice of reading and writing skills while they are also simultaneously learning English. Dual language immersion (DLI) is a proven strategy to close the opportunity gap as students practice their native language literacy skills while they learn English. Several researchers (Cotton, 2003; Fullan, 2001; Hattie, 2012; Marzano, Waters \& McNulty, 2005) have contributed to the body of literature that established the role of the principal and its effect on student achievement. Tellez and Waxman (2006) state that principals who are knowledgeable about bilingual programs, research, and best practices were focused on improving student achievement and integrating bilingual programs into the school. However, there is little research that more specifically looks at leadership characteristics of dual language principals who successfully increase student achievement. As more dual immersion programs focus on 
the needs of EBs, it is important to examine more closely leadership characteristics of successful dual language principals. While Tellez and Waxman do not discuss the principal role within dual language specifically, they do confirm the need for more research in the field.

Although dual language leadership may seem of concern to only a small group of educators, it should, in fact, concern all school leaders, particularly given the increase of EBs in our schools in recent years. The results of this study serve three purposes: 1) inform principal preparation programs so that future immersion leaders will be better prepared to provide more specific information about leadership in a dual language immersion school; 2) increase practitioner understanding of how leadership affects student growth among EBs; and 3) contribute to the literature base regarding successfully educating EB with a specific focus on DLI educational leadership.

Schools continue to struggle to address the language needs of the EBs. Not only are students experiencing the demands of the new Common Core State Standards, but in addition, EBs must reach Oregon's new English Language Proficiency standards, which according to ODE were developed to address the increased rigor and language demands of college and career ready standards (ODE, 2014).

The study employs a multi-method qualitative approach (Creswell, 2013) to understand the leadership characteristics of DLI principals in the state of Oregon. Creswell follows the structure presented by Lincoln and Guba (1985) regarding case studies. In each case, the problem, the context of the issues, and lessons learned are examined. I used this approach to address the following research question: What are the 
leadership characteristics of dual immersion principals who have successfully increased the achievement of EBs? The study focused on investigating the perspective of three principals who have had success in increasing student growth among EBs in dual immersion schools. The research further investigated the qualities of their school leaders from teachers who worked in successful DLI schools.

This chapter addresses 1) justification for the selection of methods, 2) a description of the participants, including rationale and sampling methods, procedures, 3) data collection measures the role of the researcher, 4) data collection, and 5) data analysis. This chapter concludes with a summary of the research design.

\section{Methods}

Krathwohl (2009) describes qualitative research as a holistic approach, which is inductive-emergent: "Describing or exploring for an explanation, a holistic approach, describing in words, and a bottom-up frame of reference form another type of approach to problems. This approach is characterized as qualitative" (p. 30). Creswell (2013) includes Denzin and Lincoln's (2011) definition of qualitative research as

A situated activity that locates the observer in the world. Qualitative research consists of a set of interpretive, material practices that make the world visible. These practices transform the world. They turn the world into a series of representations, including field notes, interviews, conversations, photographs, recordings, and memos to the self. At this level, qualitative research involves an interpretive, naturalistic approach to the world. This means that qualitative researchers study things in their natural settings, attempting to make sense of or interpret, phenomena in terms of the meanings people bring to them (Denzin \& Lincoln, p. 3). 
Maxwell (2013) concurs by describing qualitative research as "inductive rather than following a strict sequence or derived from an initial decision" (p. 2). Thus, the key of qualitative research is to construct and deconstruct, rather than follow and implement.

Creswell (2013) states, "qualitative research will be conducted in order to empower individuals to share their story and to minimize power relationships that often exits between researcher and the participants in a study" (p. 48). A standard way of thinking of qualitative methods is

Qualitative approaches are characterized by an inductive, bottom-up, emergent approach, beginning without structure but structuring the study as it proceeds, by exploring to find what is significant in the situation, by trying to understand and explain it, by working in a national situation and by describing in words. They are particularly well suited to studying complex processes (Krathwohl, 2009, p. 33).

Maxwell (2013) describes qualitative research as "do-it-yourself” process that looks at the interconnection and interaction among different components (p.3). Many school districts have recently applied for grants to expand, support and develop more dual language programs for students here in the state of Oregon. According to the Oregon Department of Education, "the purpose of the grant was to support school districts, consortia of school districts or charter schools to design, implement and improve Dual Language/Two-Way bilingual programs in Oregon. These programs assist students in becoming academically proficient in two languages" (ODE, 2014). Schools that employ dual language models hope to maximize on Thomas and Collier (1997) research practice in order to address the needs of our Emergent Bilinguals. 
Seidman (2013) states, "using a phenomenological approach to interviewing focuses on the experiences of participants and the meaning they make of that experience" (p. 16). In essence this research captured the experience of all stakeholders, which would include community members, administration, parents, teachers, and students. The idea of creating cultural portrait ethnography, as described by Creswell (2013) further opens possibilities of sharing and comparing a human experience when leading a dual language program.

Thomas and Collier (1997) state that students in DLI will reach the achievement level of their peers by fifth grade. However, some DLI schools persistently underperform. This research was a case study of the characteristics of three elementary school principals who increased the achievement among EBs. The case study of these principals will include interviews, document review, and teacher focus groups. The results of this study have implications for principal preparation program, district hiring practices, and professional development of DLI principals in districts.

\section{Selection of Participants}

This study sought potential participants through purposeful sampling. Krathwohl refers to purposive sampling (p. 172), as a "strategy where particular settings, persons, or activities are selected deliberately to provide information that is particularly relevant" to the study (p. 97). Purposive sampling has a focused approach to attaining a quality sample in order to fully understand the nuances of the field.

The subjects for this study were experienced principals who are determined to be successful in terms of student achievement for EBs as measured by school performance 
exceeding their district performance average and that of comparison schools. The selection process consisted of asking consulting state report cards and asking ODE for names of principals who match the profile of this study. The principals needed to be in their role for at least two years. The potential participants, once identified, were contacted by email to obtain their consent to participate in the study and to have access to their school data, public documents, and teachers. Next, the principal and their research department and/or superintendent provided consent to review documents, interview principal(s) and conduct a teacher focus group. The principal signed a consent form (Appendix A) as did participants of the focus groups (Appendix B). The potential schools were in the state of Oregon.

\section{Procedures}

Creswell (2013) explains that "data collection in a qualitative study means gaining permissions, conducting a good qualitative sampling strategy, developing means for recording information both digitally and on paper, storing the data, and anticipating ethical issues that may arise" (p. 145). Creswell suggests displaying these procedures through the interrelated circle of activities. Thus, this circle is utilized to illustrate the engagement of activities: 
Figure: 3.1: Creswell's interrelated circle of activities

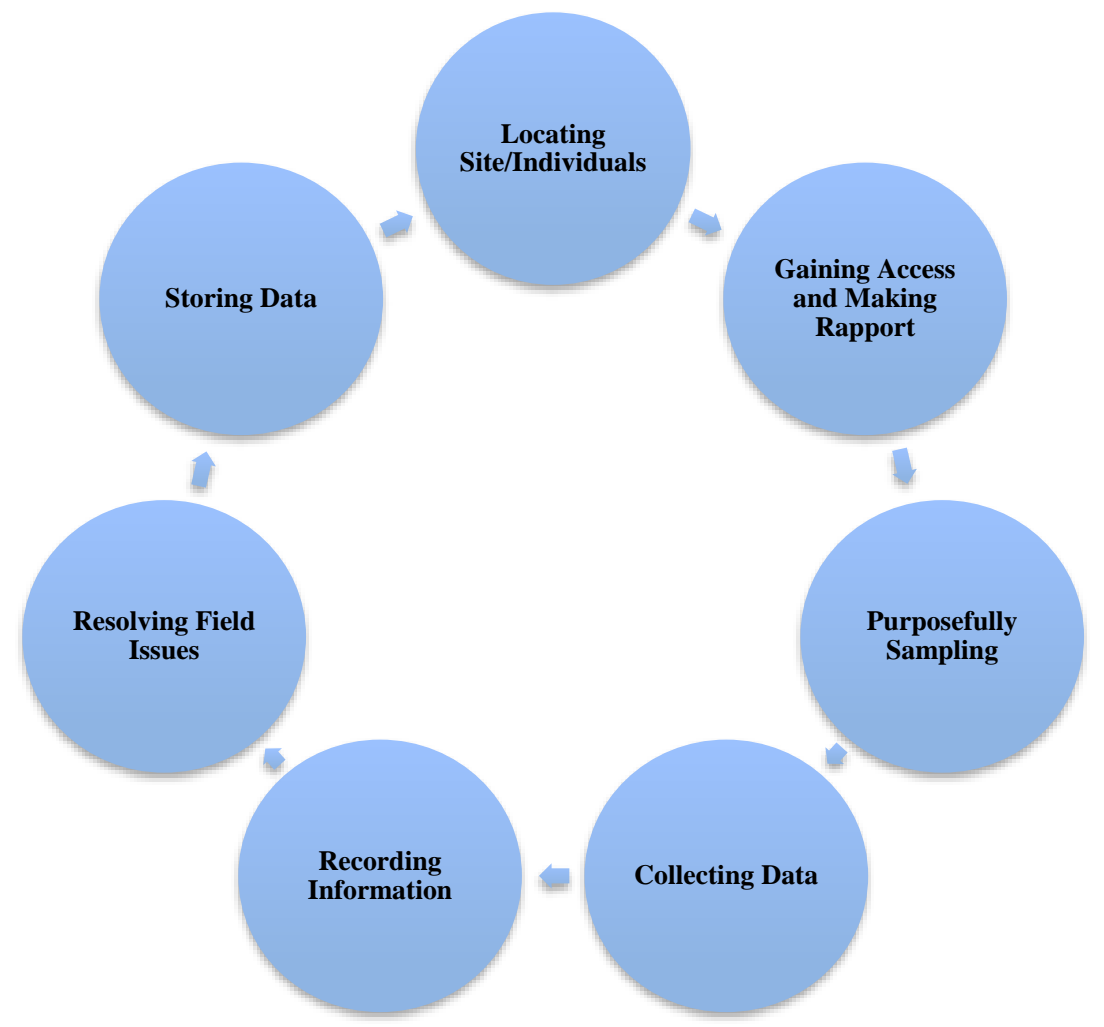

Creswell (2013) advises that while new forms of qualitative data emerge, data collection methods are grouped in one four categories: observation, interviews, audiovisual materials and documents. This study collected data through document review, interviews, and focus groups.

\section{Document Review}

The first set of data came from current and archived records of each of the three subject schools (Appendix C). Bowen (2009) depicts document analysis as a systematic procedure for reviewing and evaluating documents (p. 27). Bowen explains that document analysis "is a process of evaluation documents in such a way that empirical knowledge is produced and understanding is developed" (pp. 33-34). In addition, Bowen 
explains, "documentary evidence is combined with data from interviews and observation to minimize bias and establish credibility" (p. 38).

\section{Interviews}

Interviewing is an important data collection tool in qualitative research (Krathwhol, 2009; Creswell, 2013; Seidman, 2013). Krathwohl (2009) posits that interviewing is thought of as straightforward with questions and answers between two individuals; he clarifies that varies and it is much more complicated noting that "Qualitative researchers often gather data by interview; interviews and observations interact - observations provide meaning to the interviews, and interviews suggest things to look at our attach new meanings to the observations" (p. 296). For this study, the interview protocol and content (Appendix D) explored broad areas to find significance as well as probe for details. Krathwohl (2013) describes this as a focused interview as it "allows exploration and targeted information gathering in the same sitting" (p. 299).

\section{Focus Groups}

According to Krathwohl (2013) focus groups are defined as a group of individuals, typically a small group that represents the population. He explains that interviews of the group start broadly and then become more focused as people share within the group. He claims, "The group setting gives them the chance to discuss and react to one another's ideas, possible expressing ideas and reactions that we as researchers might not have asked about, and stimulating thoughts that might not have come up in individual interviews" (p. 248). 
Morgan (2013) emphasizes the importance of planning. In his review of focus group design, he says,

The first decision concerns who will participate in the groups. The next decision determines how structured the groups will be, including the level of moderator involvement. After that there are further decisions about the number in each group and the total number of groups for the project ( $\mathrm{p}$. $34)$.

The information, for this study, was recorded within the sample protocols and followed the practice used by Bowen (Appendix C) to create a table to organize the analysis. The interview protocol (Appendix D) provides a script for the interview. Interviews were also audio recorded, backed up in multiple folders, and transcribed for accuracy. The focus groups were also transcribed and followed a protocol (Appendix E). Lastly, all information and data in this study was kept confidential and will never be released. Transcripts, audiotapes, and documents were identified in a systemized manner and names of individuals or institutions were not used. Children were not identified in any of the data collection methods. All data was saved in a secure place and was available to the researcher and supporting university.

\section{Instruments and measures}

As Creswell (2013) defines, "qualitative research begins with assumptions and the use of interpretive/theoretical frameworks that inform the study of research programs addressing the meaning individuals or groups ascribe to a social or human problem" (p.44). This study employs document review, survey, and focus group. Instruments for the document review include Bolman and Deal's (2003) conceptual framework for 
examining organizational behavior. The framework, which is rooted in social sciences and managerial practice, categorizes leadership behaviors into one of the four frames: structural, human resources, political, and symbolic. Bolman and Deal claim, "Learning multiple perspectives, or frames is a defense against cluelessness" (p. 18). Frames serve multiple functions. They are maps that aid navigation, and tools for solving problems and getting things done. I created a form for every document in which I analyzed the focus of the document (Appendix C) that was consistent to the frames; I then categorized leadership behaviors.

Principals were interviewed using a protocol aligned with research principles for interviewing subjects. Creswell (2013) notes the importance of several steps in interviewing: 1) decide the research question; 2) identify interviewees; 3) determine the type of interview (phone, in person); 4) using adequate recording procedures; 5) develop an interview protocol; 6) pilot test; 7) place of interview; 8) consent procedures; 9) follow interview protocol. The interview was done in person. The researcher requested permission to record the interview using an iPhone app iTalk Recorder Premium and backed it up with a second phone recording, which was uploaded to a computer. While the interview was recorded, the researcher also took notes on key concepts. The interview protocol (see Appendix D) included introductory welcoming comments, a review of the consent procedure, a reminder that the subject can halt participation at any point, and that they will be provided a transcript of the interview to ensure the data was accurately reflected in the transcription. The researcher provided light refreshments of water, fruit, crackers and cheese. The protocol was practiced on two former principals of a dual 
immersion school; the protocol was revised based on debriefing after the experience. All interviews took place in an enclosed room in a private location of the principal's choice. The consent procedures followed expectations of the Institutional Review Board and were reviewed prior to the beginning of the interviews and focus groups. The interview protocol (Appendix D) included all aspects required by the IRB.

The goal of this study is to identify leadership characteristics of successful dual immersion principals. When speaking of leadership Theoharis (2009) explains, "In many ways the reaction to the external accountability pressures heightens the need for leadership that centers school reform around issues of equity, access, and creating a warm and engaging school climate.” Lindsey, Robins and Terrell (2009) align cultural proficiency along a continuum, which explores the examination of our own values, working with colleagues to examine policy, as well as learning with and from the community you serve. As more dual immersion programs emerge, some districts embrace the cognitive benefits of dual immersion programs and the rich cultural benefits. Others deride dual immersion programs. Gay, (2000) provides the following reasons as to why this may be. First, multicultural education is a relatively young reform effort; the other is the perceived threat to the American was. Gay and Howard (2000) further explain,

The resistance this threat provokes causes the re-entrenchment of attitudes, behaviors, programs and practices that violate policies of racial and ethnic inclusion and equality even as they are being issued. The tendency this is to foist upon multicultural education intention of malice against destruction of 'the American Way' and indictments of pedagogical insignificance. Quite the contrary is true (p.215) 
Leaders, in order to properly lead a dual immersion school, understand that dual immersion is complex as are the changes required to develop and expand immersion programs (Fullan, 2001). With change leaders seek both informal and formal leaders as they work to eliminate the barriers that are there for EBs face in their education system. While these assumptions may seem as though they are reactionary it may be more fruitful for leaders to take into account what Gay (2000) says about multicultural education. She says, "Multicultural education is a product of the US context and exemplifies the highest democratic ideals. It is committed to developing techniques for achieving educational equality, particularly for students from ethnic groups who historically have been marginalized, dispossessed, oppressed, mis-educated, and undereducated in schools" (p.215). These theorists and researchers provide frameworks for leadership as well as tools for educational equality and the transformation of education.

\section{Role of the researcher}

Maxwell (2013) encourages researchers to look at their own bias and how it may affect our research. According to Maxwell, "Two broad types of threats to validity that are often raised in relation to qualitative studies are researcher bias, and the effect of the researcher on the individuals studied, often called reactivity" (p. 124). As a dual language immersion principal who emigrated from Colombia to the US in elementary school, and as such was an emergent bilingual, my leadership experiences influence my perception of the problem, beliefs, and perceptual lens and knowledge of leadership in immersion schools; this lens may influence participants' contributions in the interviews and focus groups. It may also influence my interpretation of their data. Thus, Maxwell provides 
eight strategies that reduce validity threats, four of which I will use: 1) rich data, which will include verbatim transcripts of the interviews as well as the focus groups; 2) respondent validation; 3) discrepant evidence and negative cases; and 4) data triangulation. I used multiple data sources: document review, interview, and focus groups. Next, I incorporated respondent validation. Maxwell explains the importance of respondent validation: "This is the single most important way of ruling out the possibility of misinterpreting the meaning of what participants say and do and the perspective they have on what is going on, as well as being an important way of identifying your biases and misunderstanding of what you observed" (pp. 126-127). I also searched for discrepant evidence and negative cases. As Maxwell explains:

The basic principle here is that you need to rigorously examine both the supporting and the discrepant data to assess whether it is more plausible to retain or modify the conclusion, being aware of all the pressures to ignore data that do not fit your conclusions. Asking others for feedback on your conclusions is a valuable way to identify your biases and assumptions and to check for flaws in your logic or methods (p. 127).

Fourth, by conducting a document review, principal interview, and teacher focus groups in order to confirm possible findings from multiple sources, I triangulated the data, thus increasing the trustworthiness of my interpretation of the data.

\section{Data collection and analysis}

For this study, the data collected was analyzed through the document review (Appendix C), the principal interviews, and the teacher focus groups. The researcher audio-record the interviews and focus groups and transcribed each verbatim. The analysis of data began with the transcription, a recommendation of Creswell (2013). 
Next, the data was reduced into themes by coding the data. As Creswell (2013) describes, "data analysis in qualitative research consists of preparing and organizing the data (i.e. text data as in transcripts, or image data as in photography for analysis, then reducing the data into themes through a process of coding and condensing the codes and finally representing the data in figures, tables, or a discussion" (p. 180).

I methodically coded themes, following the guidance of Attride-Sterling (2001): "if qualitative research is to yield meaningful and useful results, it is imperative that the material under scrutiny be analyzed in a methodical manner" (p. 386). Thus, the interviews were coded for themes using Attride-Sterling's six-step process: the first three were a means to reduce or breakdown text, the next two explored the text and the last is defined as integration of exploration. The six-step process is described as follows: 1 . Code the material using a coding framework (in this study the framework is the organizational behavior framework); 2. Identify themes; 3. Construct thematic networks; 4. Describe and explore thematic networks; 5. Summarize thematic networks; and 6. Interpret patterns. Attride-Sterling's notes the power of this methodical process: "The value of qualitative research lies in its exploratory and explanatory power, prospects that are unachievable without methodological rigour in all stages of the research process from design, to field work, to analysis" (p.403).

This study also included a document review. Bowen (2009) states, "Document analysis involves skimming (superficial examination), reading (thorough examination), and interpretation. This iterative process combines elements of content analysis and thematic analysis" (p.32). Bowen goes on to say that not only is it important to 
understand how to analyze the documents but to also evaluate the type of documents you choose for the study. "The researcher should consider the original purpose of the document - the reason it was produced - and the target audience" (p.33).

\section{Summary}

This chapter focused on the research methodology, justification of methods, participants, procedures, data collection, and data analysis. In light of the lack of literature that exists specific to educational leadership in dual immersion, this qualitative study aims to add to the body of literature by identifying characteristics of dual immersion principals' characteristics who have shown success in student achievement for EBs. 


\section{CHAPTER 4}

\section{RESULTS}

\section{Introduction}

The purpose of this case study was to identify leadership characteristics of three K-5 dual immersion principals and to understand the relationship of such characteristics to the student growth of Emergent Bilinguals (EBs). The problem remains: schools continue to struggle to address the language needs of the EBs. Not only are students experiencing the demands of the new Common Core State Standards, but EBs must reach Oregon's new English Language Proficiency standards, which according to ODE were developed to address the increased rigor and language demands of college and career ready standards (ODE, 2014). Therefore, the purpose of this study is to examine the characteristics of leaders who successfully support student growth among EBs.

Dual language programs have proven to be a successful strategy for EBs (Collier $\&$ Thomas, 1999). Although dual language leadership may seem of concern to only a small group of educators, it should, in fact, concern anyone who cares about our ever changing demographics, the increase of Emergent Bilinguals, in our schools and meeting the needs of all students. Understanding the characteristics of principals successfully leading dual language programs will provide an opportunity to inform the field of educational leadership. The results of this study serve three purposes: 1) future immersion leaders will be better prepared as programs are able to provide more specific information about leadership in a dual language immersion school, 2) an increased understanding of how leadership affects student growth among EBs, and 3) as DLI 
programs grow and expand, so should the research base supporting their success.

Therefore, this study adds to the body of literature with specific focus on DLI educational leadership.

This chapter presents an analysis of data and the results of this study. Results are presented in four sections. The first contains information about the empirical findings as they relate to the four organizational frames identified by Bolman and Deal (2003). The second, presents the data organized into themes using Attride-Sterling's (2001) framework, which identifies organizational themes followed by basic themes. The themes and their respective characteristics are supported by the comments from this study's participants. The aim of this study was to identify leadership characteristics of successful dual immersion principals. Thus, the third section summarizes the participants' perspectives of these characteristics. The fourth section examines a comparison to the focus group data. Lastly, this chapter will interpret the data, discuss limitations of the study, which includes findings of the document review and concludes with a summary of the chapter, which attempts to answer the research questions posed in chapter three. The research questions include:

- How do principals in dual immersion schools understand and communicate the program model and its effect on Emergent Bilinguals?

- How do school principals influence school climate in schools and communities with English - only and dual immersion programs within one school?

- What focus is explicit within the vision and mission of the school? 
- What is important for leaders of immersion schools to know about successfully leading an immersion school?

This chapter will interpret the data, discuss limitations of the study, and conclude with a summary of the findings.

Three decades of research has contributed to the expansion of dual language programs in the United States. While much of this research contributes to the understanding of dual language immersion as a proven program for EB's, Thomas and Collier (2014) provide the rich reality of day-to-day life and decision-making in dual language schools, as told by experienced dual language administrators. This chapter will add to the literature by providing a rich synthesis of the characteristics of DLI school leaders successful with EBs.

\section{Analysis of Data}

Grounded on the premise that effective organizations need to understand the multiple frames, understand how to operate within them, and that leaders need to apply and accurately map frames to different situations, the case study of three school leaders provided insight to the leadership characteristics that lead to success with EBs.

In order to organize the data, Attride-Sterling's (2001) thematic framework was followed in order to extract meaningful data. 
Figure 4.1: Attride-Sterling's structure of thematic framework

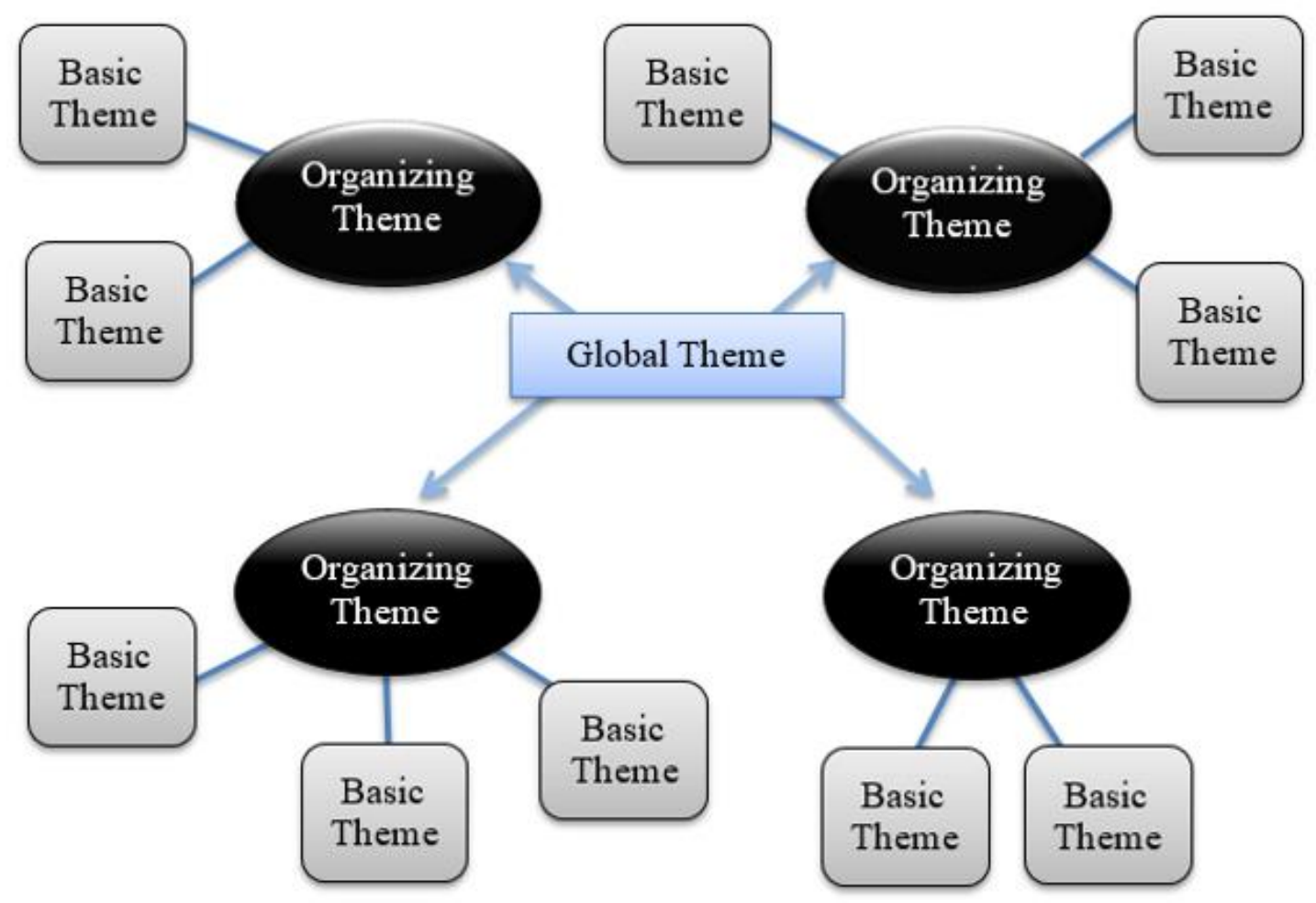

Presentation of Results

\section{Four Organizational Frames: Global Theme}

This case study included three principals as subjects. The principals in this case study represented a wide variety of expertise and perspectives. These included, gender, race, years of leadership, program status, bilingual expertise, grade level expertise, and DLI program design. In order to reveal key concepts and meaningful results, a thematic framework was used: "If qualitative research is to yield meaningful and useful results, it is imperative that the material under scrutiny is analysed (sic) in a methodical manner" (Attride-Sterling, 2001, p.386). Thus, it was essential to explore a methodical analysis of the data in order to explore meaningful and useful results. In order to do this, the first 
step was to look at coding for the four frames or organization - or global theme. Bolman and Deal's (2003) theoretical framework denotes the global theme that frames an argument, position, or assertion about the subject's reality (Attride-Sterling, 2001). In order to quantify the responses, the quotes, from each principal, were categorized according to the corresponding frame and were gathered and organized individually, by principal response, and collectively, data from the three principals (Krathwohl, 2009). Figure 4.2 illustrates the responses as coded according to each organizational frame by individual principal response.

Figure 4.2: Summary of data by individual principal response

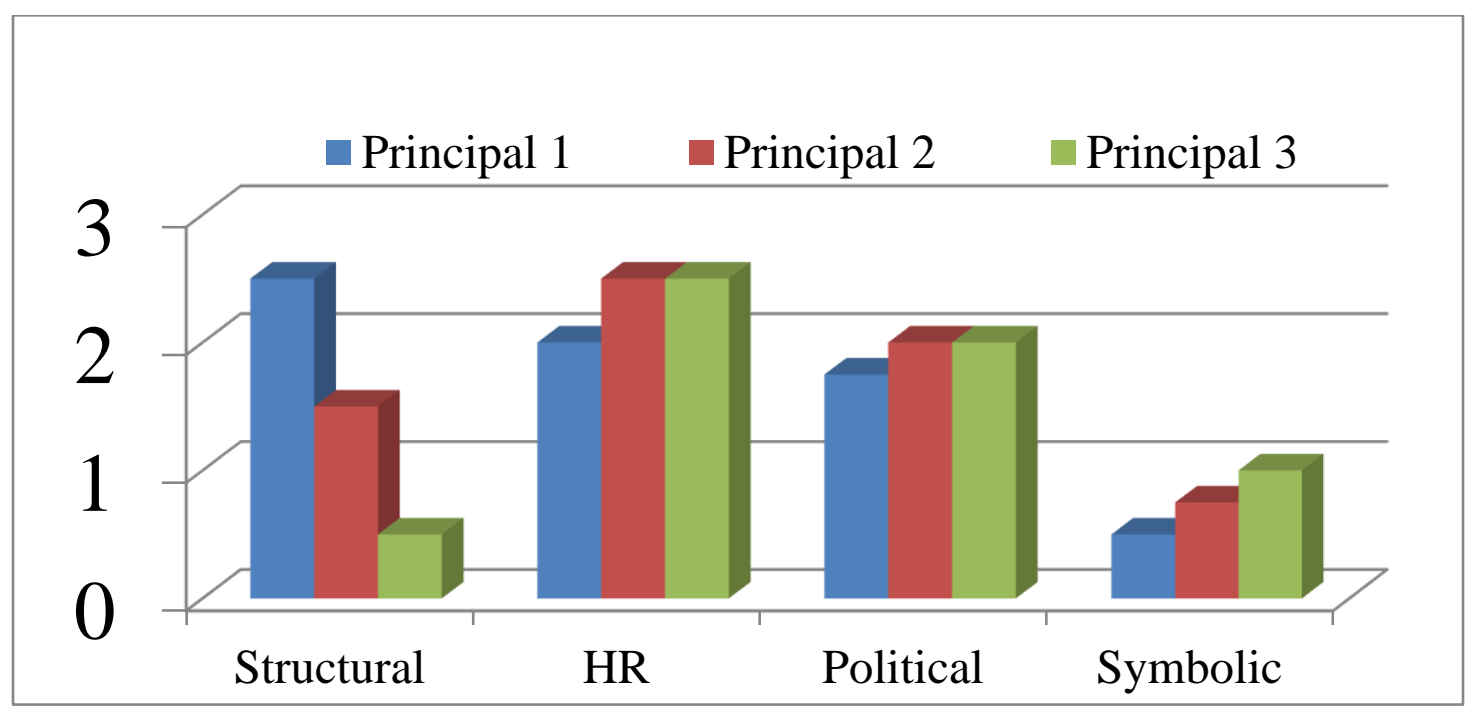

Each principal shared their perspective and the data recorded demonstrates individual frames. Figure 4.3 aims to encapsulate the frames as a collective data point. For figure 4.3 the human resource frame had a higher percentage than the political frame, which was closely followed by the structural frame. 
Figure 4.3: Summary of data by collective principals' response

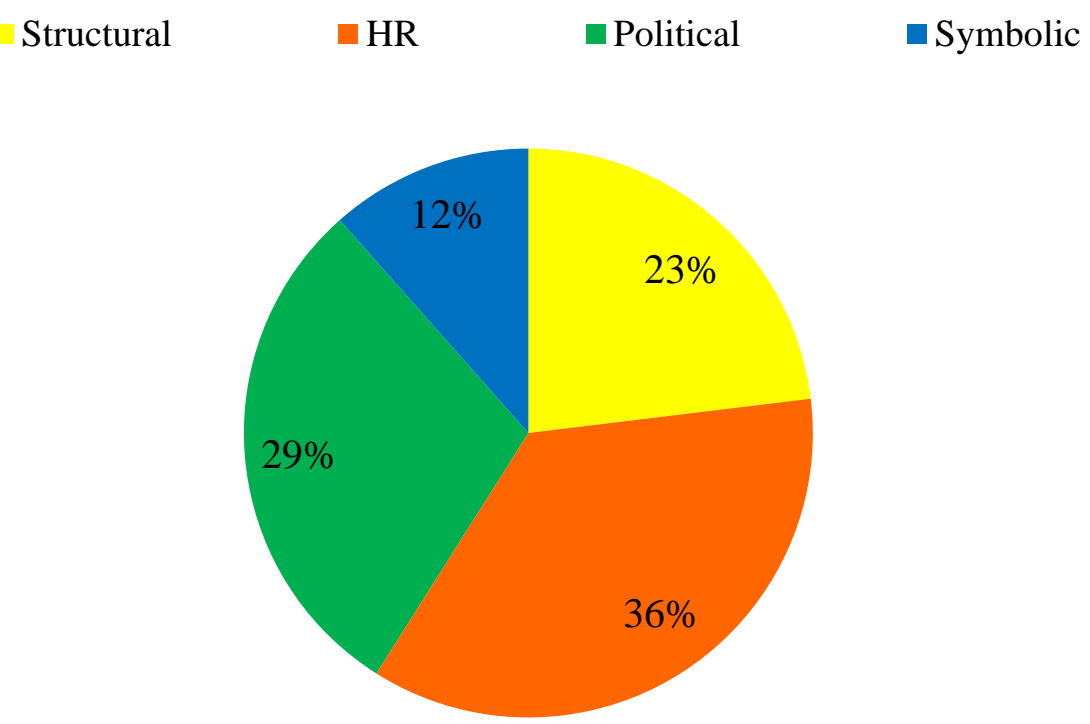

\section{Identification of Themes - Organizational Themes:}

Attride-Sterling (2001) instructs researchers to go through the text segments in each and extract the salient, common or significant themes in the coded text segments. The organizational themes identified were conversations addressing DLI policy at the school sites, the role of the district, hiring, and perception of the partner language - in this study's cases the partner language is Spanish. Attride-Sterling suggests, "following this procedure allows the researcher to reframe the reading of the text, which enables the identification of underlying patterns and structures" (p. 392).

An analysis of the data revealed several patterns and key themes, including key conversations about DLI policy with staff, the role of the district, hiring and perception of language. 
Conversation addressing DLI policy at the school site. The principals in this

study all mentioned situations in their tenure where they had to have difficult conversations with staff regarding DLI policy. Each of these conversations has an underlying organizational frame. One principal had a conversation with specialist regarding the schedule not being an adult centered schedule, but one that would be best for DLI program minutes.

Um, another area, which is kind of Nuts and Bolts, is kinda pushing back on people that want specials. Especially if they want to have this time or that time in the day so they can have their classes together or this or that...NO! The first priority is that there's a solid Spanish core program and we are not going to play with that. You know so being able to make tough decisions and say to the PE specialist "sorry you don't get to have your kinder and your first together because this is when our Spanish intervention time is, this is when our ELL time is and this is, so being able to make those tough decisions and say no this is the vision, we are sticking with it and it's important that kids have PE, but this is the most important thing. So, being able to consistently do that when people try to encroach on that structure that we start with.

The second principal shared a historical perspective of anti-immersion sentiments

that the staff held. After a year of trying to build cohesion and understanding, the principal addressed the staff.

There was all this infighting going on between them and the ELD teachers so I had to figure out; ok what are the issues going on for you guys, what are the issues going on for you guys and then finally we were able to bring everybody, you know the whole team of 7 together and begin to have healthy conversations about what was going on. So trying to get some of that fixed, you know trying to get some getting it out on the table starting to talk about it. I had it, in my second year I had a really big elephant in the room kind of discussion with the staff that was probably the gutsiest thing I've ever done as a principal and that helped us start to move a little bit and also help people move out of the building. 
The last principal had a conversation with her staff after years of work to create an environment that was uniting instead of divisive and it came with a cost.

I think I neglected them a little and I had a big pep talk as we were closing out this school year. And I said when I first got to the dual immersion program and the non-dual immersion teachers -- there was a huge divide there was a lot of conflict and animosity, jealousy, whatever you think. The immersion teachers and kids were outperforming the other kids and that was one of the reasons that the building was one of the many reasons.

Role of the district. The three principals in this study indicated that their success was in some part due to the support of the district. Two of the three principals stated that the district was changing for the better and new personnel, whether superintendents, coordinators, or directors, were proponents of DLI and therefore supported efforts to improve it. The other principal expressed it was the district's mission to assure that DLI would be a program in that school. All three shared the lack of resources and the continuous advocacy for materials in their programs. All three principals shared that the district office was, in a sense, a partner in the work that contributed to the success of DLI.

During the interview, participants were asked: "What do you believe has contributed to your success as a dual immersion principal?" Each response included a comment on the importance of district support, with the following comment representative of this theme:

The district's support of the program would be number two for me even though we've had a lot of changes with leadership and you know all of that it's remained and I've had to do a lot of advocating you know because of that changing of the guard all the time but people believe in the work and they want to see this happen for our kids. So that's definitely been a contributor. 
Another principal's comments echoed this theme as follows:

Support from my supervisor that first year. I don't think anyone understood how much of a difficult building it was. You know, sometimes people are scapegoated or you know they think it's one person causing trouble, but it's really a system problem. Right? So, she stuck with me; she almost, lived with me that first year. If I needed anything, cause you know there were a lot of things that that had to be fixed, she was just there with me and she pushed me and 'you can do this' and 'have that talk with that teacher and this is what you say - this is what you do' that year...a lot of people, I had to write them up.

Later in the interview, the participant added,

I had actually another thing that I forgot to mention along with what thing that helped me is after my first year when I realized the big hot mess (the school) was in. I stood in front of my colleagues, administrators, and I said I need change at (the school) and I'm not going to accomplish it with the current staff, I have there. I need some of you to take some of my teachers without giving me any of your teachers so I can have openings and I can hire -- and they did! That's wonderful, they took them, it created a vacancy, and the more vacancies I have the more change I can implement in the more uncomfortable other people got and so slowly.

While not a direct answer to this question, the last participant expressed the following regarding district support, which ultimately led to a more cohesive program and improvement of school climate: "I think 2012/13 school year the school district and the current leader that was there at the time - her name was (name) - made a decision to make it to not a strand program, but a school-wide program and that's helped with the climate."

The participant, when asked to clarify about district support, added:

So one thing they started last year, we have a new administrator (name), he's here now and he's been very supportive of improving immersion across our district. So with his tenure we started an immersion task force last year and so all of the immersion principals have been speaking with each other, as a start (laughs), so that's one thing. So, we've met fairly regularly and we started this year to really start to implement some changes; changes in some of that school choice policy, possibly some 
changes in policy in transportation and some practices with our ELL populations, as well so it may be that there's some bigger changes that they're ahead and that's exciting and we've actually been able to submit budgets, as a group, to the district to see if we can get some more supports, which has never been done.

When speaking about hiring, Bolman and Deal (2003) write, "Strong companies

are clear about the kind of people they want. They only hire those who fit the mold"

(p.137). The participants in this study were clear about the importance of hiring.

Hiring. The participants' responses indicated that hiring was a key issue to

success in DLI leadership. Reflecting on hiring, one principal stated,

Hiring is the most important thing to do for your building. If you do not invest and if you're lazy about it and if you take shortcuts you're going to hurt your kids, you are going to hurt your building and... and you're going to hurt yourself because you're going to add work for you. The best thing I could have done for this building, to be honest, is this staff at the way I have staffed it; amazing wonderful teachers who want to be at our school, understand our demographics, understand the background of our kids. You can't have people come in here thinking they're going to save children -- that's not - we're not here to do that. So that is the most important job you can do. That's not always, you know I tell people that the stars aligned for (school name), during my tenure most principals can't say that they've hired over $70 \%$ of their staff - they can't... I can! But, that's how bad it was here.

Hiring for the front office is also important. Another principal shared,

Well, just like any school - the secretary and your front office staff is so important for helping you stay organized and helping you communicate with families. And I think that's sometimes underestimated. The quality of the experience in the front can help make or break a strong principal. Even if they are a really strong principal, and you feel like it's a very unwelcoming space and non-communicative, where there's lots of barriers um, people don't want to go to your school (laughs).

The third participant also indicated the importance of hiring, noting the following: 
First of all, the hiring; the hiring as a principal of a dual immersion school is so stressful and is completely a different process than hiring are English-speaking teachers. So that has been such a giant learning curve for me and or finally getting to a place I feel as the two elementaries and we're starting to grow more of our own and that's helping with some of our hiring but that's been a very challenging piece and a very time consuming piece for me which has almost taken me out of the mix for a couple of months every year to just do HR and it's been very challenging for me.

These shared experiences provide examples of how the subjects relied heavily on the human resource frame (Bolman \& Deal, 2003) to effect change in their schools.

Perception of partner language - Spanish. Another theme that surfaced was how the principals viewed the use of the partner language Spanish. The variety of perspectives provided a deeper picture to what this theme signifies in our larger society. One principal defines the language as a hindrance as their lack of speaking it kept them from feeling competent to evaluate the educational program and instruction, the other spoke of the elevation of the language and the importance to keep it a focus in an English dominated society. The third participant responded to the work in changing attitudes as Spanish is considered a deficit versus an asset. These will be represented respectively.

The first principal participant shared the following regarding the importance of elevating the Spanish language in the school:

I think some of the challenges are also being able to elevate Spanish enough in the school, so that it's valued...is helping make sure that people are valuing the Spanish. I mentioned that before, but I think that people will tend to go English really easily and you know there's an image that you have probably seen before where you've got lot this big blue cloud of space that's all English and then you've got this little teeny family home unit, which is in Spanish and this little teeny part of our day, which is in Spanish and we are trying to make them learn lots of Spanish in this English dominant environment and that huge umbrella of English is all the time means that it's very easy to encroach on spaces. 
This comment on the perception of language came from a monolingual principal,

Well I think that the not being able to speak Spanish has been a massive deficit for me, so I would definitely say that districts need to look for a highly-qualified Spanish speaking principals and be growing those you know I mean that's the best way to do it is grow those principles in your District to help lead the work and that was really, I feel like that's a real deficit for me...I'm an English-speaking principal and I need to be supporting my new Spanish-speaking teachers. The whole process of being in their classroom and I'm trying to evaluate in a way and offer support in a way that is helpful to them, and some things I can do easily and then other things like really judging the content and the rigor of the content, and the rigor of the questioning and you know some of those things that the critical thinking pieces that are going on - I can't, I really struggle with that.

The sad reality of the low esteem, which in given Spanish-speaking students, is shared by the third principal who is a bilingual, bicultural principal:

I think just that...you know I have always known you know I grew up speaking Spanish but it's still surprising to me that some people see an extra language, in this case Spanish, as - as negative. You know, if you say to somebody that someone speaks Italian, it's "oooohhh!, how exotic"! and "how brilliant of you if you speak French", "It's amazing" and "wonderful" and you speak Spanish... its "Meah"... "We have to teach them English". And so I think even - even in my community, this community of (school name), where we have such a large group of parents, it's been surprising to me that a lot of our Latino parents are still resisting learning Spanish. When the kids... to learn Spanish they want to just learn English and you know that was true in Houston with growing up. You know the focus in Houston -- or in Texas in general, was learn English, learn English. But um...it's surprising that in this time, this year, our families still feel that there's a negative stigma with español versus ... like I said you know you speak any other language and people think you are brilliant. But, if it's Spanish, argh, bummer! (laughs) Now you are going to have a learning difficulty (laughs).

To explain the coding, the thematic framework provides a structure to understand the following: the global theme represents the four organizational frames. The organizational themes that emerged, which encompass conversations addressing DLI at 
school site, the role of the district, hiring, and the perception of language gave light to common significant themes among the principal interviews. The basic themes were school specific. The organizational themes that surfaced were significant because they gave voice to the experience of the leaders in the school and also confirmed that principals navigate through the organizational frames. In essence, these themes described their reality and also illustrated characteristics of Bolman and Deal's (2003) frames, which shape organizations. Figure 4.4 illustrates the data of this study organized through the Attride-Sterling's (2001) thematic framework, in order to arrive at meaningful findings. The frames are color coded, as they were in the analysis. The structural frame is coded in yellow; human resource frame is orange; political frame is green, and the symbolic frame is blue.

Figure 4.4: Summary of principal interview themes coded within the organizational frames

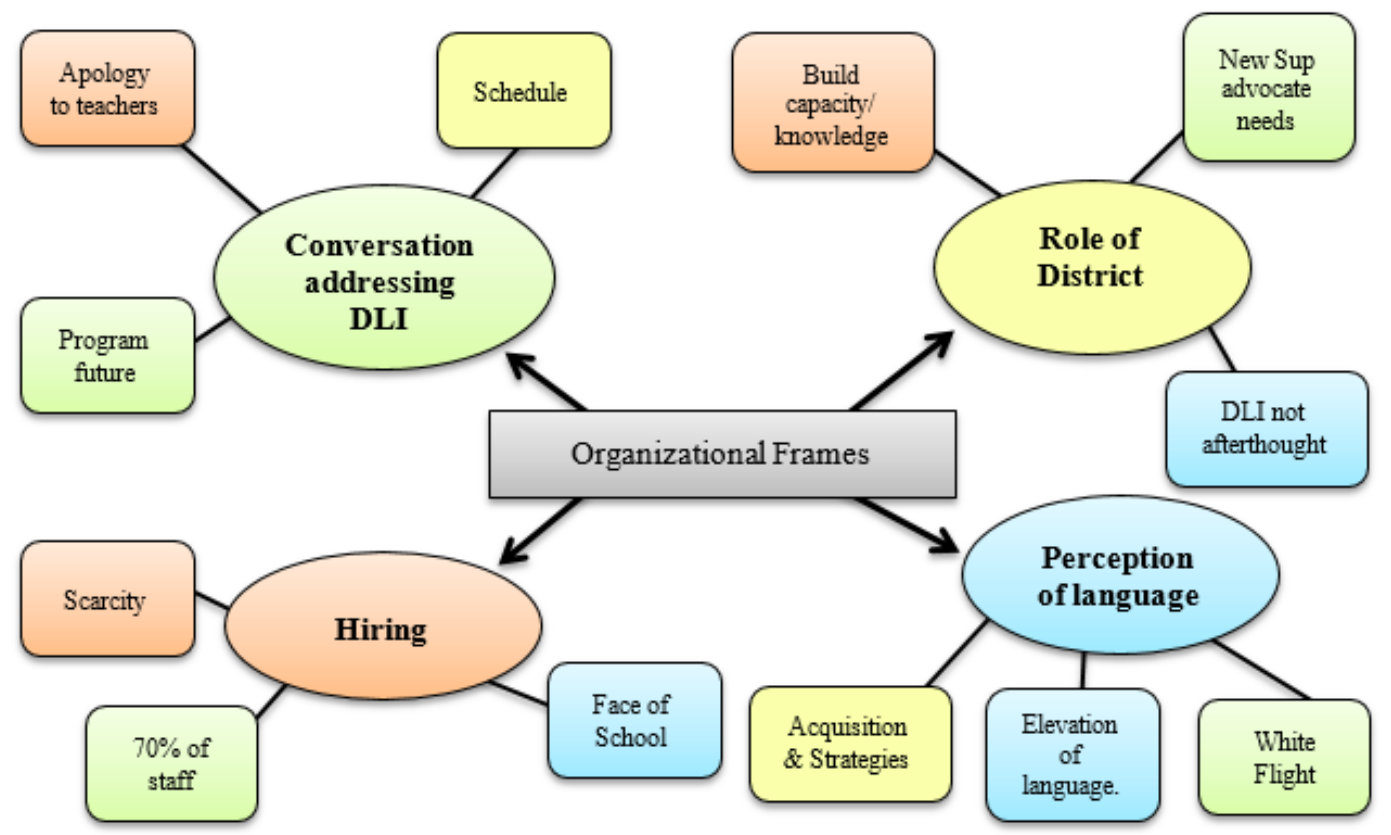


acknowledged principal characteristics of behavior have along with actions that pertain to those behaviors. (Cotton, 2003; Diamond, 2013; Gay, 2010; Hattie, 2012; Marzano, Waters, \& McNulty, 2006; Schmoker, 2006) The aim of this study was to examine the characteristics of leaders who successfully support student growth among EBs. Therefore, principals were asked to reflect on this question as it pertained to their experience as a dual immersion school leader.

\section{Qualities/Characteristics of Successful Dual Language Immersion Principals}

When asking participants "What qualities are needed of dual immersion principals?" the theoretical framework presented in this study, supports the claim, which implies that successful DLI principals need to have a grasp of the four frames and equity in mind. Principals should hold space to promote student achievement as a guide for what they do as a school leader (Gay, 2010; Hattie, 2012; Marzano, Waters, \& McNulty, 2006; Theorharis, 2007). When analyzing the data, all principals answered the question regarding qualities and characteristics in a way that interwove the four frames.

Additionally, each answer focused on equity - the basic theme. One of the principals spoke about providing a balance of the values of the school as well as the district initiatives while building a climate of care for parents and community. "Understanding how to navigate district initiatives and balance the immersion values of the school is very very important. Also, building relationships with parents and families and helping them feel comfortable and safe in the school and building that climate is important". The second principal provided feedback in providing information about the benefits of the program, giving adults autonomy, while also setting boundaries and encouraging 
movement if adults were not on board. This principal said, "I mean, I have stood in front of them and said, 'this isn't going away, so if you can't handle it, you gotta go to a different school, you can't be here, this in not for you'." The third principal focused on how we perceive students and families. This principal shared,

The culture that comes with that language, cuz it's not just language in isolation, there is a language that is not oral and if you don't get that you will miss the whole child; and you will not be able to teach it and again you don't have to be bilingual or Latino to do that, you just need a look at a child and their entirety and understand a community.

In analyzing this question as a collective body the following concepts emerged: language, people, and values, all within the theme of equity. Equity seems to be a tacit theme that is interwoven when principals' responses emerged.

Language: Each principal discussed language to some degree. Their thoughts scanned the spectrum from, principals should absolutely know the partner language to not mattering whether the principal speaks it or not. However, all discussed the importance of knowing the place of language as it reflects the student need. For one, it was about elevating the language to assure status and importance; for another it had more to do with instructional leadership and being able to fully connect with the teachers and their practices. The other connected language as a tool, but gave importance to the intellect and expectations that we hold for our students. All of these are examples of how these leaders utilize language to form their social architecture, strategize, and form objectives all qualities of the structural frame.

People: Whether connecting with a student, teacher, or parent. All principals spoke to the importance of assuring connection, relationships, and communication with 
the different individuals they interact with as leaders in their schools. Ultimately, this provides insight to the HR frame, which promotes the positive interactions that we have with people as leaders.

Values: The values that were collectively shared by the participants included building, understanding, trust and appreciation. In looking at the political frame, the values were in line with such as when discussed; they were correlated to influence, agenda, negotiation, and advocacy.

Lastly, all principals shared a story or provided thoughts on vision, which are part of the symbolic frame. Thus, once again falling in line with the intersectionality of the four frames and equity and how they play out in the success of these three different professionals that have brought about change.

Senge (2000) reminds that teachers play a critical role in the transformation of institutions. In his view, "When everyone is respected as an intellectual colleague, turf moves into the background and the debate centers around ideas"(p. 444). This study collected the views of teachers through focus groups in an attempt to confirm, construct, and debate results from the principal interviews.

\section{Comparison to Focus Group Data}

For the purpose of comparison, the same thematic framework that used for principal interviews was used to analyze the focus groups. In conducting this case study, ten teachers participated. The teachers in this case study's focus groups represented a wide variety of expertise and perspectives. These included, gender, race, years of leadership, program status, bilingual expertise, grade level expertise, and DLI program 
design. In order to reveal key concepts and meaningful results, a thematic framework was used: "If qualitative research is to yield meaningful and useful results, it is imperative that the material under scrutiny is analysed (sic) in a methodical manner" (Attride-Sterling, 2001, p.386). Thus, it was imperative to explore a methodical analysis of the data in order to explore meaningful and useful results. In order to do this, the first step was to look at coding for the four frames or organization - or global theme. Bolman and Deal's (2003) theoretical framework denotes the global theme that frames an argument, position, or assertion about the subject's reality. (Attride-Sterling, 2001) In order to quantify the frames quotes, from the three focus groups, were categorized according to the corresponding frame and were gathered and organized individually, by focus group response, and collectively, data from the three focus groups combined. (Krathwohl, 2009).

Figure 4.5 illustrates the individual responses by focus group and how it corresponds with the principal interview. Thus, Principal 1 and Focus Group 1 are from the same school.

Figure 4.5: Summary of data by individual focus group response

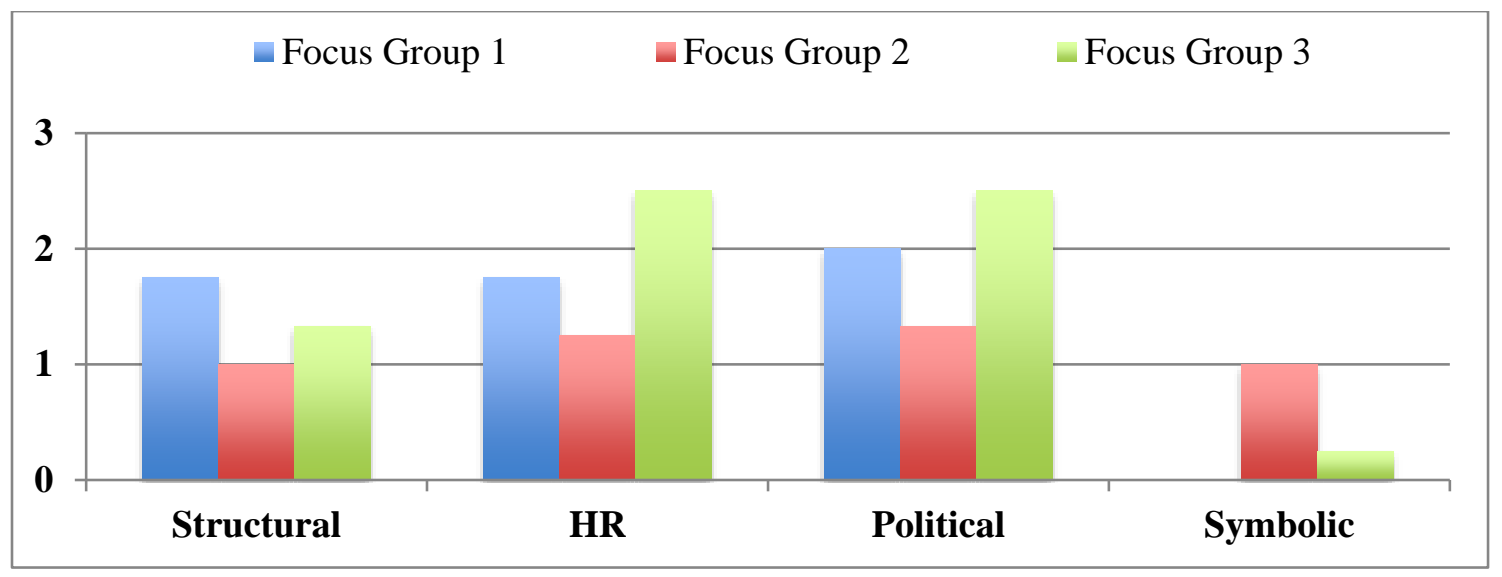


Then, Figure 4.6 details the four organizational frames gathered from the collective responses of the three focus groups.

Figure 4.6: Summary of data by collective focus group responses

$$
\begin{array}{lll}
\text { Structural } & \text { HR } & \text { Political Symbolic }
\end{array}
$$

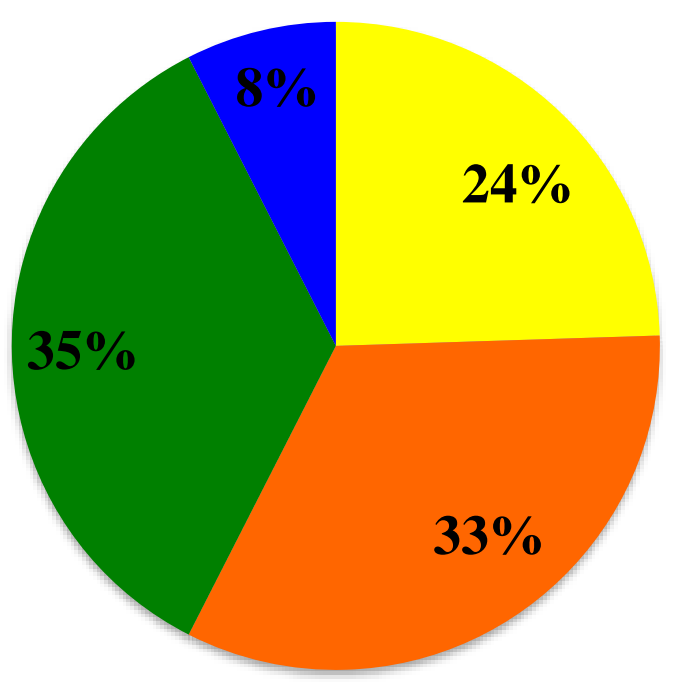

Bolman and Deal's (2003) organization themes, which were identified to represent the global theme through Attride-Sterling's (2011) thematic framework in the principal interviews, were also embodied in the focus groups. All focus groups discussed issues with communication addressing DLI policy/direction at school site, the role of the district, hiring, and perception of the partner language. In the areas of communication of policy and district support, the teachers presented thoughts in a way, which showed how these themes impacted them as teachers. For example, two of the principals presented examples of these tough conversations in a way that contextualized a means to a goal. For one, the end goal was to stabilize instructional minutes when the norm had been 
about making schedules that made sense for adults, not student learning. For the other, it was a line in the sand about the direction of the school. For teachers, they perceived it as group agreements for content allocation and natural attrition of teachers respectively. There was one focus group where principal and group called out the same incident and teachers perceived its impact as intended. The principal clearly spoke about an incident where she apologized to her staff for neglecting them in hopes to bring the school together. The staff saw this in the same way and felt validated and encouraged. In the arena of district support, it is not surprising that the disconnect that exists between higher-level management and classroom level support, contributes to a misunderstanding of what support is given and what is not. The principals clearly stated that district support was a key to their success, yet this was not the perception that classroom teachers had regarding the district role. While the description of such role was not negative, nor acrimonious, it did reflect a disparity of support in the area of understanding of the program and the resources it needs. All focus groups did provide examples of which the district office was making efforts to meet the demands of dual language programs.

The teacher focus groups also shared the same perception as the principals regarding hiring and perception of the partner language. Teachers provided examples where hiring disparities caused problems with workload and where lack of compensation also meant that the school would lose valuable resources. They understand that there is not a large workforce, thus making it harder to find a good qualified staff. Additionally, both principals and teaches agree that the struggle to elevate Spanish is one that is shared amongst the school community. There is no definite agreement on whether the principal 
should or should not speak the language. While the teachers see it as a plus, most said that it was more important to understand the program model and to know what this program does for students and for the opportunity gap. In their words, the quotes from each focus group illustrate a correlation to the themes presented by the principals.

Communication: During the interview with the first principal, the theme of communication addressing DLI policy at the school site surfaced. The principal identified this as a nuts and bolts issue, which correlates with his structural theme strengths. In sharing their personal perspective, the conversation set limitations and boundaries regarding the scheduling of content and instructional minutes. There was push back with what had been done before and the focus remained on a strong instructional program that would serve student needs over adult needs. The teachers also discussed and linked it to group agreements. These agreements were goals shared in order to create the best program for students and learning from mistakes in the past. They also gave credit to their principal in achieving this because before this tenure, so many administrators had come and gone. The focus group shared the following about this theme:

Some other challenges, along those lines, are making group agreements and then deciding on group agreements and then carryi8ng out the group agreements on all the minutes that exist in within the program. And so, some of those we've accomplished them, some of them we haven't, but they all relate to the elevation of Spanish and trying to be as balanced as we can. And then just deciding on structure because many of our first years, the students...

Another teacher added how the current $8^{\text {th }}$ grade cohort suffered from the changes of a changing program model: 
We started the program, I had a group of first graders and the decision we made was to start with kinder and first, which was a very bad decision, now I know. And so, we, in theory, accelerated these first graders with the kinder curriculum for the first half of the year, and then we slammed in all of first grade curriculum the second half of the year. And then that poor little group, who knows it's small and they're in eighth grade this year, they got a different structure and program every year. They got a huge patchwork of structure. And so that's been challenging. And then the other challenge was our string of different administrators who had their own idea of what was best and not best. And then they would leave and then we'd get the next person. And so, that's one part, is just structure, group agreements, decisions, so that we can portray that to families, and I feel like now we've done that. And when we give our descriptions to families, we know what we're doing.

Both the principal and teachers identified this challenge, only to mirror the reality of their roles. It makes sense that the teachers would not be privy to personnel conversations and further shows that the principal created clear communication as to why the structure of the model was important. So much so, that the teachers have taken ownership and see it as a strength in their communication with families.

In another focus group, there was a clear disconnection as to how and why DLI policy existed in their school. The principal shared the agony of the experience that first year. Failed attempts had marred the establishment of DLI at the school. The principal reflected on that experience as the "gutsiest thing she ever did", which resulted in many staff members moving out. The teachers however did not have that same perspective. When speaking about the DLI program at their school they expressed confusion about how it finally settled and gave credit to the principal for establishing the programs despite several attempts. They said: 
She's the one that brought the dual language here. And I know they've talked about it before for many years. And, I don't know, I was excited to see her do that. And I know it took her leadership skills to do it.

Another echoed, "Cause it really had... I mean with (name of past principal), we had had a committee together, we had met with parents, and we had done... I've been on that committee too and went through the whole thing and then no, it didn't go through".

The teacher further explained the different activities that the committee explored to establish DLI and added,

Then it just kinda fizzled out with the first principal. It just didn't go forward. So, I don't know if that was a lack of leadership on his side, or if it was the district not ready. We never really found out where it fizzled, where that happened and what came of it. And then, when (name) came in, it all picked up again, but it kept going.

As with the first principal and focus group the difference in perspective is influenced by their role. Nevertheless, there is confirmation that both principal and teachers identified this theme.

A public apology, in hopes of school unity, showed a vulnerable side to our third principal. The teachers in the third focus group collected the importance of this conversation:

With the humility that she had, she did learn from us. She learns from us all the time. And she listens to what we say and takes it into her thought when she's making big decisions. The other day she, in front of the entire staff, apologized to the immersion staff saying that she had neglected us this year. And we were feeling it; we were all really stressed to the max. Our test scores were lower than we wanted; everybody was really upset. And she felt that and she did it in front of everyone. And I was so happy that she did that. It made me so... Everybody was just so happy, and that she was gonna pay more attention to us next year and that we need... She's 
a very humble person, which goes a long way with people like us. That's all we want. We just wanna be validated, and understood, and heard. And so she's good at that.

The three principals in this case study had to address the direction of DLI at their site. Each conversation revealed characteristics of the frames. Just as each conversation resembles frames, different individuals also receive these in different ways. This makes navigating and balancing the four frames vital.

District Support: In the area of district support all principals noted that the central office either was or had become an asset to the work that they did within the program. This support manifested in collegial co-construction of budgets for resources and personnel, direct support of expectations and movement of personnel, as well as the establishment of the program and direct support of the principal for program viability. Understandably so, it would not be customary for teachers to be part of this understanding as the principal is often a conduit to the larger picture of central office. So, each focus group commented on the central role of the district office. Some aspects shared addressed frustration, especially when curriculum decisions are considered. They did, however, share positive statements of support for their program.

The teacher focus groups shared the following regarding the central office support. Each statement is shared respectively from the above list of principal support. One group shared that the district had begun and immersion task force. This group inquired principals and teachers in order to build as they shared, "some cohesiveness to all the different language programs." Another group reflected on their district's support 
role as bringing teachers together to discuss the program and its needs as well as build a linear articulation for the transition into the middle school program model. The last group's contribution recognized an important and crucial step to the viability and understanding of immersion as it pertains to the success of EB's. They shared,

Well, we wrote our new Lau plan last year. And that was the first time that dual language was included in the Lau plan, so that was really exciting, a huge step. We have a new multi-lingual executive administrator who has worked in immersion, taught in immersion, has spent time in Spain. So she understands us. And she's an advocate for us, finally, up higher than just school principals. And the fact that it's in the Lau plan, and it's considered in the ESL program now. And so this was our first implementation year, where they're gonna be researching our program, compared to ESL pull-out and push-in, and stuff like that. So that's very exciting. That's a huge step for us.

District support as well as site leadership is important to the success of schools. These principals and focus groups confirm this as they share experiences that either validate them as professionals or give support of the program in which they believe.

Hiring: Another theme that emerged was that of hiring. Principals shared that this may be the most important element to your success. The teachers also had examples to add. One group discussed challenges that came with hiring late and the problems it created:

I got hired the day before school started, because they had enough people to make another class. Last minute... Yeah. I think because it was just too last minute. If they could have, they would have hired a Spanish speaker.

Another group added,

I think she's hiring good teachers, though, too. That's really important. And unfortunately with the TWI program, you have less people to gather from, and that's always been a struggle too, is you just don't have as many people available, but she's choosing really quality people. And I think something that I like that she did this year is, and I can't say if it was her or the district, but hiring people ahead of time, so we have a team member 
who is teaching regular fourth grade, but will be a TWI teacher next year. And I think that's really valuable.

The last example from a focus group was:

I would also agree that keeping staff is also a challenge, or hiring staff. Our district is one of the districts that hires the latest in the year. So all the good ones are picked through already, teachers and staff and what not. And we've been really lucky to get some of the people we do so late in the game because I think it's usually July or August that we're doing our hiring, which is just atrocious.

Collier and Thomas, (2014) confirm, "Clearly the greatest challenge for dual language administrators in the U.S. at the present time is recruiting and retaining highly qualified bilingual staff” (p.62). As on principal shared, "your program is only as strong as your teachers". Thus, making hiring for DLI programs a top priority.

The United States today is at a crossroads with immigration policy, making the next theme an even more politicized arena that challenges DLI leadership. While there may be assumptions that this only impacts white English only speaking families, it should be noted that leaders have to exert the same of more effort to educate Spanish-speaking families. Principals provided example about how much they work to elevate Spanish as the partner language.

Consequently, the teachers also felt this burden and had the following to say about it, all represent a collective view from each focus group:

Teacher A: I think the biggest one is why we have immersion to close the racial achievement gap and try to really provide a program that can help students be successful and teach students our native language and also be able to communicate with parents and support. That was... 
Teacher B: Yeah. I agree. One of the challenges that I see that's glaring in my mind is that there's a need to educate families on what this really is because there's a misconception amongst the Latino community that, "Well, my child already speaks Spanish, I don't need them to learn Spanish, if that's what we speak at home." But it's completely different because we're talking academic Spanish. And they would rather them come into the school and learn English, because that's what they'll need to succeed in their minds.

Teacher B: It becomes difficult to create that 50/50 when you don't have that native speaker to become the expert [chuckle] in your classroom. It's an imbalance and it becomes a more arduous task as a teacher to be able to move that around, if that makes any sense, to make it work that way. Just makes it a little more challenging. I think educating families... Because English-speaking families, they're are all in...

English families see it as a benefit.

Teacher B: Absolutely.

Teacher C: And sometimes our Latino families don't see it as a benefit.

Teacher B: Right. And on the same token, the imbalance of registrations almost becomes, I struggle with this one and I'm just gonna put it out there, 'cause it's a challenge, it becomes an equity thing, in my opinion. We then take away... We don't take away... Those families who are not educated don't realize that they're taking away this beautiful strength and handing it over to keep that imbalance stronger and... Does that make any sense?

[chuckle]

Teacher A: I think promote bilingualism and by learning about each other's cultures, I think that's a big part of it as well. And just like as a nation, we're not very good at supporting learning languages in younger grades. And I think immersion programs can really help change that if they become more popular. It starts from the classroom like inspiring kids, "This is a really cool thing that's happening, becoming biliterate, bilingual, and it's gonna really help you in the future," and just giving them that understanding as well. 
Another focus group had this to say about language. They reflected on what perceptions

can create based on test scores as well as perceptions about intelligence.

Teacher A: ...I've sat through some of the principal meetings where they'll pull out the ESL data or the SBAC data, and then they'll sit by... She'll be with a group of teachers that teach in similar demographic schools, and they don't have immersion programs. Well, our kids don't... It's a six, seven-year... They're not gonna bump out of ESL or pass SBAC until they're almost sixth grade, most of them, which... Just having faith in the program and advocating for them and having those difficult conversations...she could easily back off on the Spanish and change our program because it's not getting the results that she wants, or that everybody thinks she should be getting. But she doesn't, she hasn't touched the model at all as far as the division of language. We're still 90/10, even though... Even the 50/50 school at our district gets better results faster, but she has faith that ours are gonna be overall better.

Teacher C: Like, the long-term better.

Teacher A: Long-term. So, that says a lot about her, for sure.

Teacher C: ... And their Spanish is a lot stronger, and then we see the faster transfer in third and fourth grade, I think, than (name) said that they saw when she was at the 50/50. It's like the fourth and fifth grade; it's kind of cool... If they're on grade level, it's cool to see how quickly they can, "Oh, this is the same," and shoot up. We had several kids that made two years' growth this year in English, so they're just like, "Oh, I know this... "

[overlapping conversation]

Teacher A:"I know how to read already." Yeah.

[chuckle]

Teacher C: And so I think she said you don't see that, it's just kind of... It goes like this and, just neither is super strong for a long time. Yeah. So she's a big supporter of that too.

Later in the interview a teacher shared their understanding of the challenges of students in DLI programs: 
I can't imagine going to my first day of school in another language, trying to put myself in their shoes and I just think those kids in the Spanishspeaking classes were happy and they felt smart. And I think that was hard... And I still see that. But not knowing a language sometimes gets misinterpreted as not being able to do, or not being smart, or being able to show all that they know.

The latter statement made by the teacher gives weight to the argument that their principal shared. Too often, students, families and communities see our partner language as a deficit. It is only perceived as an asset for English only speakers.

The last focus group shared a poignant and symbolic example:

Teacher A: One more benefit, I wanna talk about is how we have students who can be successful in their native language, which not all schools do. So we have students who can come here and they can be low in English but they're on grade level in Spanish. And I think that's really nice for the families for them to be like, "Okay, my child's not behind, they're where they need to be." And then I also have students, who are native English speakers and they're reading just as well in Spanish as they are in English, which I love.

Teacher B: And I would say that for our bilingual families, they are getting a little bit of restorative justice in a way. Because for so long, our country looked down, frowned upon, beat the Spanish out of them. That this is a way of restoring maybe what their grandparents, their parents and maybe themselves have lost the language but they want it back. So it's reclaiming part of their heritage, which I think is super important. And their kids are having that love or esteem or it's not even a privilege it's a right that they need to have, and so they're having that right restored in a way.

Teacher B: Slowly, I think there's a change, still there's a lot of ignorance when it comes to bilingual school because... Or a lot of push back. Because people sometimes think that because they are learning in Spanish that they're somehow the English is in jeopardy of being lost. Which there's a lot of myths and we've had book studies on the myths and what is actually true, which also helped the teachers and the staff when we had ignorant comments like that, to be able to say, "Actually, did you know?" Just arming ourselves with the knowledge of, "Bilingual schools don't make your kid less good in English." It helps the English, the better they 
are in their own language, the faster it trans... Transports is not the correct word but...

Teacher C: Transfers...

Lindsey et al (2009) reminds us of the barriers for immigrants who speak Spanish as their first language, "For Latino groups in general and U.S. citizens of Mexican and Puerto Rican ancestry in particular, state laws that forbade children from speaking Spanish in schools heightened Latinos' alienation from the dominant society" (p. 35). Hence, it is not difficult to correlate this to why many may want to dispel the opportunity to study in their native language when they have been marginalized and oppressed by the society that will further benefit from being bilingual. Culturally proficient leaders must adopt strategies that keep the students that need the program most, EBs, at their core decision-making.

\section{Interpretation of Findings}

The results of this study suggest several areas that future immersion leaders and district human resources departments should consider. The data from the subjects in this study, all of whom are successful Spanish immersion principals, indicate that they often operate within two Bolman and Deal (year) frames: the human resource and the political frames. Leading a DLI school may well mean the principal must be adept at navigating a political environment while meeting the needs of individuals in their DLI school by focusing on the HR frame.

Bolman and Deal $(2001,2014)$ explain assumptions of the human resource frame: organizations should exist to serve human needs and that organizations and people need each other in order to have viability. In this study, principals and teachers shared 
numerous examples of learning from each other and feeling valued in their work. When explaining the political frame Bolman and Deal share these assumptions: The political frame looks at organizations as coalitions of people and groups, decisions involve allocating scarce resources, and goals emerge from negotiation of competing stakeholders. Subjects in this study negotiated building and district politics to secure resources and keep the achievement of EBs and the opportunity gap as a focus.

In order to identify the leadership characteristics of successful dual immersion K5 principals and to understand the relationship of such to the growth of student achievement of EBs this study sought to answer: What are the leadership characteristics of K-5 principals who have successfully increased the achievement of EBs? Related questions included the following:

- How do principals in dual immersion schools understand and communicate the program model and its effect on Emergent Bilinguals?

- How do school principals influence school climate in schools and communities with English - only and dual immersion programs within one school?

- What focus is explicit within the vision and mission of the school?

- What is important for leaders of immersion schools to know about successfully leading an immersion school?

These questions guided the study, as the intention of this study is to conduct qualitative research, in which the researcher explores to find what is significant in the situation and describe in words that significance (Krathwohl, 2009). In this next section, I will synthesize key findings for each question and provide sample support quotes. 
In reviewing 21 responsibilities of school leaders, researchers shows communication as a key responsibility (Marzano, Waters, \& McNulty, 2006): “This responsibility seems self-evident - good communication is a critical feature of any endeavor in which people work in close proximity for a common purpose" (p. 46). The first question in this study was: How do principals in dual immersion schools understand and communicate the program model and its effect on Emergent Bilinguals? Communication for these principals is about a using both languages equitably; communication connects parents to the school community as well as educates. These principals spoke of having to think and communicate in both languages and using this communication to provide opportunities for involvement. More importantly, communication, via of newsletters, also serves as a conduit to support DLI research and program effectiveness.

Principal data collected from the interviews provides the following support:

You've got to be really organized and you know, be I think be, I think, an even better communicator. Than if you had one language in your school. You have to be able to think in two languages even if you don't speak in two languages which that been a really big learning curve for me when I finally do it. I feel like I think in English and Spanish all the time even though I don't speak Spanish and that's gotten me out of a lot of trouble. (Laughs) that's gotten me into trouble when you are not thinking in two languages. I guess that would be good advice too to give a new principal.

Communication is also used as a conduit to family involvement. One principal reflects on ways in which the school communicates: "We communicate with families a number of different ways and that's I think super important - in at least 
informing with a least what's going on and at least they have chances to be involved.

This principal shared that communication not only connected families to involvement, but also shared program data and research, as a simple newsletter became a way to educate parents on the benefits of the program.

So in order to get our families well informed and make a choice whether they want to be involved, we have to do that - it's just the backbone of the school. And it has helped being more consistent; having a weekly newsletter that's a little simpler has helped me make sure I'm delivering consistent information for them. And if there's not a lot going on that week, I use it as a chance to just educate them about a topic. Like I'll put in; something about basics of dual-language or I'll put something about importance of attendance or I'll put something about another topic, which are probably familiar to you (laughs) yeah so, that's a little bit about our parent involvement.

Teachers also commented on the importance of communication. They shared communication, in a language parents understand, connects school to family. Also, ensuring regular communication marks a trait of a good leader. The teacher focus groups generated the following regarding communication:

Communicating that with our school and why we continue to have this program, because we get that information as the TWI Team, the research and the results and like that. We know that it's... but continuing to communicate and fight for that.

All the communication going out to families, it needs to be translated. It needs to be sent a copy, we need to make one side in English, one side in Spanish, and that's something that I don't think other principals have to worry about in other schools

My teaching partner and I send Friday reports home and we've gotten a really good response from that, I think that's a good way to communicate with parents, it's been really effective, 'cause then they have the whole weekend to find time to look at it and read it. 
Try to really provide a program that can help students be successful and teach students our native language and also be able to communicate with parents and support.

Needs to be a good communicator

The communication between the office and the families I think is wonderful too and every week (name) puts out a bulletin that he sends email and hard copy to families keeping them abreast of what's going on. And I think those cafecitos can't be celebrated enough because my room's right here and when the people... And they're mostly the moms with the little kids, but it's such a sweet precious thing

These are examples of practices and strategies shared by both leaders and teachers. Collier and Thomas (2014) stress the importance of communication, especially when leading a new program. They remind us, "the communication plan should state the purpose of implementing a dual language program, the goals of the program, and the research behind the program" (p. 30). While these are practical ideas for communication is establishing dual language, the data suggests that established programs should continue the practice and adjust communication to the needs of the families.

Both leaders and teachers overwhelmingly reported that these leaders positively impacted school climate. Creating this positive culture was noted as a responsibility of a leader, a finding supported by Marzano, Waters and McNulty (2006): “Although a culture is a natural by-product of people working in close proximity, it can be a positive or negative influence on a school's effectiveness. An effective leader builds a culture that positively influences teachers, who, in turn, positively influence students" (p. 47). Each principal in this study described the negative school environment that existed when they were appointed. They used words such as "complex," "toxic," "harmful," and 
"negative" to explain the climate in their schools. However, this changed during their tenure.

We have school choice...and that's complex; there are times where it feels very warm and endearing; because it's a dual-language school, somewhere along the way, I think 2012/13 school year the school district and the current leader...made a decision to make it to not a strand program but a school-wide program and that's helped with the climate. I believe a lot because we didn't have a strand and an English only strand, it made it easier to build a climate and to promote the language and culture of Spanish and so when students start to attend our school, they learn that it's a dual language program and that it's a way of life that you have to learn Spanish here. There isn't a friction or a resistance too much in our school... So the climate and feeling changed once most people became more comfortable with the concept of dual immersion here.

Principals dealt with managing and replacing staff members who did not believe in the program or students. After finding staff that believe and work to provide the best for students, this is the result.

Fast forward, now it's amazing it's an amazing amazing Community! It's in the teachers - I'm speaking about the teachers now and they are wonderful. They are loving they are culturally competent they look like the kids, they love our kids, and they're amazing teachers, but at the same time you need to know that I think I've hired over $80 \%$ of them so it's been beautiful.

Another principal reiterated the need to hire teachers who wanted to support DLI and the students in the program:

Now it's amazing! We have had incredible staff turnover every year that I've been here. And, last year was probably the biggest turnover we had and and I guess last year I felt like we finally kind of reached the top of the mountain and started to come down. You know we peeked in terms of climate and that we have this positive energy about who we are and what we're trying to do for kids and, and now you know the challenge now has really been in terms of hiring people both English speaking and Spanish speaking teachers is getting them to collaborate together so that we're not 
creating this, you know, division amongst languages at our school. And that's been challenging but not in a way that people don't want to collaborate, it's just been challenging and terms of the programming or how do we come together and have a common goal and common instructional strategies and we are still working towards a lot of that. But, we are getting there and people want to do it. You know that's what's awesome! The entire office has turned over that was a huge piece of climate at our school and in making sure that we are creating an atmosphere of a bilingual welcoming school for all of our families and that has really made a huge difference um, and also just some key people who are incredibly supportive of all of her teachers and you know my leadership team is a real powerful model of how we move a school climate forward.

The teachers mirrored principal sentiments on school climate. After sharing many positive reviews on their school climate, this teacher focus group confirmed what their administrator did to impact a positive school climate:

We have an administrator that supports us. We have just the right mix of people that we don't just see each other as colleagues, but even friends. And we hang out not just in a school setting, but afterwards. Some of that is self-care of building community within one another, to build each other up

And then one more thing, along with what you said that our principal right now supports us, and moves us to great heights. He connects us with people from the university and within the community. And I think he knows everybody in town that has anything to do with the Latino community, and with dual immersion, with language immersion in general. And that spills into our high expectations. And so, given our population, I think that we're known as, "It's not easy to come here, but it's so fun. And you leave with these incredible skills."

Fink and Markholt (2001) say, "Teaching is a highly complex and sophisticated endeavor." (p.xix). It can be said that this principal understands the complexity of teaching and what DLI adds. In understanding this, this leader stands as someone that is an instructional leader and someone that leads for improvement. 
I would also say that even though it's really hard, we know the importance of our work. And I think also our administrator realizes how hard we work, and provides professional development to continue to help us grow in our skillset. I don't think I've ever been in a building that is just like, "You're gonna learn about this, about this, about this." And there's always something new, or always something to I guess, improve our skill to be a better teacher. And I've worked in other buildings, and that just doesn't happen. You're just still or you just go to your tried and true tricks, but you don't add to your repertoire. And I feel like I'm constantly adding to my bag of tricks. And if I would've had all the PD that I have now when I first started, I think I would've been a better teacher for sure.

Another focus group discussed the student population, demographics of families and the staff's shared passion for students and added this about their school leader,

I think (name) values that, that we have that viewpoint of wanting to be here and wanting to work with our kids, and...

Thinking about (name), I also think that her background also helps the families feel safe. Not only because she's Hispanic herself, but also she speaks both languages, they feel comfortable coming to the office and speaking to [principal] in English or Spanish, doesn't matter. And also I like [the principal], honestly as a person, as the type of principal that is very relatable. She has open door policy all the time, at least with me.

[laughter]

I think it's for everybody, [chuckle] but I feel safe and I can talk to her anytime, and I appreciate that as well.

The third focus group first shared examples of student enjoyment of school, parent involvement and teacher collaboration and hiring, as well as putting a great amount of time and focus on school-wide positive behavior systems, which really added to their instructional minutes to be spent on instruction. Then this was added this about their principal, followed by agreement from the others:

On that vein, administration as well. As a new teacher and being in other schools where I feel that I don't feel comfortable coming... I didn't as a 
student teacher at least, maybe that's why, but I feel very comfortable going and talking to administration and getting support, or I have an idea, like recently, about equity project, it was fully welcomed with a group of other people and we were able to make it happen and it was welcomed. So just that sentiment, for sure.

Cotton (2003) reminds us, "the principal's contribution to the quality of the school climate is arguably a composite of all the things he or she says or does" (p.14). Cotton later cites other researchers that give weight to the argument that a principal's contribution to school climate is critical to school success. In focusing on their influence to school climate, a leader can navigate the complexity of co-located programs, hiring practices that promote a racially and linguistically diverse workforce as well as creating opportunities for parent engagement and involvement.

Kafele (2015) indicates that, time and again, school leaders have a difficult time believing that their schools could be successful because of the challenges their students face. This is especially true for those leading in communities that may have high poverty and societal issues with drugs and violence. However, he stresses, "I have said to countless educators over the years that earnestly envisioning success is more than half the battle" (p.7). This sentiment came through in that all subjects unanimously reported that each of the three principals had a strong vision.

One principal was clear that when their tenure began, a vision did not exist. Thus, a vision was created and articulated, and all subsequent decisions were made through that lens. This principal shared:

When I started here in 2014 there wasn't a clear vision and it was like three paragraphs thing about rigor relevance and relationships which no one followed and no one cared about so I made it two sentences of 
basically that; we are a bilingual school we want our students become bilingual, biliterate and bicultural and we want them to perform at high levels, at grade level or better... So what I've tried to do is first create a vision that everyone could understand and live on a daily basis and then fill in the gaps, provide the structure that everyone needed, so that we could get there to those goals - behind the vision... If the vision is clear, on what we're doing - like I mentioned before, and everyone knows that we're going towards that goal and they feel like we're going the right direction...so being able to make those tough decisions and say no this is the vision, we are sticking with it.

The focus group shared the principal's sentiments. They added, "Vision and mission, and say it all the time. Say it out loud. And on the topic of bilingual, bicultural, all those parts." They emphasized the importance of working towards this common goal.

The other two principals did not necessarily articulate creating a vision; however, in one school the teachers answered, "have a vision" when they were asked teachers were asked, "What qualities are needed of DLI principals?" The other focus group articulated the connection of the vision to school success. They shared:

She's had a vision and she's stuck to that vision of... And, making maybe some bold moves that other people might not have made in order to hold true to that vision. And I think it's shown in our school and our changes in the last couple of years

Three schools identified vision as an important component of leadership. Whether it was an articulated answer by the leader, an answer that ties directly to the scope of this study, or as a measure of school improvement, having a vision made an impact among these schools. 
Palmer (1999) reminds us, "Teaching, like any truly human activity, emerges from one's inwardness, for better or worse" (n.d.). He emphasizes that in order to be a good teacher, one must know oneself in order to know the students in your classroom. He accentuates that self-knowledge is required of good teaching. Administrators are teachers first. So it makes sense to say that administrators must look inwardly and know their strengths, their selves, in order to lead.

This study was guided by the question, "What is important for leaders of immersion schools to know about successfully leading an immersion school"? The theoretical framework proposed in this study was based on the idea that a principal needed to be centered in Bolman and Deal's (2003) four frames of organizational thinking coupled with a focus on equity. What this study has shown is that the human resource frame along with the political frame are two frames that address the principalship in DLI. While the structural and symbolic frames are important, these frames were utilized if the principal had support in the structural and symbolic frames. Leaders should understand that hiring is an integral part of the success of the program and that the advocacy, not only for the program, but to advocate for why the programs exists, which is to increase student achievement among EBs, must be emphasized.

While principal interviews revealed that principals mainly operated in the human resource and political frames, the data illustrated a balance when answering the question: What qualities are needed of dual immersion principals? The principals' responses to this question illustrated characteristics of the four frames, thus demonstrating a balance. This balance can be explained in the following: 1) Strategies for communicating with 
parents as well as the organization of ideas/questions when hiring for DLI are qualities of the structural frame; 2) Qualities of the human resource frame included building relationships and trust as well as empowering staff to take risks and show appreciation; 3) Qualities such as navigating district and school initiatives, elevating the partner language, and promoting the program to make an impact on the opportunity gap and creating advocacy around this, were demonstrated as part of the political frame, and: 4) having a vision and creating a culture that honors the values of the vision as well as creating meaning around language and the whole child were qualities, which support the symbolic frame.

The teacher focus groups also included examples of the four frames in their answer to this question. The factors that correlate with the principal interviews are principals need to know the program inside and out, connect with parents and build trust, advocate for the benefits of the program, and have a vision and be a role model for that vision, which correspond with the structural, human resource, political and symbolic frames respectively. Additionally, both principals and focus groups added a layer that gave meaning to the importance of equity. One cannot lead a dual language immersion school without believing that this program will make the most impact on the success of EBs. Something, which captured and transcended through other focus groups, is the idea that their leader was their voice and ultimately the success of the program (meaning students) rested on them. They shared, "She's been a strong leader when she's among other leaders in the schools because as you were mentioning earlier, she has to be the 
voice, she has to stand firm, and not backing up with because it could affect our program"

From a principal's perspective, this idea also resonated. One shared,

Our kids need something, our kids are changing, and we're going to leave them behind if we don't find a way to meet their needs and I think if you don't have that appreciation or in my case just the appreciation that these kids are brilliant you're just using the wrong language with them and you're not understanding the nuances of, of a cultural body language if you don't get those two things that's when you do harm and that's when the achievement Gap grows. So I think you have to have an appreciation for language - language acquisition and the culture that comes with that language cuz it's not just language in isolation there is a language that is not oral and if you don't get that you will miss the whole child and you will not be able to teach it and again you don't have to be bilingual or Latino to do that you just need a look at a child and their entirety and understand a community.

Thus, whether you acted within one frame, or multiple frames, the idea that your actions had impact on student achievement meant the program is protected and work to strengthen at all times. Collier and Thomas (2014) share the great responsibility of all dual language educators as we shape their learning, not just as an immediate benefit for them, but also for their contribution to our global society.

\section{Document Review}

This study intended to include a document review. However, the document review exposed that there was an inconsistency in the method and the amount of documents that were shared, the origin of the documents did not necessarily belong to the principal, and the principals chose what to share. Thus, a limitation of this study is the failure of the document review to adequately provide sound data that could be compared to the data of the interviews and focus groups. 


\section{Limitations of Study}

All studies have limitations, including this one. Some case study limitations exist outside of the conventional limitations of qualitative research. The limitations of this study include, limited data, limited subjects that fit criteria, and researcher bias. The most evident limitation with the span of this study was the failure to gather conclusive and objective data within the document review. One principal provided dozens of artifacts, one provided a schedule, and the other did not provide a single artifact. While this method was designed to increase validity, it did not add or diminish data from the findings, yet it is a limitation.

Besides not using the aforementioned method, a limitation exists in the quantification of data. For example, if the participant were more verbose than another, the amount of examples quantified in a particular category, or frame for the purpose of this study, would cause a greater occurrence to be counted for that of someone that articulates more than another. Nevertheless, the focus groups serves as validity check for this reason.

As a sitting principal in a DLI school, my experience creates a bias when listening to principals and focus groups. A way that I attempted to minimize bias was to examine perspectives of teachers and principals, to ask clarifying questions when interviewing conducting focus groups. However, with a small sampling group, it is difficult to assess the impact of this bias. 


\section{Summary}

In summary, this chapter examined the characteristics of principals leading DLI schools. The data analysis provided insight to how they may operate within the four frames of organizational theory. The findings were validated through the accounts shared by principal interviews and teacher focus groups. The final chapter will address a synthesis of the findings, how these outcomes are situated in a larger context and implications for policy and practice. 


\section{CHAPTER 5}

\section{DISCUSSION}

\section{Introduction}

The purpose of this case study was to identify leadership characteristics of three successful K-5 dual language immersion principals. Dual language programs have proven to be a significant strategy that works for EBs (Collier \& Thomas, 1999). Zacarian (2011) supports dual immersion programs, citing Collier and Thomas (2002) finding that "students who participated in a bilingual, biliterate model had the best outcome among all of the program models that they studied" (p. 29). EBs should continue to solidify their native language through practice of reading and writing skills while they are also simultaneously learning English. Dual language immersion (DLI) is a proven strategy to close the opportunity gap as students practice their native language literacy skills while they learn English. Several researchers (Hattie, 2012; Marzano, Waters \& McNulty, 2005; Cotton, 2003); Fullan, 2001) have contributed to the body of literature that established the role of the principal and its effect on student achievement. Tellez and Waxman (2006) state that principals who are knowledgeable about bilingual programs, research, and best practices were focused on improving student achievement and integrating bilingual programs into the school. However, there is little research that more specifically looks at leadership characteristics of dual language principals and the relationship to student achievement. As more dual immersion programs focus on the needs of EBs, it is important to examine more closely leadership characteristics of successful dual language principals. 
Although dual language leadership may seem of concern to only a small group of educators, it should, in fact, concern all school leaders, particularly given the increase of EBs in our schools in recent years. The results of this study serve three purposes: 1) inform principal preparation programs so that future immersion leaders will be better prepared to provide more specific information about leadership in a dual language immersion school; 2) increase practitioner understanding of how leadership affects student growth among EBs; and 3) contribute to the literature base regarding successfully educating EB with a specific focus on DLI educational leadership.

Schools continue to struggle to address the language needs of the EBs. Not only are EBs students experiencing the demands of the new Common Core State Standards (Takanishi \& Menestrel, 2017) they must also reach Oregon's new English Language Proficiency standards, which according to ODE were developed to address the increased rigor and language demands of college and career ready standards (ODE, 2014).

The approach of this research employed a multi-method qualitative approach (Creswell, 2013) to understand the leadership characteristics of successful DLI principals. Creswell follows the structure presented by Lincoln and Guba (1985) regarding case studies. In each case, the problem, the context of the issues, and lessons learned are examined. I used this approach to address the following research question: What are the leadership characteristics of dual immersion principals who have successfully increased the achievement of EBs? The study focused on investigating the characteristics of three principals who have had success in increasing student growth among EBs in dual immersion schools. 
This chapter addresses a synthesis of the findings, how the findings are situated in larger context and the implications of these findings. This chapter concludes with a summary.

\section{Synthesis of Findings}

In this final chapter, a few conclusions will be presented. I share three conclusions that I drew from the study. These include the following: 1) principals navigated the organization primarily using the human resource and political frames (Bolman \& Deal, 2003); 2) principals kept equity at the center of their work while supporting the program outcomes; and 3) the absence of a co-located program allowed a principal to focus less on the political aspect of the job and instead address needs characterized among the remaining Bolman and Deal frames.

This study aimed to answer the question, "What are the leadership characteristics of K-5 principals who have successfully increased the achievement of EBs"? Leaders in this case study navigated the organizational demands showing a focus on the human resource and political frames. There were examples of the structural and symbolic frames being used to direct decision-making under certain situations. Bolman and Deal (2003) explain that utilizing multiple frames, in order to gather perspective and seek understanding. Therefore, leaders that relied on the less utilized frames may have done so out of necessity or perhaps a leadership strength. While the human resource and political frames were the primary frames through which these successful principals operated, the use of the structural frame and the symbolic frame was also available to them when needed. Each leader needs to apply the Bolman and Deal frame that allows 
them to act accordingly in their context, in the interest of their school communities. In the words of Bolman and Deal (2003),

Both managers and leaders require a high level of personal artistry in response to today's challenges, ambiguities, and paradoxes. They need a sense of choice and personal freedom to find new patters and possibilities in every life at work. They need versatility in thinking that fosters flexibility in action. They need the capacity to act inconsistently, when uniformity fails, diplomatically when emotions are raw, nonrationally when reason flags, politically in the face of parochial self-interest, and playfully when fixating on task and purpose backfires (p. 431).

Regardless, the data shows that the use of the human resource and political frames best represent the characteristics of these principals.

\section{The Human Resource and Political Frames}

The subjects in this study primarily relied on the human resource frame and the political frame to ensure the success of EBs in their schools (see Figures 4.2, 4.3, 4.5, 4.6). The school leader is often thought of as a change agent (Bolman \& Deal 2014; Fullan, 2001; Silins, Mulford \& Zarins, 2002). As a change agent, leaders must have people follow and believe in them as leaders. Bolman and Deal (2014) speak of leaders as change agents who balance the perception of command versus influence. They speak of leaders that are either carriers or catalysts of change. It can be argued that school leaders have to carry out both carrier and catalysts characteristics and manage a duality within frames. DLI leaders must carry out district mandates, curriculum adoptions, and other district mandated initiatives. Yet, they must inspire teachers to teach the complex learners in their schools. Within the human resource frame, leaders must take the role of 
a coach. As coach, leaders can involve people, provide training and give support. They do this as they also evaluate performance, which can be seen as being at odds with the characteristics mentioned above.

Within the political frame, change "alters power relationship and undermines existing agreements" (p. 370). Therefore, the idea that change agents understand that change is constant (Bridges, 2003) and that as Bolman and Deal (2014) point out, change creates alterations to the status quo and creates conflict. One can see that characteristics of leaders using the human resource frame and political frames can complement each other yet also potentially conflict with one another.

The human resource frame views people as "an investment rather than a cost" (p.129). The subjects in this study, indicated the need for hiring teachers within a narrow pool of applicants, who believe in students, the program model, are culturally competent, and they felt fortunate to have teachers that exemplified these qualities. This too is supported in current research (Collier \& Thomas, 2014; Garcia Matheson, 2017; Espinoza Fernandez, 2016). While hiring is difficult as more DLI programs expand nationwide, participants shared the need for alleviating workload for DLI teachers and leaders and the need for higher compensation to recognize their skills as bilingual professionals. Additionally, participants shared the importance of learning from one another. The idea of principal as instructional leader also meant that the principal learned from the expertise in the building in order to create an environment that values people doing the work. All of these examples were addressed and characterize the human resource frame. 
As mentioned above, school leaders serve in numerous roles; as Bolman and Deal, (2014) note, leaders are both politicians and peacemakers. Subjects in this study identified the leader as an advocate for the school and program model and the key person to elevate the partner language and breaking the mindset that Spanish is not valued. Additionally, leaders also had the responsibility of addressing "White flight" of families not wanting their White children in a program with Latina/o children, as well as lack of resources for the vitality of their program. The lack of resources created a conflict between school leaders and central office; in addition, leaders had to navigate complex political realities with resource allocation when they had co-located programs in their buildings.

The findings show that successful principals of EBs used both the human resource and political frames. Principals prioritized hiring quality individuals and advocating for their schools. Focus groups appreciated the principal as someone that learns with them and appreciates their efforts as well someone who is their "cheerleader" and advocate and who not only "supports", but also "believes" in their program.

\section{Equity as a Focus}

Dual Language Immersion programs have reduced the educational disparities in our educational system. It is understandable that dual language leaders must be transformational leaders. Lindsey et al. (2009) cite Ibarra (2008) who notes "transformational leaders influence follower to look beyond self-interest" (p.47). Leading in a DLI setting is leading for equity and requires cultural responsiveness. As dual language research continues to show notable results for EBs (Thomas and Collier, 
2003, 2004, 2014; Lindholm-Leary 2005), leaders must define equity and explore ways in which to balance the interplay of the four frames as they lead their school communities. Sugarman (2012) writes,

The focus on dual language serves as a unique lens through which to explore the concept of equity. Furthermore, unlike mainstream programs that attempt to build equity into their educational paradigms after-the-fact, dual language programs offer an opportunity to investigate the work of practitioners and policy makers as it applies to a program that is designed to create equity through access to the curriculum and to challenge the monolingual norms of school and society. The findings provide powerful illustrations of the interrelationship between society, the educational system, the program model, and teacher actions in terms of creating an equitable learning environment for students

Therefore, equity must not be an additional factor when thinking about organizational leadership in dual immersion programs. Instead, it should be considered in every aspect of leadership moves. The participants in this study illustrated their focus on equity by articulating the authenticity of DLI as a main factor for student success and trusting that students would achieve outcomes as predicted by the research. Their leadership moves were student centered. These moves included creating schedules that reflected a prioritization of program minutes and student interest, making decisions around blended classrooms that would benefit the DLI strand, advocating for materials and FTE that would support the teachers of DLI. Additionally, all participants discussed the importance of a culture and atmosphere that welcomed families and searched for meaningful ways to engage them, even if it looked different than the stereotypical parent involvement activities. 


\section{The Impact of Co-located Programs}

Two of three principal participants exist in a co-located environment. Figure 4.2 provides a snapshot that may point to the idea that co-located programs increased the level of which these principals interacted with elements of the political frame, which include a high level of interaction with power coalitions, conflict, advocacy and influence. The amount of time which these principals managed within this frame took away from them interacting with the tasks that can be characterized in the structural and symbolic frames.

The principal that led under this environment showed great a personal strength and the need for focus on structural aspects to support the school and program model. This leader voiced,

(Name) made a decision to make it to not a strand program but a schoolwide program and that's helped with the climate. I believe a lot because we didn't have a strand and an English only strand, it made it easier to build a climate and to promote the language and culture of Spanish and so when students start to attend our school, they learn that it's a dual language program and that it's a way of life that you have to learn Spanish here. There isn't a friction or a resistance too much in our school.

Additionally, this leader added,

The school needed a lot of structure! When I started here... what I've tried to do is first create a vision that everyone could understand and live on a daily basis and then fill in the gaps, provide the structure that everyone needed, so that we could get there to those goals - behind the vision.

When discussing district demands, assessments, and resources, this leader assessed priorities based on the structure established at the school by saying, "It affects everything in the school whether your structure is working and you're able to get the results that you 
want and always looking for that". In response to what it takes to be an effective dual language immersion principal, the following was said after pointing out the importance of a strong and bilingual office staff, "if you don't have that in place, that's the first thing I would try and fix and work on the structures". Additionally, this principal shared the importance of structure when working on scheduling. The participant shared, "So helping people stick with non-negotiables and remind them consistently is another kind of structure. Um, another area which is kind of Nuts and Bolts is kinda pushing back on people that want specials". As noted, this principal was able to notice and name structures as a key component to their success as a DLI principal. While advocacy still ranked high among the political frame, this leader was able to prioritize the work in the area characterized by the structural frame and named it as a key feature of success.

\section{Situated in Larger Context}

The review of the literature indicated that research on dual language immersion leadership is limited. As dual language immersion programs increase, so too should the research on dual language immersion leadership. This study addressed this gap by looking at leadership in dual language immersion through a framework that employs the four frames presented by Bolman and Deal (2003). This next section addresses the findings within the framework and modifications to the framework as it pertains to dual language immersion leadership.

\section{Guiding framework for the Study from the Review of the Literature}

This study applied the four frame organizational theory (Bolman \& Deal, 2003) to successful dual immersion leadership. I also explored models for 
organizational leadership and theory in the field, as well as a history of dual language immersion, and the principles of learning and practice for dual immersion.

As shown in Figure 2.1 the theoretical framework used for this study positions the leader in the midst of the four frames of organizational leadership. This illustrates that the leader must navigate the four frames of organization based on the needs of the specific situation. Given that dual language immersion exists for the advancement of EBs and the impact of this on the opportunity gap, it seems appropriate to include equity in the framework.

The literature review provided the historical perspective of DLI. The data from principal interviews and teacher focus groups also supported the importance of knowing the program in order to posit each leader to support and believe in the program. This may be more important than actual teaching in the field. While many might believe that successful immersion principals were also immersion teachers, none of the principals in this study were K-5 immersion teachers. However, all participants voiced the importance of knowing, understanding, and believing in the dual language immersion model. It seems fitting to say that leaders in a dual language immersion setting should study the history of dual language immersion programs as well as study the program models in order to be situated to fully understand the instructional practices employed by their staff to ensure outcomes for EBs. This sentiment was voiced in both the principal interviews and focus groups. 


\section{Modification of the Conceptual Framework}

The framework presented in figure 2.1 posits the idea that leaders must sit among the four frames of organizational leadership. The emphasis was on a complete balance of the four frames guided by equity. After conducting this study, I modified the conceptual framework to mirror the findings in this study and reflect the literature situated in educational paradigms. Figure 5.1 shows the modification.

Figure 5.1: Modification of Theoretical Framework

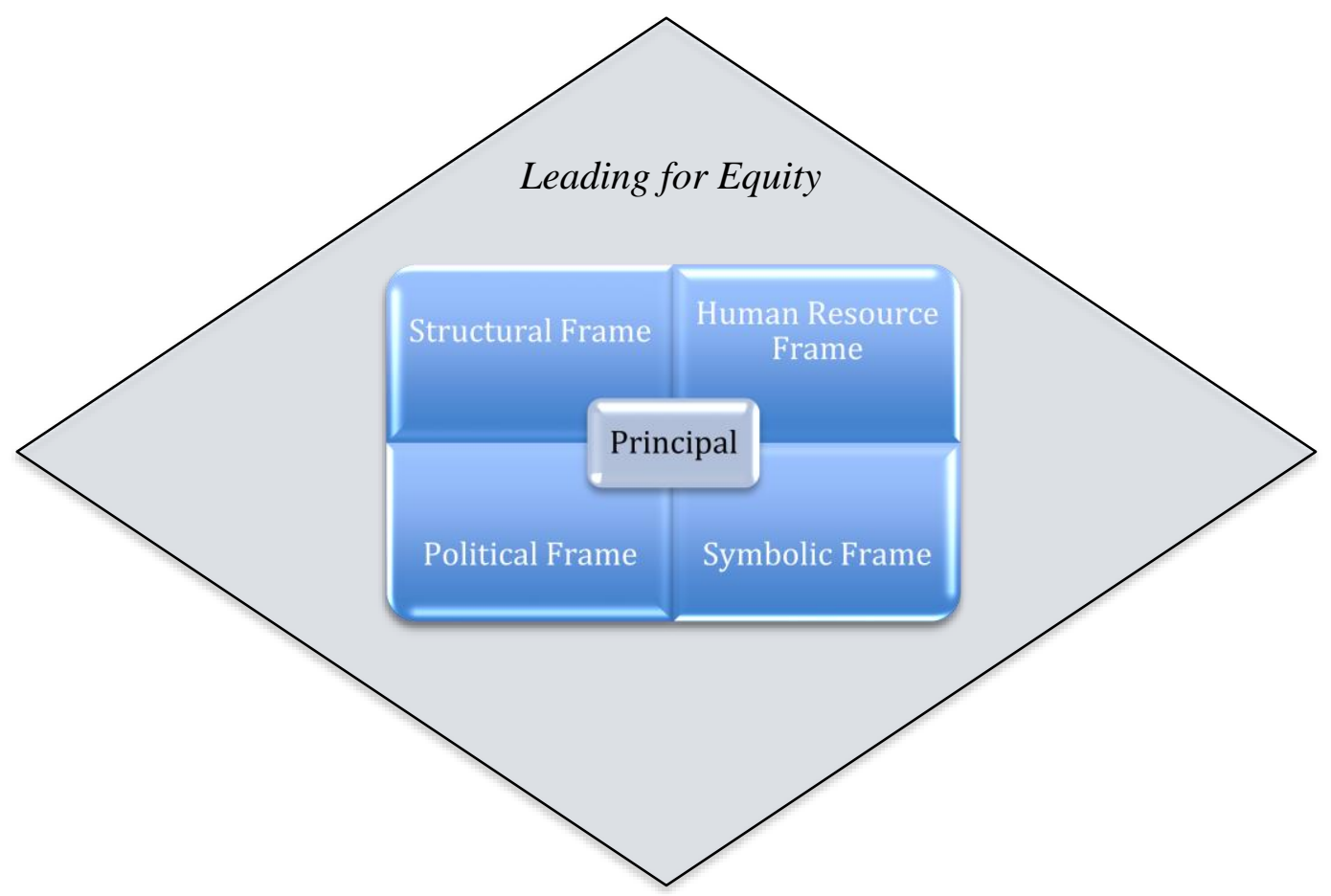

Figure 5.1 remains true to the frames, but takes in account that the findings showed that the frames are not static and one-dimensional. Instead they are dynamic and situational. Bolman and Deal (2003) emphasize the idea that leaders live within change and must have strategies to deal with their organizations' circumstances. Bolman and Deal discuss 
how working within the frames, help leaders think before they act, which in turn allows them to respond to challenges and cross roles characterized by each frames; leaders can navigate roles of coach, architect, politician and storyteller in order to meet the needs of their organization. Not only does this modification of the theoretical framework align with the four frames presented by Bolman and Deal, but it also directs implications for policy and practice.

\section{Implications}

The findings for this study provide an understanding into the characteristics that of DLI leaders who have shown success with EBs. Additionally, the study provides insight to implications for policy and practice, as well as recommendations for further research.

\section{Implications for Policy}

There were two key findings that inform implications for policy. One addresses the needs for staffing and compensation, aspects of the human resource frame. The other, addresses recommendations for co-location of programs, which refers to the political frame.

Hiring and compensation/resources. Of significant attention is the finding that hiring is key to the success of the program, leadership, which impact the success of EBs. Collier and Thomas write,

Clearly the greatest challenge for dual language administrators in the U.S. at the preset time is recruiting and retaining highly qualified bilingual staff. Dual language programs are spreading very rapidly, even in states that have not encouraged bilingualism in the recent past. Rapidly changing student demographics, along with the increasing popularity of 
these programs for native English speaking families, has accentuated our shortage of certified bilingual teachers, and many universities are not yet geared up to provide the needed coursework (p. 62).

Thus, it makes sense that sponsor districts and universities create a pipeline for dual language educators and provide insight to dual language immersion for future DLI leaders.

Many of the participants indicated that the workload they shared and the materials needed were not equitable to the workload and resources of their monolingual counterparts. Hence, school districts, collective bargaining units, and state departments should look for ways in which to reward the skillset that these educators bring. Sugarman (2012) writes to this same notion that identifies a conflict with values, district/school decisions, financial decisions, which "deprioritize Spanish materials and resources" (p. 229) and "create and undue burden on teachers" who may spend additional hours translating. Sugarman states, "These challenges are distinct from other types of challenges that teachers face because they stem from the sociolinguistic status of Spanish and Spanish-speakers in American society" (p.229). Furthermore, stakeholders should work to fund and prioritize the enhancement of the DLI educator pipeline in order to create a more robust group of qualified candidates. This should not be a district-bydistrict initiative, but should be part of the states capacity and implementation plan. Human resource departments should understand the needs of dual language immersion schools and work with universities to create an alternative certification program that has focus on immersion history, language, as well as instruction, curriculum, and assessment. If tied to a state capacity and implementation plan, this could be a strategy that could 
increase the number of student receiving the Seal of Biliteracy, an Oregon initiative, as well as provide access and supports, and eliminate barriers for possible teaching candidates.

Co-location of programs. Although one participant's tenure existed in a whole school program, the findings made it clear that school districts should look at their organization of programs and perhaps move away from a co-located model. Evidence showed that the political aspects of being a DLI principal negatively impact the climate and culture of their school communities. Collier and Thomas (2014) write,

The interdependent roles of first and second languages are pivotal to both the development of biliteracy and to its influence on academic language and academic achievement. The interdependent use of the first and second languages relies on the informed and intentional design of instruction, assessment, curriculum, and staff for dual language education.

It is understandable that when districts and schools communities were beginning their dual language programs, they would have to share the location of these programs out of necessity. However, as programs have grown within districts and statewide, this practice should be examined. One could argue that co-location of programs can create another example that perpetuates the hegemony of the English language and that DLI battles for resources, acceptance, and is in constant conflict with the dominant school strand. In other words, Freire (2012) believes, "Cultural conquest leads to the cultural inauthenticity of those who are invade; they begin to respond to the values, the standards, and the goals of the invaders" (p. 153). Langston Billings (1998) adds, Members of minority groups internalize the stereotypic images that certain 
elements of society have constructed in order to maintain their power.

Historically, storytelling has been a kind of medicine to heal the wounds of pain caused by racial oppression. The story of one' s condition leads to the realization of how one came to be oppressed and subjugated, thus allowing one to stop inflicting mental violence on oneself (p.14)

Knowing this, how could we respond to and assure the program outcomes when children live amongst the dominant, when clearly stakeholders feel oppressed? School districts must look for ways in which programs are not propagate further oppression for students that are already marginalized.

\section{Implications for practice}

As noted, Bolman and Deal (2014) discuss the aspect of thinking before doing. In order to think, prioritize and plan schools and districts need to find ways in which to assess the work of DLI schools in a way that goes beyond state tests and standardized scores. Participants of this study voiced their concern with being measured in a way that pitted their work against monolingual schools. Collier and Thomas (2014) provide insight from former assistant superintendent for the Oregon Department of Education, David Bautista. Bautista writes of the 5 initiatives that formed the district's strategic plan in order to assure success for students. Within the initiatives, Bautista speaks of "aligned and articulated instruction frameworks for best practices" and a new focus on how standardize testing will inform their practice and decision-making. It seems fitting that leaders find leadership frameworks that transform their schools.

In October of 2012, the University of Kansas was awarded a 24 million dollar grant by the Department of Education, Office of Special Education Programs, where Oregon is one of 5 partner states. The SWiFT framework, Schoolwide Integrated 
Framework for Transformation, outlined 5 domains that would capture a road map for inclusion of all students in a school community. Sailor (2009) notes that fully integrated organizational structures ensures that all students who need additional resources and supports are successful. Additionally, Kozleski \& Smith (2009) state, “A policy framework must exist at the school, district, state, and federal levels that is fully aligned with inclusive reform initiatives and removes barriers to successful implementation". Thus, school districts and schools must adopt a framework that provides guidance and assessment in order to fully benefit the students that are often marginalized. State results are not responsive to the needs of a DLI program. The scores provide a snapshot that is often misinterpreted. Leaders, both district and site, must use frameworks that provide authentic goals and assessments in order to assure implementation of the program and program outcomes.

It is my opinion that often the talk of leading for equity is coupled with adaptive leadership. Barbara (2010) quotes Heifetz and Linsky, "Adaptive problems, on the other hand, are more challenging because they require people within the organization to change their ways: "As the people are the problem, the solution lies with them" (2002). However, it can be argued that if structures and technical alignment are not present, a leader can be constantly adapting. Creating a dual language immersion program/model requires thought and planning. In a study done to identify organizational learning and leadership qualities, Silins, Mulford \& Zarins, (2002) equate structure of the following: "The extent to which the principal establishes a school structure that promotes participative decision making, supports delegation and distributive leadership, and 
encourages teacher autonomy for making decisions" (p. 619). I agree that structure, a point that needs emphasizing since others believe it to be technical and not fitting of an equity conversation. Silins et al, provide a perspective that may enrich the impact of the DLI leader, as they have to make decisions on factors that their monolingual peers do not. Thus, it is recommended that a framework is used to plan and assess the work for authentic program outcomes.

Additionally, Initial Administrative Licensure and Continuing Administrator Licensure programs should also provide classes on frameworks that guide the work. Adichie (2009) warns of the danger of a single story. During her talk she emphasizes,

Stories matter. Many stories matter. Stories have been used to dispossess and to malign, but stories can also be used to empower and to humanize. Stories can break the dignity of a people, but stories can also repair that broken dignity.

Furthermore, in order for our universities to respond to the call of preparing educators who are culturally competent we must understand the power of stories in order to learn and form perspectives that do not create myopic responses to problems we must address. Gay (2010) states,

Even though "story" is usually associated with people telling about themselves and/ or events in which they have been involved, the explanations of educational ideas, paradigms, and proposals constitute "story" as well. Educators need to organize their conceptions and experiences in working with students of color into meaningful "tales of important happenings," as much as individuals need to do so with their personal encounters. Without being so ordered, successful efforts cannot be easily shared or replicated. And educating some students of color is in dire need of much more success than currently exists. This is why I want to create a "story" of power pedagogy in the form of culturally responsive teaching (p. 4). 
Therefore, such programs should aspire to teach the four frames and other pertinent frameworks that foster learning from vignettes, stories, and perspectives of DLI leadership.

A vision for the future. As Collier and Thomas conclude their focus on administrators and their stories as leaders in DLI, a connection is seen to the evidence in this study. DLI leaders are visionary and are social justice educators. DLI leaders are storytellers and create meaning by inspiring others to do great things for students. For this, I define social justice by the work of Theoharis (2007). He defines social justice leadership in the following manner:

I define social justice leadership to mean that these principals make issues of race, class, gender, disability, sexual orientation, and other historically and currently marginalizing conditions in the United States central to their advocacy, leadership practice, and vision. This definition centers on addressing and eliminating marginalization in schools. Thus, inclusive schooling practices for students with disabilities, English language learners (ELLs), and other students traditionally segregated in schools are also necessitated by this definition (p.223).

As stated in chapter 4, not all principals articulated having a vision, however, it was evident that the leaders were indeed visionary. One principal articulated that the vision guides the work, decision-making and communication of everything that transpires in that school setting. The second principal's teachers recognized the task of bringing DLI to the school, they recognized the turmoil created by the community and gave the principal credit for creating a plan for successful implementation. The third principal lives within the stories she shared. Every point that was made regarding the success of the school had a story behind it. Because of this, staff saw her as understanding, vulnerable, and 
approachable. All participants corroborated with their leaders having a vision for the success of their students. As Collier and Thomas (2014) state, through shared stories provided by dual language immersion educators, "We now have the research knowledge base and the practical experience of dedicated dual language administrators to guide the way as we expand these opportunities for all our students" (p.166). While this thought is inspiring, it is also important to identify that leading for social justice is hard work. Theoharis (2007) summarizes, "The principals described how the personal toll they felt took physical, emotional, and mental forms. This toll repeatedly had serious implications on their emotional and physical well-being". He adds, "These principals were descriptive about the resistance they faced as well as the consequences that resistance had on them as individuals" (p.243).

\section{Future Research Recommendations}

To learn more about dual language immersion leadership, future research recommendations supports the examination of university education programs and their preparation of not only dual language immersion leaders, but also of dual language immersion educators. The participants of this study navigated through the demands of the DLI leadership although they had not been DLI teachers. It can't be assumed that leaders will only come from a teaching pipeline, so how universities meet the needs and prepare future leaders will be important to study.

This study focused on the characteristics of dual immersion principals successful with EBs. However, there are still a number of marginalized groups that exhibit needs that are not being met. In some districts, there are concerted efforts to increase DLI 
access to speakers of less commonly taught languages as well as Black students. Future work could include a comparison of immersion programs and their effects on other marginalized student populations.

When speaking of inclusion, special education can't be ignored (Theoharris, 2007; Sailor, 2009). Therefore, studies could include an analysis of immersion and its impact on students with disabilities. It is known that dual language immersion is the proven model to eliminate the opportunity gap for EBs (Collier and Thomas, 2014) and it could be suggested that DLI would have the same effects on students who have been marginalized by our educational system.

\section{Conclusion}

The current political climate is not supportive of students and individuals not born in the United States. Countless articles address the current administration's view that English is the language of choice in this country. Principals in DLI must navigate the complex political environment while ensuring the success of EBs. Sugarman (2012) reminds us that "Equity stems from societal attitudes toward bilingualism and minority languages and cultures which then shape educational priorities, and then are mediated at the program or classroom level by practitioners, creating equitable or inequitable experiences for students" (p. 218). Thus, dual language immersion leaders should create coalitions to protect and continue to serve the program that has results for success of EBs. The findings of this study identify characteristics of successful DLI leaders; however, more research is needed to determine how to best prepare DL school leaders; the impact 
of DLI on other marginalized populations; and how to maximize the outcomes for recent immigrants. 


\section{REFERENCES}

Adichie, C. N. (2015, October 21). The Danger of a Single Story. Lecture presented at TEDGlobal 2009 in UK, Oxford. Retrieved from

https://www.ted.com/talks/chimamanda_adichie_the_danger_of_a_single_story

American Indian Relief Council. (n.d.). Retrieved from http://www.nrcprograms.org/site/PageServer?pagename=airc_index

America's Foreign Language Deficit. (n.d.). Retrieved February 9, 2014, from http://www.forbes.com/sites/collegeprose/2012/08/27/americas-foreign-languagedeficit/

Attride-Stirling, J. (2001). Thematic networks: An analytic tool for qualitative research. Qualitative Research, 1(3), 385-405.

Bernhardt, E. B. (Ed.). (1992). Life in language immersion classrooms (Vol. 86). Multilingual Matters.

Bolman, L. G., \& Deal, T. E. (2003). Reframing organizations: Artistry, choice, and leadership. San Francisco: Jossey-Bass.

Bolman, L. G., \& Deal, T. E. (2014). How Great Leaders Think: The Art of Reframing. John Wiley \& Sons.

Bowen, G. A. (2009). Document analysis as a qualitative research method.Qualitative research journal, 9(2), 27-40.

Bridges, W. (1991). Managing transitions: Making the most of change. Reading, Mass: Addison-Wesley.

Bridges, W. (2003). Managing transitions: Making the most of change.Cambridges (MA).

Brown v. Board of Education, 347 US 483 (Supreme Court 1).

Bureau, U. C. (2017, August 28). More Than 77 Million People Enrolled in U.S. Schools. Retrieved February 13, 2018, from https://www.census.gov/newsroom/pressreleases/2017/school-enrollment.html

Castaneda v. Pickard, 648 F. 2d 989 (Court of Appeals, 5th Circuit June 23, 1981).

Chomsky, N. (1965). Aspects of the Theory of Syntax. MIT Press.

Collier, V. P., \& Thomas, W. P. (1999). Making US schools effective for English language learners, Part 1. TESOL Matters, 9(5), 1. Retrieved from http://www.thomasandcollier.com/Making\%20U.S.\%20Schools\%20Effective\%20 $\% 20 . P D F$

Collier, V.P., \& Thomas, W.P. (2004). The astounding effectiveness of dual language education for all. NABE Journal of Research and Practice, 2(1), 1-20.

Corbaz, P. (2014, December).Leadership in Language Immersion Schools: Case Studies of Four Elementary Principals. Oklahoma State University, Tulsa, Oklahoma. 
Cotton, K. (2003). Principals and Student Achievement: What the Research Says. Association for Supervision and Curriculum Development (ASCD), 1703 N. Beauregard Street, Alexandria, VA 22311

Creswell, J. W., \& Creswell, J. W. (2013). Qualitative inquiry and research design: choosing among five approaches. Los Angeles: SAGE Publications.

Cummins, J. (1999). Alternative paradigms in bilingual education research: Does theory have a place? Educational Researcher, 26-41.

Cummins, J. (1986). Empowering minority students: A framework for intervention. Harvard educational review, 56(1), 18-37.

Cummins, J. (1981) The role of primary language development in promoting educational success for language minority students. In California State Department of Education (Ed.), Schooling and language minority students: A theoretical framework. Evaluation, Dissemination and Assessment Center, California State University, Los Angeles.

Cummins, J. (1984). Wanted: A theoretical framework for relating language proficiency to academic achievement among bilingual students. Language proficiency and academic achievement, 10, 2-19.

Cummins, J. (December 07, 2000). Academic Language Learning, Transformative Pedagogy, and Information Technology: Towards a Critical Balance. Tesol Quarterly, 34,3, 537-47.

Darling-Hammond, L. (2007). Race, inequality and educational accountability: The irony of 'No Child Left Behind'. Race Ethnicity and Education, 10(3), 245-260.

Denzin, N. K., \& Lincoln, Y. S. (2011). The SAGE Handbook of Qualitative Research. SAGE.

Disparities remain in America's schools. (n.d.). Sandusky Register. Retrieved March, 2014, from http://www.sanduskyregister.com/article/5450251

Educating Americans on the problems of uncontrolled immigration and offering solutions for sensible immigration reform. (n.d.). Retrieved from https://www.numbersusa.com/

Friedman, T. (2005). The world is flat. Farrar, Straus \& Giroux.

Fullan, M. (2001). Leading in a culture of change. San Francisco: Jossey-Bass.

García, Ofelia, Flores, Nelson and Chu, Haiwen (2011) Extending Bilingualism in U.S. Secondary Education: New Variations. International Multilingual Research Journal, 5: 1, $1-18$

Gay, G. (2010). Culturally responsive teaching: Theory, research, and practice. Teachers College Press. 
Gay, G., \& Howard, T. C. (2000). Multicultural teacher education for the 21st century. The Teacher Educator, 36(1), 1-16.

Friedman, T. (2005). The world is flat. Farrar, Straus \& Giroux.

Freire, P., Ramos, M. B., \& Macedo, D. (2000). Pedagogy of the Oppressed, 30th Aniversary Edition (30th Anniversary edition). New York: Bloomsbury Academic.

Fullan, M. (2001). Leading in a culture of change. San Francisco: Jossey-Bass.

García, O., Kleifgen, J. A., \& Falchi, L. (2008). From English Language Learners to Emergent Bilinguals. Equity Matters. Research Review No. 1. Campaign for Educational Equity, Teachers College, Columbia University.

Goldenberg, C. (2008). Teaching English Language Learners What the Research Does and Does Not Say. American Educator, (Summer).

Gomez v. Illinois State Bd. of Educ., 811 F. 2d 1030 (Court of Appeals, 7th Circuit April 8, 1986).

Hattie, J. (2011). Visible Learning for Teachers: Maximizing Impact on Learning (1 edition). London; New York: Routledge.

Heifetz, R. A., \& Laurie, D. L. (1997). The work of leadership. Harvard business review, 75, 124-134.

Heifetz, R. A., \& Linsky, M. (2002). Leadership on the line. Harvard Business School Press, Boston.

Kerper-Mora, J. (2009). From the box to the classroom. Educational Leadership, 66(7), $14-19$.

Krashen, S. D. (1982). Principles and practice. Learning, 46(2), 327-69.

Krashen, S. (n.d.). Stephen Krashen's Theory of Second Language Acquisition. Retrieved from http://www.sk.com.br/sk-krash.html

Krashen, S. D. (1987). Principles and practice in second language acquisition. PrenticeHall International.

Krathwohl, D. (2009). Methods of Educational and Social Science Research: the logic of methods (Third). Long Grove, Illinois: Waveland Press.

Lau v. Nichols, 414 US 563 (Supreme Court December 10, 1973).

Lave, J. (July 01, 1996). Teaching, as learning, in practice. Mind, Culture, and Activity,3, 3, 149-164.

Lincoln, Y. S. (1985). Naturalistic Inquiry. SAGE.

Lindholm-Leary, K., \& Block, N. (2010). Achievement in predominantly low SES/Hispanic dual language schools.International Journal of Bilingual Education and Bilingualism,13(1), 43-60. http://doi.org/10.1080/13670050902777546 
Lindsey, R., B., Robins, K, \& Terrell, R., D. (2009). Cultural proficiency: A manual for school leaders (3rd ed.). Thousand Oaks, CA: Corwin.

Lyons, J. J. (1990). The Past and Future Directions of Federal Bilingual-Education Policy. The ANNALS of the American Academy of Political and Social Science, 508(1), 66-80. http://doi.org/10.1177/0002716290508001007

Macedo, D., \& Chomsky, N. (2004). Chomsky on Mis-Education. Rowman \& Littlefield Publishers.

Marshall, C., \& Gerstl-Pepin, C. I. (2005). Re-framing educational politics for social justice. Boston: Pearson/Allyn and Bacon.

Marzano, R. J., Waters, T., \& McNulty, B. A. (2005). School leadership that works: From research to results. ASCD.

Maxwell, J. (2013). Qualitive Research Design An Interactive Approach(third). Los Angeles: Sage.

MenuSite Navigation Statewide Annual Report Card. (n.d.). Retrieved February 13, 2018, from http://www.oregon.gov/ode/schools-anddistricts/reportcards/Pages/Statewide-Annual-Report-Card.aspx

Morgan, D. L. (2013). Integrating Qualitative and Quantitative Methods: A Pragmatic Approach. SAGE Publications.

National Center for Educational Statistics (n.d.). Retrieved February 13, 2018, from https://nces.ed.gov/programs/coe/indicator_cgf.asp

Office, U. C. B. P. I. (n.d.). New Census Bureau Report Analyzes Nation’s Linguistic Diversity - American Community Survey (ACS) - Newsroom - U.S. Census Bureau. Retrieved December 11, 2013, from http://www.census.gov/newsroom/releases/archives/american_community_survey _acs/cb10-cn58.html

Office, U. C. B. P. I. (n.d.). U.S. Census Bureau Projections Show a Slower Growing, Older, More Diverse Nation a Half Century from Now - Population - Newsroom U.S. Census Bureau. Retrieved January 24, 2016, from https://www.census.gov/newsroom/releases/archives/population/cb12-243.html

Ogbu, J. U. (1992). Understanding cultural diversity and learning. Educational researcher, 21(8), 5-14.

Omaggio, A. (1986). Teaching Language in Context: Proficiency-Oriented Instruction (first). Boston, Massachusetts: Heinle and Heinle Publishers, Inc.

Oregon Department of Education. (n.d.-a). Retrieved from http://www.ode.state.or.us/home/

Oregon Educators Prioritize Bilingual Education. (n.d.). Retrieved July 16, 2014, from http://www.opb.org/news/article/bilingual-education/ 
Oregon English Learners Statewide Strategic Plan 2013 - 2016. (n.d.-b). Retrieved from http://www.oregon.gov/gov/docs/OEIB/FinalEL.pdf

Ovando, C. J. (2003). Bilingual Education in the United States: Historical Development and Current Issues. Bilingual Research Journal, 27(1), 1-24.

http://doi.org/10.1080/15235882.2003.10162589

Peterson, D. S. (2012). Latino student success in Oregon high schools. LEWIS AND CLARK COLLEGE. Retrieved from http://gradworks.umi.com.proxy.lib.pdx.edu/34/95/3495806.html

Plyler v. Doe, 457 US 202 (Supreme Court December 1, 1981).

Popkewitz, T. (1990). The Paradigm Dialog. Sage, 46-66.

Portes, A., Rumbaut, R.G. (2001). Legacies: the stories of the immigrant second generation.

Berkeley: University of California Press

US Department of Education. (n.d.). Retrieved fromhttp://www.ed.gov/

Ravitch, D. (1974). The great school wars: New York City, 1805-1973; a history of the public schools as battlefield of social change. New York: Basic Books.

Rethinking Schools Online. (2003). Retrieved March 31, 2014, from http://www.rethinkingschools.org/special_reports/bilingual/Bili172.shtml

Senge, P. M. (2000). Schools that learn: a fifth discipline fieldbook for educators, parents, and everyone who cares about education. New York: Doubleday.

Schmoker, M. (2006). Results now: How we can achieve unprecedented improvements in teaching and learning. ASCD.

Seibens, J., \& Julian, T. (2011). Native North American Languages Spoken at Home in the United States and Puerto Rico: 2006-2010 American Community Survey Briefs. Retrieved from http://www.census.gov/prod/2011pubs/acsbr10-10.pdf

Seidman, I. (2012). Interviewing as Qualitative Research: A Guide for Researchers in Education and the Social Sciences. Teachers College Press.

Serna v. Portales Municipal Schools, 499 F. 2d 1147 (Court of Appeals, 10th Circuit March 20, 1974).

Spillane, J. P., Halverson, R., \& Diamond, J. B. (2001). Investigating school leadership practice: A distributed perspective. Educational researcher, 23-28.

Steele, J. L., Slater, R. O., Zamarro, G., Miller, T., Li, J., Burkhauser, S., \& Bacon, M. (2015). Effects of Dual-Language Immersion on Students' Academic Performance. 
Takanishi, R., \& Menestrel, S. L. (2017). Promoting the educational success of children and youth learning English: promising futures. Washington, D.C.: The National Academies Press.

Téllez, K., \& Waxman, H. C. (Eds.). (2006). Preparing quality educators for English language learners: Research, policy, and practice. Routledge.

The advantages of being bilingual by Lauren Migliore. (n.d.). Retrieved from http://psychcentral.com/lib/the-advantages-of-being-bilingual/0007753

Theories of Intelligence in Second Language Learning: A review of Skinner, Chomsky, Bandura, Vygotsky, Krashen, and Gardner. (n.d.-b).Lingtechguistics. Retrieved February 2, 2014, from http://lingtechguistics.com/2008/08/13/theories-ofintelligence-in-second-language-learning-a-review-of-skinner-chomsky-banduravygotsky-krashen-and-gardner/

Tillman, L. C., \& Scheurich, J. J. (2013). Handbook of research on educational leadership for equity and diversity. New York: Routledge.

Thomas, W. P., \& Collier, V. (1997). School Effectiveness for Language Minority Students. NCBE Resource Collection Series, No. 9.

Thomas, W. P., Collier, V. P., \& Center for Research on Education, Diversity \& Excellence. (2002). A national study of school effectiveness for language minority students' long-term academic achievement. Washington, DC: Center for Research on Education, Diversity \& Excellence.

Vygotsky, L. 1978. Mind and Society: The Development of Higher Psychological Processes Cambridge, MA: Harvard University Press

Zacarian, D. (2011). Transforming Schools for English Learners: A Comprehensive Framework for School Leaders. Thousand Oaks, CA: Corwin. 


\title{
APPENDICES
}

\author{
APPENDIX A
}

\section{INFORMED CONSENT FORM}

"Dual Immersion Leadership: A Case Study of Three K-5 Principals Who Show Success with Emergent Bilinguals"

\section{Dear Participant,}

You have been selected to participate in a study, which looks at successful dual immersion leaders. The following information is provided for you to decide whether you wish to participate in the present study. You should be aware that you are free to decide not to participate or to withdraw at any time without penalty.

The purpose of this study is to examine the characteristics of principals leading dual language immersion programs needed to increase student achievement among Emergent Bilinguals. A researcher will conduct case studies in several dual language immersion schools that have been recognized as successful programs by the Oregon Department of Education and/or Center for Advanced Research in Language Acquisitions (CARLA).

You will participate in a one-time interview that will last for sixty minutes with a possibility of a follow up interview to clarify remarks. The interview will be audio recorded for accuracy. I will provide a hard copy of the transcript for each interview. You many make any changes to the transcript if you wish.

Data collection will involve a review of documents (principal communication, local and state assessments), a sixty-minute interview (transcripts), and teacher focus groups.

There are no known risks and/or discomforts associated with this study. The expected benefits associated with your participation are a contribution to a body of literature that will assist future dual immersion principals. If you are interested, a copy of the results of the study can be provided when it is finished.

All information about you will be kept confidential and will not be released. Transcripts, audiotapes, and documents will be de-identified in a systemized manner and will not use names of individuals or institutions. Children will not be identified in any of the data collection methods. All data will be saved in a secure place and will only be open to the researcher and university advisor. Results of this study will be analyzed as a whole and be presented with a dissertation committee that and other appropriate members of 
Portland State University. The dissertation results will be published in hard and digital format and will be housed in the Portland State University library.

I appreciate your time to this study, which will help me as well as future immersion leaders.

Place your initials on the line below if you are in agreement to participate in this study:

I wish to participate in the research described above and agree to be audio taped. I agree to allow the researcher to shadow me and conduct observations at my school throughout the day. I understand that the recording will be transcribed for accuracy and that I will receive a copy of the transcript to verify that my words are accurate. I agree to provide documents that I have shared with my staff and community.

I understand that participation is voluntary and that I may withdrawal at any time. I have read the consent form and understand that I am signing this willingly.

Ivonne K. Dibblee

ikdibbs@gmail.com

University Supervisor:

Deborah Peterson

dpeterso@pdx.edu

Printed name of participant

Signature of participant

Date

I, as primary researcher, have explained this document before requesting a signature from participant.

Printed name of researcher

Signature of researcher

Date 


\title{
APPENDIX B
}

\section{INFORMED CONSENT FORM}

\begin{abstract}
"Dual Immersion Leadership: A Case Study of Three K-5 Principals Who Show Success with Emergent Bilinguals"
\end{abstract}

\section{Dear Participant,}

You have been selected to participate in a study, which looks at successful dual immersion leaders. The following information is provided for you to decide whether you wish to participate in the present study. You should be aware that you are free to decide not to participate or to withdraw at any time without penalty.

The purpose of this study is to examine the characteristics of principals leading dual language immersion programs needed to increase student achievement among Emergent Bilinguals. A researcher will conduct case studies in several dual language immersion schools that have been recognized as successful programs by the Oregon Department of Education and/or Center for Advanced Research in Language Acquisitions (CARLA).

You will participate in a one-time focus group that will last for sixty minutes. The focus will be audio recorded for accuracy. I will provide a hard copy of the transcript if you wish to review. You many make any changes to the transcript if you wish.

Data collection will involve a review of documents (principal communication, local and state assessments), a sixty-minute interview (transcripts), and teacher focus groups.

There are no known risks and/or discomforts associated with this study. The expected benefits associated with your participation are a contribution to a body of literature that will assist future dual immersion principals. If you are interested, a copy of the results of the study can be provided when it is finished.

All information about you will be kept confidential and will not be released. Transcripts, audiotapes, and documents will be identified in a systemized manner and will not use names of individuals or institutions. Children will not be identified in any of the data collection methods. All data will be saved in a secure place and will only be open to the researcher and university advisor. Results of this study will be analyzed as a whole and be presented with a dissertation committee that and other appropriate members of Portland State University. The dissertation results will be published in hard and digital format and will be housed in the Portland State University library. 
I appreciate your time to this study, which will help me as well as future immersion leaders.

Place your initials on the line below if you are in agreement to participate in this study:

I wish to participate in the research described above and agree to be audio taped. I agree to allow the researcher to shadow me and conduct observations at my school throughout the day. I understand that the recording will be transcribed for accuracy and that I will receive a copy of the transcript to verify that my words are accurate. I agree to provide documents that I have shared with my staff and community.

I understand that participation is voluntary and that I may withdrawal at any time. I have read the consent form and understand that I am signing this willingly.

Ivonne K. Dibblee

ikdibbs@gmail.com

University Supervisor:

Deborah Peterson

dpeterso@pdx.edu

Printed name of participant

Signature of participant

Date

I, as primary researcher, have explained this document before requesting a signature from participant.

Printed name of researcher

Signature of researcher

Date 
APPENDIX C

PROTOCOL FOR DOCUMENT ANALYSIS

\begin{tabular}{|l|l|l|l|l|l|}
\hline $\begin{array}{c}\text { Name of } \\
\text { Document }\end{array}$ & $\begin{array}{c}\text { Date of } \\
\text { Document }\end{array}$ & $\begin{array}{l}\text { Structural } \\
\text { (include 4 } \\
\text { bullets) }\end{array}$ & $\begin{array}{c}\text { HR } \\
\text { (include 4 } \\
\text { bullets) }\end{array}$ & $\begin{array}{c}\text { P } \\
\text { (include } \\
\text { 4 bullets) }\end{array}$ & $\begin{array}{c}\text { S } \\
\text { (include 4 } \\
\text { bullets) }\end{array}$ \\
\hline $\begin{array}{l}\text { School } \\
\text { Improvement } \\
\text { Plan }\end{array}$ & $9-15-15$ & $\begin{array}{l}\text { PBIS } \\
\text { "all } \\
\text { children } \\
\text { deserve..." } \\
\text { Develop }\end{array}$ & $\begin{array}{l}\text { teacher } \\
\text { leaders } \\
\text { vision } \\
\text { statement; } \\
\text { increase } \\
\text { library } \\
\text { posters in } \\
\text { Spanish }\end{array}$ \\
\hline & & & & \\
\hline & & & & & \\
\hline & & & & \\
\hline & & & & & \\
\hline & & & & & \\
\hline & & & & & \\
\hline & & & & & \\
\hline & & & & & \\
\hline
\end{tabular}




\section{APPENDIX D}

\section{INTERVIEW PROTOCOL}

Time of Interview:

Date:

Place:

Interviewee:

Position of interviewee:

Interviewer:

Good afternoon! My name is Ivonne Dibblee and I am the principal of Atkinson Elementary and I'm a doctoral student at PSU. I'm interested in learning about the characteristics of successful dual immersion principals. You have been selected for this study because you have led your school for more than two years and you've shown student results that are above other schools with similar demographics.

Today you have an opportunity to participate in this study. I will use the data from this interview to increase our understanding of the characteristics of effective dual immersion principals. Prior to finishing my analysis, I will share with you the findings, asking you to confirm the findings to ensure I've correctly interpreted the data. I want to confirm that all information is confidential and I will not share your name with anyone and any information that you share that identifies you or your school will be de-identified to protect you, your identity and your school's identity.

If at any time you would like to stop the interview, let me know and I will stop. Also, if at any time after the interview you would like your comments deleted, please let me know and I'll delete your data. Here is a piece of paper with my contact information and the informed consent form. Take as long as you'd like to read it and if you agree to participate, sign it and we'll continue with the interview (After reading and signing, I'll give a copy of the contact information and a copy of the consent form.) Here is a copy of my contact information and a copy of the consent form.

I have been looking forward to the opportunity of learning from you. Let's get started!

This study is to examine the characteristics of successful dual immersion principals. 
Questions:

1. Please tell me a little bit about yourself. What is your professional background? How did you come upon leading dual immersion?

2. Can you please describe your school, the school climate, and parent involvement?

3. As an immersion leader, what do you feel is your primary role?

4. Do you feel that the dual immersion leadership is the same or different as being a principal at a non-immersion school? Why or why not?

5. What are the challenges and benefits of having a dual immersion program in your school?

6. How do you go about planning for professional development? (is it different for different staff member dli v. non dli?)

7. Are there district policies and decisions that impact dual immersion and if so, how do you deal with them?

8. What qualities are needed of dual immersion principals?

9. How do you stay current with best practices in immersion and or other instructional best practices?

10. In your tenure as a dual immersion principal what is something that has been surprising for you? Or, Do you feel you were prepared for this position. (Please explain)

11. What do you believe has contributed to your success as a dual immersion principal? 
12. As you reflect on your experience and if you were to provide some advice for administrative leadership programs, what would that be?

13. What advice would you have for a new dual immersion principal? 


\section{APPENDIX E}

\section{FOCUS GROUP PROTOCOL}

Time of focus group:

Date:

Place:

Interviewer:

Good afternoon! My name is Ivonne Dibblee and I am the principal of Atkinson Elementary and I'm a doctoral student at PSU. I'm interested in learning about the characteristics of successful dual immersion principals. You have been selected for this study because your school has shown student results that are above other schools with similar demographics.

Today you have an opportunity to participate in this study. I will use the data from this focus group to increase our understanding of the characteristics of effective dual immersion principals. Prior to finishing my analysis, I will share with you the findings, asking you to confirm the findings to ensure I've correctly interpreted the data. I want to confirm that all information is confidential and I will not share your name with anyone and any information that you share that identifies you or your school will be de-identified to protect you, your identity and your school's identity.

If at any time you would like to stop the interview, let me know and I will stop. Also, if at any time after the interview you would like your comments deleted, please let me know and I'll delete your data. Here is a piece of paper with my contact information and the informed consent form. Take as long as you'd like to read it and if you agree to participate, sign it and we'll continue with the interview (After reading and signing, I'll give a copy of the contact information and a copy of the consent form. Here is a copy of my contact information and a copy of the consent form.

I have been looking forward to the opportunity of learning from you. Let's get started!

This study is to examine the characteristics of successful dual immersion principals.

Questions:

1. Please tell me about yourselves. What is your professional background? How did you come upon teaching in dual immersion? 
2. Can you please describe your school, the school climate, and parent involvement?

3. What do you feel is your primary role of an immersion principal?

4. Do you feel that being a principal of a dual immersion school is the same or different as being a principal at a non-immersion school? Why or why not?

5. What are the challenges and benefits of having a dual immersion program in your school?

6. How is professional development delivered? (is it different for different staff member dli v. non dli?)

7. Are there district policies and decisions that impact dual immersion and if so, how do hear about them?

8. What qualities are needed of dual immersion principals?

9. What do you believe has contributed to the success of your principal?

10. If you were to give advice to a new principal in dual immersion what would that be? 